\title{
Monetary Policy under Flexible Exchange Rates: An InTRODUCTION to INFLATION TARGETING
}

\author{
Pierre-Richard Agénor \\ World Bank
}

Both policymakers and economists increasingly accept that the main medium- to long-run goal of monetary policy is the pursuit of price stability, defined as maintaining a low and stable rate of inflation. A high and variable inflation rate is socially and economically costly. These costs include price distortions, lower savings and investment (which inhibits growth), hedging (into precious metals or land), and capital flight (into foreign assets). In addition, short-term manipulation of monetary policy instruments to achieve other goals-such as higher output and lower unemployment-may conflict with price stability. The attempt to achieve these conflicting goals tends to generate an inflationary bias in the conduct of monetary policy without, in the end, achieving systematically higher output and employment.

To achieve the goal of price stability, monetary policy in many countries was for a long time conducted by relying on intermediate targets such as monetary aggregates or exchange rates. During the 1990s, however, several industrial and developing countries began to focus directly on inflation itself. This new approach to the problem of controlling inflation through monetary policy is known as inflation targeting. ${ }^{1}$ It essentially makes inflation-rather than output or unemployment-the primary goal of monetary policy. It also forces the central bank to predict the future behavior of prices in order to tighten policies before sustained inflationary pressures develop.

I would like to thank, without implication, Esteban Jadresic, Brian Kahn, and Murat Ucer for useful comments on an earlier draft, and Nihal Bayraktar for excellent research assistance.

Inflation Targeting: Design, Performance, Challenges, edited by Norman Loayza and Raimundo Soto, Santiago, Chile. (c) 2002 Central Bank of Chile.

1. As discussed below, two major reasons why countries chose to implement inflation targeting over alternative monetary policy frameworks were exchange rate crises and money demand instability. 
A large literature examines the practical experience of industrial countries with inflation targeting (see, most recently, Bernanke, and others, 1999; Schaechter, Stone, and Zelmer, 2000). The purpose of this paper is to provide an overview of analytical issues associated with inflation targeting, with a focus on the policies, structural context, and recent experience of developing countries. Whether inflation targeting has a wider applicability to developing economies has been a matter of debate in recent years, with authors like Masson, Savastano, and Sharma (1997) taking a rather cautious view. They argue that poor data on prices and real sector developments, the absence of reliable procedures for forecasting inflation, the difficulty of maintaining de facto independence for the central bank, and the lack of an anti-inflationary history may preclude the establishment of a transparent framework for conducting monetary policy and therefore any attempt at inflation targeting. Other authors, however, including Mishkin (2000) and Morandé and SchmidtHebbel (1999), adopt a more favorable position at least for the case of high- and middle-income developing countries, where the financial system is sufficiently developed to permit the use of indirect monetary policy instruments. Understanding the terms of this debate is essential. Several developing countries have recently adopted floating exchange rates (often as the result of unsustainable exchange rate pressures on their adjustable peg regimes), and they must therefore find another nominal anchor to guide domestic monetary policy over the medium and long term.

The remainder of the paper is structured as follows. Section 1 presents an analytical framework for understanding the nature of an inflation-targeting regime, based on the important work of Svensson (1997a, 1999a). A closed-economy model provides the starting point for the discussion; the model is then extended to an open-economy setting to highlight the role of the exchange rate in the transmission process of monetary policy. Section 2 compares inflation-targeting regimes with money supply and exchange rate targeting regimes and highlights the risks associated with pursuing implicit exchange rate targets. Section 3 identifies three basic requirements for implementing an inflation-targeting framework, namely, central bank independence, the absence of implicit targeting of the exchange rate, and transparency in the conduct of monetary policy. The operational framework of inflation targeting is the focus of section 4 . It discusses, in particular, issues associated with the measurement of inflation (including sources of imperfection in traditional measures), whether a 
target band for inflation is more appropriate than a point target, the time horizon of monetary policy, the inherent difficulties associated with forecasting inflation, and whether asset prices should be taken into account in assessing inflationary pressures. Section 5 reviews the recent experience of both industrial and developing countries with inflation targets, with a particular emphasis on the latter group. The last section focuses on some unresolved analytical issues in the design of inflation-targeting regimes, namely, the role of nonlinearities and asymmetric effects (related to both the form of policy preferences and structural relationships, most notably the Phillips curve), uncertainty (about behavioral parameters and the transmission process of monetary policy), and the treatment of credibility and reputation in empirical macroeconomic models of inflation. New results regarding the convexity (or lack thereof) of the Phillips curve are also presented for six developing countries. The conclusion summarizes the main results of the analysis and offers some final remarks.

\section{INFlation TARgETING: A CONCEPTUAL FRAMEWORK}

The first step in understanding the nature of an inflation-targeting framework is to analyze the relation between explicit policy goals, policy instruments, and preferences of the central bank (which affect the form of its reaction function). ${ }^{2}$ This section begins by examining the link between inflation targets and the nominal interest rate - viewed as the main instrument of monetary policy - when the central bank is concerned only about deviations of actual inflation from its target value. The analysis is then extended to consider the case in which both output and inflation enter the central bank's loss function. In both cases the analysis focuses on a closed economy; open-economy considerations are discussed later in the section.

\subsection{Strict Inflation Targeting}

Following Svensson (1997a), consider a closed economy producing one composite good. The economy's structure is characterized by the following two equations, where all parameters are defined as positive:

2. In what follows, the term instrument is used in a broad sense to refer both to the operational target of monetary policy and to the actual instruments available to achieve this target. 


$$
\begin{aligned}
& \pi_{t}-\pi_{t-1}=\alpha_{1} y_{t-1}+\varepsilon_{t} \text { and } \\
& y_{t}=\beta_{1} y_{t-1}-\beta_{2}\left(i_{t-1}-\pi_{t-1}\right)+\eta_{t},
\end{aligned}
$$

where $\pi_{t} \equiv p_{t}-p_{t-1}$ is the inflation rate at time $t$ (with $p_{t}$ denoting the logarithm of the price level), $y_{t}$ is the output gap (defined as the logarithm of actual to potential output), $i_{t}$ is the nominal interest rate (taken to be under the direct control of the central bank), and $\beta_{1}<1$. The variables $\varepsilon_{t}$ and $\eta_{t}$ are independently, identically distributed (i.i.d.) random shocks.

Equation 1 indicates that changes in inflation are positively related to the cyclical component of output, with a lag of one period. Equation 2 relates the output gap positively to its value in the previous period and negatively to the ex post real interest rate, again with a one-period lag. In this model, policy actions (that is, changes in the nominal interest rate) affect output with a one-period lag and, as implied by equation 1 , affect inflation with a two-period lag. ${ }^{3}$ In the discussion, I refer to the lag between a change in the policy instrument and inflation as the control lag or control horizon.

The assumption that the central bank directly controls the interest rate that affects aggregate demand warrants some discussion. In principle, what affects private consumption and investment decisions is the cost of borrowing; given the prevailing characteristics of the financial structure in many developing countries, this is equivalent to the bank lending rate. In general, bank lending rates depend on banks' funding costs, a key component of which is either the money market rate or (ultimately) the cost of short-term financing from the central bank. ${ }^{4}$ To the extent that bank lending rates and money market rates respond quickly and consistently to changes in policy rates, the assumption that the central bank directly controls the cost of borrowing faced by private agents can simply be viewed as a conve-

3. Note that introducing a forward-looking element in equation 1 would imply that monetary policy has some effect on contemporaneous inflation; this would make the solution of the model more complicated but would not affect some of the key results discussed below. See appendix A for a discussion. Nevertheless, the assumption of model-consistent expectations has drawbacks, most notably that it downplays the role of model uncertainty-which, as discussed later, may be very important in practice.

4. Bank lending rates also depend on the perceived probability of default of potential borrowers and, in an open economy, on the cost of funding on world capital markets. See Agénor and Aizenman (1998) for a model that captures these features of bank behavior. 


\section{Figure 1. Response of Money Market Rate to One Standard Deviation Innovations in Discount Rate ${ }^{a}$}
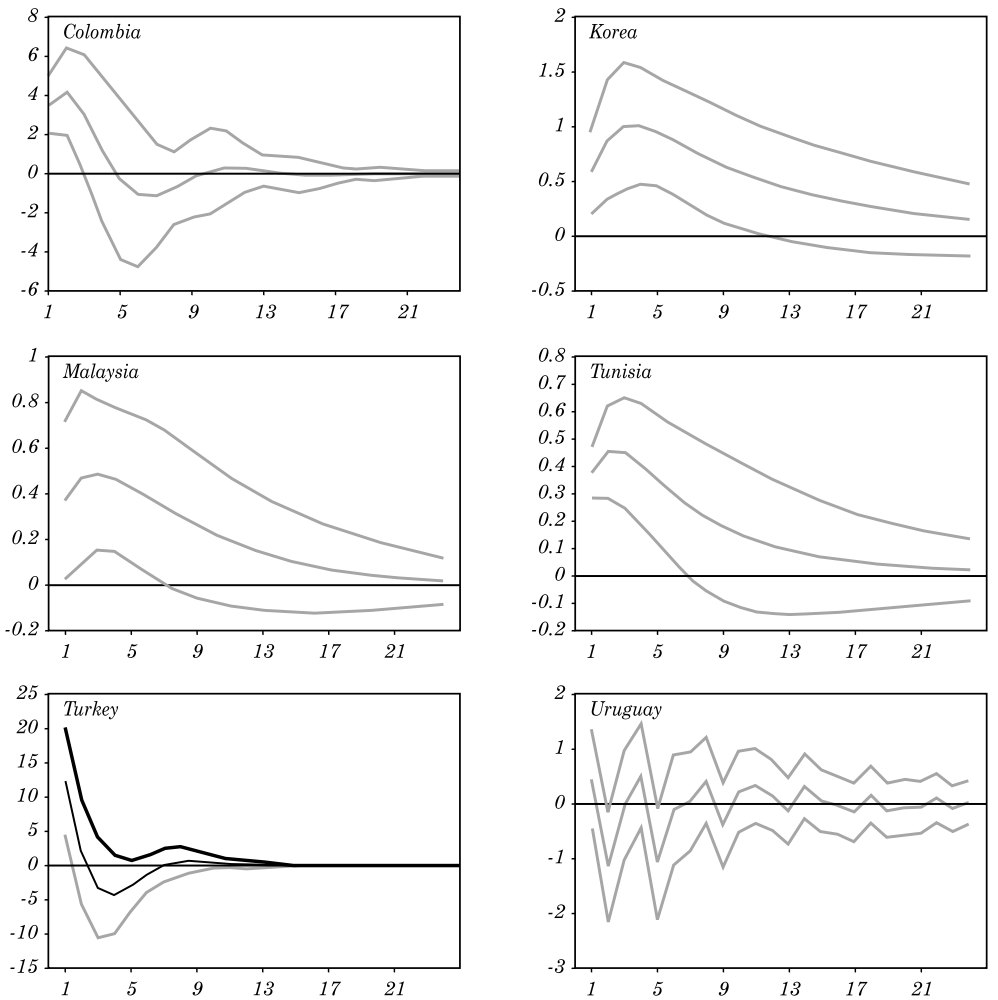

Source: Author's calculations.

a. +/- 2 standard errors.

nient shortcut. ${ }^{5}$ What, then, is the evidence? Figure 1 reports impulse response functions of an increase of one standard deviation in the central bank's discount rate (taken to be the policy rate) in a group of six developing countries for which data are readily available. These responses are obtained from a bivariate vector autoregression (VAR) model that includes the policy rate and the money market rate (see appendix B for details). The figure shows that except for Uru-

5. A similar effect would arise if aggregate demand depends on longer-term interest rates. This is because longer-term rates are partly driven by expected future movements in short-term interest rates, which are, in turn, influenced by current and expected future policy decisions of the central bank. 
guay, market interest rates respond relatively quickly and significantly to changes in official interest rates. It is thus a reasonable analytical approximation to assume that the central bank directly controls the interest rate that affects aggregate demand.

The central bank's period-by-period policy loss function, $L_{t}$, is taken for the moment to be a function only of inflation. It is given by

$L_{t}=\frac{\left(\pi_{t}-\tilde{\pi}\right)^{2}}{2}$,

where $\tilde{\pi}$ is the inflation target. An alternative assumption would be that the price target is specified in terms of the price level, as opposed to the inflation rate. The conventional view is that a price-level target entails a major benefit, on the one hand, in that it reduces uncertainty about the future level of prices. On the other, if the economy is subject to supply shocks that alter the equilibrium price level, attempts to disinflate and lower the price level back to its pre-shock value may generate significant real costs and increased volatility in inflation and output. ${ }^{6}$ In practice, as discussed later, all inflation-targeting central banks have opted to define their price objective in terms of the inflation rate; accordingly, it is assumed in the present that the price target is indeed specified in terms of the inflation rate.

The central bank's policy objective in period $t$ is to choose a sequence of current and future interest rates $\left\{i_{h}\right\}_{h=t}^{\infty}$ so as to minimize the expected sum of discounted squared deviations of actual inflation from its target value, $U_{t}$, subject to equations 1 and 2 :

$\min U_{t}=E_{t} \sum_{h=t}^{\infty} \delta^{h-t} L_{h}=E_{t}\left\{\sum_{h=t}^{\infty} \delta^{h-t} \frac{\left(\pi_{h}-\tilde{\pi}\right)^{2}}{2}\right\}$,

where $\delta$ denotes a discount factor $(0<\delta<1)$ and $E_{t}$ is the expectations operator conditional on the central bank's information set at period $t$.

The most direct way to solve this optimization problem is to use dynamic programming techniques. As shown by Svensson (1997a), however, problem 3 can be recast in a simpler form, which allows a

6. This argument has been challenged in some recent papers, however, including Dittmar, Gavin, and Kydland (1999), Svensson (1999b), and Vestin (2000). The latter two studies, in particular, show that under certain conditions, pricelevel targeting may deliver a more favorable trade-off between inflation and output variability than does inflation targeting. 
more intuitive derivation of the optimal path of the policy instrument. Because the nominal interest rate affects inflation with a two-period lag, $\pi_{t+2}$ can be expressed in terms of period $t$ variables and shocks occurring at periods $t+1$ and $t+2$. Equation 1 can thus be written as

$\pi_{t+2}=\pi_{t+1}+\alpha_{1} y_{t+1}+\varepsilon_{t+2}$.

Updating equation 2 in a similar manner and substituting the result in the above expression for $y_{t+1}$ yields

$\pi_{t+2}=\left(\pi_{t}+\alpha_{1} y_{t}+\varepsilon_{t+1}\right)+\alpha_{1}\left[\beta_{1} y_{t}-\beta_{2}\left(i_{t}-\pi_{t}\right)+\eta_{t+1}\right]+\varepsilon_{t+2}$,

that is,

$\pi_{t+2}=a_{1} \pi_{t}+a_{2} y_{t}-a_{3} i_{t}+z_{t+2}$,

where $z_{t+2}=\varepsilon_{t+2}+\varepsilon_{t+1}+\alpha_{1} \eta_{t+1}, \alpha_{1}=1+\alpha_{1} \beta_{2}, \alpha_{2}=\alpha_{1}\left(1+\beta_{1}\right)$, and $\alpha_{3}=\alpha_{1} \beta_{2}$.

From equation 5, it is clear that the interest rate set by the central bank at period $t$ will affect inflation in year $t+2$ and beyond, but not in years $t$ and $t+1$; similarly, the interest rate set in period $t+1$ will affect inflation in periods $t+3$ and beyond, but not in periods $t+1$ and $t+2$, and so on. The solution to the optimization problem described earlier can therefore be viewed as consisting of setting the nominal interest rate in period $t$ (and then $t+1, t+2, \ldots$ ) so that the expected inflation in period $t+2$ (and then $t+3, t+4, \ldots$ ) is equal to the target rate. Put differently, because equation 5 implies that $\pi_{t+2}$ is affected only by $i_{t}$ and not by $i_{t+1}, i_{t+2}$, and so forth, the problem of minimizing the objective function $U_{t}$ in equation 4 boils down to a sequence of oneperiod problems,

$$
\min _{i_{t}} \frac{\delta^{2}}{2} E_{t}\left(\pi_{t+2}-\tilde{\pi}\right)^{2}+x_{t}
$$

subject to equation 5 , with

$x_{t}=E_{t}\left\{\sum_{h=t+1}^{\infty} \min _{i_{h}} \delta^{h-t} E_{t}\left[\frac{\left(\pi_{h+2}-\tilde{\pi}\right)^{2}}{2}\right]\right\}$.

In equation $6, x_{t}$ does not depend on $i_{t}$, such that the central bank's optimization problem at period $t$ consists simply of minimizing the ex- 
pected, discounted squared value of $\left(\pi_{t+2}-\tilde{\pi}\right)$ with respect to $i_{t}$ :

$\min _{i_{t}} \frac{\delta^{2}}{2} E_{t}\left(\pi_{t+2}-\tilde{\pi}\right)^{2}$.

Standard statistical results yield ${ }^{7}$

$E_{t}\left(\pi_{t+2}-\tilde{\pi}\right)^{2}=\left(\pi_{t+2 \mid t}-\tilde{\pi}\right)^{2}+V_{t}\left(\pi_{t+2}\right)$,

where $\pi_{t+2 \mid t}=E_{t} \pi_{t+2}$. This expression indicates that the central bank's optimization problem can be equivalently viewed as minimizing the sum of expected future squared deviations of inflation from target - the squared bias in future inflation, $\left(\pi_{t+2 \mid t}-\tilde{\pi}\right)^{2}$-and the variability of future inflation conditional on information available at $t, V_{t}\left(\pi_{t+2}\right)$. Since $V_{t}\left(\pi_{t+2}\right)$ is independent of the policy choice, the problem consists in minimizing the squared bias in future inflation.

Using equation 5 , the first-order condition of problem 7 is given by

$\delta^{2} E_{t}\left\{\left(\pi_{t+2}-\tilde{\pi}\right) \frac{\partial \pi_{t+2}}{\partial i_{t}}\right\}=-\delta^{2} a_{3}\left(\pi_{t+2 \mid t}-\tilde{\pi}\right)=0$,

which implies that

$\pi_{t+2 \mid t}=\tilde{\pi}$.

Equation 9 shows that, given the two-period control lag, the optimal policy for the central bank is to set the nominal interest rate such that the expected rate of inflation for period $t+2$ (relative to period $t+1)$ based on information available at period $t$ be equal to the inflation target.

To explicitly derive the interest rate rule, note that because $\mathrm{E}_{t} z_{t+2}=0$ (from equation 5 ), $\pi_{t+2 \mid t}$ is given by

$\pi_{t+2 \mid t}=a_{1} \pi_{t}+a_{2} y_{t}-a_{3} i_{t}$.

Given the definition of $a_{1}$, this implies that

$i_{t}=\frac{-\left(\pi_{t+2 \mid t}-\pi_{t}\right)+\alpha_{1} \beta_{2} \pi_{t}+a_{2} y_{t}}{a_{3}}$.

7. This standard result is $\mathrm{E}\left(x-x^{*}\right)^{2}=\left(\mathrm{E} x-x^{*}\right)^{2}+V(x)$, that is, the expected squared value of a random variable equals the square of the bias plus the conditional variance. The decomposition in equation 8 is used below in the discussion of the role of uncertainty. 
Because interest rate changes affect inflation with a lag, monetary policy must be conducted partly on the basis of forecasts; the larger the amount by which the current inflation rate (which is predetermined up to a random shock, as implied by equation 1) exceeds the forecast, the higher is the interest rate. The fact that the inflation forecast can be considered an intermediate policy target leads Svensson (1999a) to refer to inflation targeting as inflation forecast targeting. The use of conditional inflation forecasts as intermediate targets in the policy rule is optimal, given the quadratic structure of policy preferences. ${ }^{8}$

The inflation forecast can readily be related to the current, observable variables of the model. This requires setting expression 10 equal to $\tilde{\pi}$ and solving for $i_{t}$ :

$i_{t}=\frac{-\tilde{\pi}+a_{1} \pi_{t}+a_{2} y_{t}}{a_{3}}$.

Given the definitions of the $a_{h}$ coefficients outlined above, this expression can be rewritten to give the following explicit form of the central bank's reaction function:

$i_{t}=\pi_{t}+b_{1}\left(\pi_{t}-\tilde{\pi}\right)+b_{2} y_{t}$,

where $b_{1}=1 /\left(\alpha_{1} \beta_{2}\right)$ and $b_{2}=\left(1+\beta_{1}\right) / \beta_{2}$.

Equation 11 indicates that it is optimal for the central bank to adjust the nominal interest rate upward to fully reflect current inflation and the difference between current and desired inflation rates, as well as increases in the output gap. As emphasized by Svensson (1997a, p. 1119), current inflation appears in the optimal policy rule not because current inflation is a policy target, but because it helps (together with the contemporaneous output gap) predict future inflation, as implied by equation 10 . In addition, rule 11 is certainty equivalent: the same interest rate rule would be optimal in the absence of shocks. Although the central bank cannot prevent temporary deviations of actual inflation from its target value, it can ensure that the effects of such shocks do not persist over time. ${ }^{9}$

8. As noted by Bernanke and Woodford (1997), this result does not imply that the central bank should react mechanically to private sector forecasts. Such forecasts carry the risk of perverse circularity, because private agents may find it optimal to forecast inflation equal to the announced policy target, thereby depriving their forecasts of any informational value for the central bank.

9. This results from the fact that shocks are assumed to be i.i.d. In practice, however, shocks are often persistent; as discussed later, this may have important implications under parameter uncertainty. 
In equilibrium, actual inflation in year $t+2$ will deviate from the inflation forecast, $\pi_{t+2 \mid t}$, and the inflation target, $\tilde{\pi}$, only by the forecast error $z_{t+2}$, as a result of shocks occurring within the control lag, after the central bank has set the interest rate to its optimal value:

$$
\begin{aligned}
& \pi_{t+2}=\pi_{t+2 \mid t}+z_{t+2}, \text { or } \\
& \pi_{t+2}-\tilde{\pi}=z_{t+2} .
\end{aligned}
$$

Even by following an optimal instrument-setting rule, the central bank cannot prevent deviations from the inflation target owing to shocks occurring within the control lag. This fact is important in assessing the performance of inflation-targeting regimes in practice.

\subsection{Policy Trade-offs and Flexible Targeting}

Consider now the case in which the central bank is concerned not only about inflation but also about the size of the output gap. Specifically, suppose that the instantaneous policy loss function of equation 3 is now given by

$$
L_{t}=\frac{\left(\pi_{t}-\tilde{\pi}\right)^{2}}{2}+\frac{\lambda y_{t}^{2}}{2}
$$

where $\lambda$ measures the relative weight attached to cyclical movements in output, with $\lambda>0 .{ }^{10}$ The expected sum of discounted policy losses is now given by

$U_{t}=E_{t} \quad\left\{\sum_{h=t}^{\infty} \delta^{h-t}\left[\frac{\left(\pi_{h}-\tilde{\pi}\right)^{2}+\lambda y_{h}^{2}}{2}\right]\right\}$.

Deriving the optimal interest rate rule when both inflation and output enter the objective function is more involved than was previously the case. Essentially, the problem of minimizing equation 14 cannot be broken down into a series of one-period problems because of the dependence of current inflation on lagged output and of current output on lagged inflation. Using standard dynamic programming techniques, Svensson (1997a, pp. 1140-43) shows that the first-order condition for minimizing equation 14 with respect to the nominal interest rate can be written as

10. Because the so-called bliss level of the output gap is zero, this specification has no built-in inflationary bias; see Cukierman (1992) and the discussion below. 


$$
\pi_{t+2 \mid t}=\tilde{\pi}-\frac{\lambda}{\delta \alpha_{1} \kappa} y_{t+1 \mid t}
$$

where $\kappa>0$ is given by $\kappa=\frac{1}{2}\left\{1-\mu+\sqrt{(1+\mu)^{2}+4 \lambda / \alpha_{1}^{2}}\right\}$, and

$\mu=\lambda(1-\delta) / \delta \alpha_{1}^{2}$

Condition 15 implies that the inflation forecast, $\pi_{t+2 \mid t}$, will be equal to the inflation target, $\tilde{\pi}$, only if the one-period ahead expected output gap is zero $\left(y_{t+1 \mid t}=0\right)$. In general, as long as $\lambda>0, \pi_{t+2 \mid t}$ will exceed (fall short of) $\tilde{\pi}$ if the output gap is negative (positive). The reason is that if the output gap is expected to be negative for instance at $t+1$, the central bank will attempt to mitigate the fall in activity by lowering interest rates at $t$ (given the one-period lag); this policy will therefore lead to higher inflation than otherwise at $t+2$, thereby raising the inflation forecast made at $t$ for $t+2$. For higher values of $\lambda$ (the relative weight on output fluctuations in the policy loss function), the impact of the expected output gap on the inflation forecast will be larger. ${ }^{11}$

An alternative formulation of the optimality condition 15 can be obtained by setting $E_{t} \varepsilon_{t+1}=0$. Then, from equation 1,

$y_{t+1 \mid t}=\frac{\pi_{t+2 \mid t}-\pi_{t+1 \mid t}}{\alpha_{1}}$.

Substituting this result into equation 15 and rearranging terms yields

$\pi_{t+2 \mid t}-\tilde{\pi}=c\left(\pi_{t+1 \mid t}-\tilde{\pi}\right)$,

where

$0 \leq c=\frac{\lambda}{\lambda+\delta \alpha_{1}^{2} \kappa}<1$.

This expression indicates that the deviation of the two-year inflation forecast from the inflation target is proportional to the deviation of

11. The policy loss function 13 can be further extended to account for interest rate smoothing by adding the squared value of changes in $i_{t}$. As shown by Svensson (1997a), an instrument-smoothing objective would make the inflation forecast deviate further from the inflation target-this time to reduce costly fluctuations in interest rates. 
the one-year forecast from the target; when $\lambda=0, c=0$ and the previous result (equation 9) holds. Thus when cyclical movements in output matter for the central bank, it is optimal to adjust the inflation forecast to the inflation target gradually. By doing so, the central bank reduces fluctuations in output. As shown again by Svensson (1997a, pp. 1143-44), the greater the weight on output in the policy loss function (that is, the higher $\lambda$ ), the more gradual will be the adjustment process (that is, the larger $c$ ).

The interest rate rule can be derived explicitly by noting that, from equations 1 and $2, \pi_{t+1 \mid t}=\pi_{t}+\alpha_{1} y_{t}, \pi_{t+2 \mid t}=\pi_{t+1 \mid t}+\alpha_{1} y_{t+1 \mid t}$, and $y_{t+1 \mid t}=\beta_{1} y_{t}-\beta_{2}\left(i_{t}-\pi_{t}\right)$. Substituting the first and third expressions into the second yields

$\pi_{t+2 \mid t}=\pi_{t}+\alpha_{1}\left(1+\beta_{1}\right) y_{t}-\alpha_{1} \beta_{2}\left(i_{t}-\pi_{t}\right)$.

Equating equations 16 and 17 and rearranging terms implies that

$i_{t}=\pi_{t}+b_{1}^{\prime}\left(\pi_{t}-\tilde{\pi}\right)+b_{2}^{\prime} y_{t}$,

where $b_{1}^{\prime}=(1-c) / \alpha_{1} \beta_{2}$ and $b^{\prime}{ }_{2}=\left(1-c+\beta_{1}\right) / \beta_{2}$ from which it can be verified that $b_{1}^{\prime}=b_{1}$ and $b_{2}^{\prime}=b_{2}$ when $\lambda=0$ (and thus $c=0$ ). Equation 18 indicates that as before, the optimal instrument rule requires the nominal interest rate to respond positively to current inflation and the output gap, as well as the excess of current inflation over the target. However, an important difference between reaction functions 11 and 18 is that the coefficients of equation 18 are smaller, owing to the positive weight attached to cyclical movements in output in the policy loss function. ${ }^{12}$ This more gradual response implies that the (expected) adjustment of current inflation to its target value, following a disturbance, will take longer than the minimum two periods given by the control horizon. The time it takes for expected inflation to return to target following a (permanent) unexpected shock is known as the implicit targeting horizon or simply as the target horizon. Naturally, the length of the implicit targeting horizon is positively related not only to the magnitude of the shock and its degree of persistence, but also to the relative importance of output fluctuations in the

12. Certainty equivalence holds in both cases, such that the parameters characterizing the optimal policy rule continue to be independent of variances of the shocks affecting inflation and output (see the discussion below). 
central bank's objective function. As can be inferred from the numerical simulations of Batini and Nelson (2000), it also depends on the origin of the shock - whether it is, for instance, an aggregate demand shock or a supply-side shock. This is because the transmission lag of policy adjustments generally depends on the type of shocks to which the economy is subject and the channels through which these shocks influence the behavior of private agents.

Figure 2 provides a simple illustration of the concepts of control lag and target horizon. Suppose that the inflation rate is initially on target at $\tilde{\pi}$, and the output gap is zero. From equations 11 and 18, the initial nominal interest rate is thus equal to $\tilde{\pi}$ under either form of inflation targeting. Now suppose that the economy is subject to an unexpected random shock at $t=0$ (an increase in, say, government spending) that leads to an increase in the inflation rate to $\pi_{0}>\tilde{\pi}$. As implied by the reaction function under both strict and flexible inflation targeting, the central bank will immediately raise the nominal interest rate, but because inflation is predetermined (monetary policy affects inflation with a two-period lag), actual inflation remains at $\pi_{0}$ in period $t=1$. The behavior of inflation for $t>$ 1 depends on the value of $\lambda$. If $\lambda=0$ (that is, the central bank attaches no weight to movements in the output gap), then inflation will return to its target value at exactly the control horizon, namely, in period $t=2$. The nominal interest rate initially increases to $i_{0}=\pi_{0}+b_{1}\left(\pi_{0}-\tilde{\pi}\right)$ and then returns to $\tilde{\pi}$ at period $t=1$ and beyond; the output gap does not change at $t=0$ but falls to $y_{1}<0$ in period $t=1$, before returning to its initial value of 0 at period $t=2$ and beyond. With $\lambda>0$, convergence of inflation to its target value may take considerably longer; the figure assumes, to fix ideas, that convergence occurs at $t=8 .{ }^{13}$ The interest rate initially increases to $i_{0}^{\prime}=\pi_{0}+b_{1}^{\prime}\left(\pi_{0}-\tilde{\pi}\right)<i_{0}$, which limits the fall in the output gap to $y_{1}^{\prime}<y_{1}$. Although it falls over time, the interest rate remains above its equilibrium value, $\tilde{\pi}$, until period $t=6$ (given the two-period control lag), whereas the output gap remains negative until period $t=7$. In general, the path of inflation, interest rates, and the output gap for $t>1$ will be flatter for higher values of $\lambda$.

13. With an instrument-smoothing objective in the policy loss function, returning inflation to its target value could take even longer because the central bank is also concerned about large movements in interest rates. Strictly speaking, convergence of actual inflation to target when $\lambda>0$ occurs only asymptotically, for $t \rightarrow \infty$. 
Figure 2. Behavior of Inflation, Nominal Interest Rate, and Output Gap Following an Inflation Shock ${ }^{\mathrm{a}}$

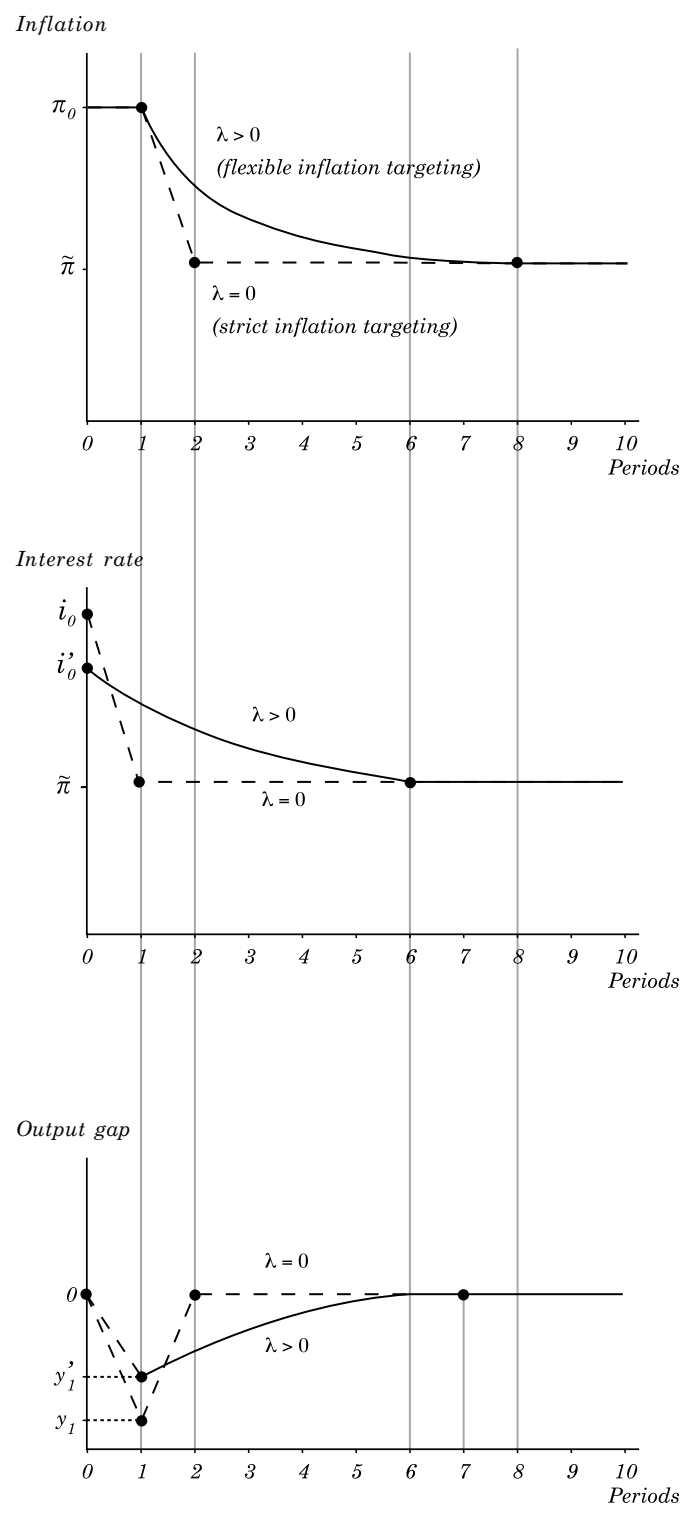

Source: Author's calculations.

a. In percent. 
The central bank's output stabilization goal thus has a crucial effect not only on the determination of short-term interest rates, but also on the speed at which the inflation rate adjusts toward its target after a shock. Policy preferences also affect the variability of output and inflation, and in the presence of supply shocks, flexible inflation targeting entails a trade-off between inflation variability and output-gap variability. By varying the relative weight that the central bank attaches to the two policy goals in its loss function, it is possible to derive an optimal policy frontier (or optimal trade-off curve), which can be defined (following Fuhrer, 1997a, p. 226) as the set of efficient combinations of inflation variability and output variability attainable by policymakers. ${ }^{14}$ The slope of the output-inflation variability frontier is also related to the slope of the aggregate supply curve (Cecchetti and Ehrmann, 1999): the flatter the aggregate supply curve, the larger is the increase in output variability that accompanies a reduction in inflation variability. In addition, the higher the relative weight attached to output fluctuations in the policy loss function, the longer it will take for inflation to converge to its target value following a shock.

\subsection{Inflation Targeting in an Open Economy}

In an open economy, the exchange rate is an essential component of the transmission mechanism of monetary policy. It affects the target variables of monetary policy (inflation and the output gap) through a variety of channels - namely, a direct exchange rate channel via the impact of imported final goods prices on domestic consumer prices, generally with a relatively short lag, and two indirect channels, operating through both aggregate demand and aggregate supply. By altering the real exchange rate, the nominal exchange rate affects aggregate demand, typically with a lag stemming from the time it takes consumers to respond to relative price changes; this affects the output gap and, with another lag, inflation. The exchange rate may also affect aggregate supply (with or without a lag), because costs of production may depend on the cost of imported intermediate inputs, whereas nominal wages may depend on either actual or expected changes in consumer prices caused by exchange rate changes (see Agénor and Montiel, 1999, chap. 8). In turn, the exchange rate is affected by interest rate differen-

14. The existence of a long-run trade-off between the variances of output and inflation does not imply a long-run trade-off between the levels of these variables. In the present setting, such a trade-off only exists in the short run. 
tials, foreign disturbances, and expectations of future exchange rates and risk premiums that depend on domestic factors, such as the size of the domestic public debt or the degree of credibility of the inflation target. The exchange rate is thus important under inflation targeting in an open economy, in transmitting both the effects of changes in policy interest rates and various disturbances. ${ }^{15}$ Because foreign shocks are transmitted through the exchange rate, and the exchange rate affects consumer price inflation, stabilizing exchange rates has remained a key consideration under inflation targeting.

These various channels can be captured in a relatively simple generalization of the closed-economy model presented earlier. Suppose that the economy produces two goods, tradables and nontradables, with the foreign-currency price of tradables set on world markets. The economy's structure is characterized by the following set of equations:

$$
\begin{aligned}
& \pi_{t}^{N}=\Delta e_{t}+\alpha_{1} y_{t-1}^{N}+\varepsilon_{t}, \\
& y_{t}^{N}=-\beta_{2}\left(i_{t-1}-\pi_{t-1}\right)+\beta_{3}\left(\Delta e_{t-1}-\pi_{t-1}^{N}\right)+\eta_{t}, \beta_{3}>0, \\
& \pi_{t}=\delta \pi_{t}^{N}+(1-\delta) \Delta e_{t}, 0<\delta<1, \\
& i_{t}=i^{*}+E_{t} e_{t+1}-e_{t}+\xi_{t}, \text { and } \\
& E_{t} e_{t+1}=e_{t}-\theta\left(\Delta e_{t}-\pi_{t}^{N}\right), \theta>0,
\end{aligned}
$$

where $e_{t}$ denotes (the logarithm of) the nominal exchange rate, $\pi_{t}^{N}$ the inflation rate in nontradables, $i^{*}$ the world interest rate, and $\xi_{t}$ an i.i.d. random disturbance.

Equation 19 is a Phillips curve relationship, which is now assumed to hold only for the nontradables sector. It differs from equation 1 in two respects: there is no lagged effect of nontradables inflation, and the rate of depreciation of the nominal exchange rate is taken to have a direct and immediate impact on the rate of increase of nontraded goods prices. As noted earlier, this effect may reflect the supply-side impact

15. The effects of interest rates and exchange rates on aggregate demand may also depend on the economy's structure of indebtedness. For instance, in a country with a large foreign debt, exchange rate changes may have important wealth and balance sheet effects, possibly offsetting their direct effects on aggregate demand. 
of changes in the price of imported intermediate goods. Equation 20 is the aggregate demand for nontraded goods; it has a form similar to equation 2 , with two modifications: there is no own lagged effect $\left(\beta_{1}=0\right)$ and changes in the real exchange rate (as given by the difference between the rate of nominal depreciation and the rate of nontradables inflation) are assumed to positively affect the demand for home goods with a lag. Equation 21 defines aggregate inflation as a weighted average of inflation in nontradables and tradables; for simplicity, the world price of tradables is assumed constant so that its rate of change is zero. Equation 22 is the uncovered interest parity condition, which relates domestic interest rates to the world interest rate (assumed constant), the expected rate of depreciation of the nominal exchange rate, and a serially uncorrelated random term. Finally, equation 23 relates expectations of future nominal depreciation to contemporaneous movements in the real exchange rate: if nontradables inflation is rising faster than the rate at which the nominal exchange rate is depreciating, the current real exchange rate is appreciating; this, in turn, creates expectations of a future nominal depreciation.

Two types of issues can be explored by studying inflation targeting rules in an open-economy setting. The first is whether the exchange rate channel matters for output stability. To address this issue, suppose that the policy objective is given by equation 14 , which assumes that the central bank targets aggregate inflation, $\pi_{t}$. If the model given by equations 19 through 23 and equation 14 is solved using the dynamic programming approach proposed by Svensson (1997a), then inflation targeting destabilizes output in an open economy. The reason is the effect of changes in the nominal exchange rate on inflation through tradables prices. Because it is the fastest channel from monetary policy to inflation in this model, large movements in the exchange rate can produce excessive fluctuations in output by inducing large changes in interest rates. ${ }^{16}$ Given that the traded and nontraded sectors may react differently in the short run to movements in the (real) exchange rate, the destabilizing effect on aggregate output can be mitigated if the central bank attaches different weights to fluctuations in sectoral output in its objective function (see Leitemo, 1999). However, simulation studies generally tend to corroborate this prediction.

16. Ball (1999) is one of the first to establish this result. Jadresic (1999) also shows that targeting the overall price level may destabilize output in a model with staggered price setting if policymakers cannot observe current realizations of aggregate output and inflation. The generality of this result, however, is unclear at this stage. 
The second issue that can be addressed with an open-economy model is whether targeting inflation in nontradables prices only is more appropriate than targeting aggregate inflation. The instantaneous policy loss function given by equation 13 assumes that the central bank targets aggregate inflation, $\pi_{t}$. If the central bank instead chooses to target nontradables inflation, its instantaneous loss function takes the form ${ }^{17}$

$L_{t}=\frac{\left(\pi_{t}^{N}-\tilde{\pi}^{N}\right)^{2}}{2}+\frac{\lambda y_{t}^{2}}{2}$.

To analyze this issue, consider a shock unrelated to fundamentals that causes a persistent depreciation of the nominal exchange rate-say, a large and sustained outflow of short-term capital resulting from an adverse shift in confidence (Bharucha and Kent, 1998). The immediate effect is an increase in inflation in the traded goods sector. If, for instance, firms producing home goods use imported intermediate inputs (or if nominal wages are indexed to the overall price level), then inflationary pressures will also develop in the nontradable goods sector and prices there may also rise, compounding the initial increase in tradables prices. Targeting aggregate inflation may involve substantial adjustment in the interest rate and increased volatility in output. By contrast, if the central bank is targeting only nontradables inflation, the adjustment of the interest rate would be of a lower magnitude, and output and nontradables inflation would be less variable - albeit at the cost of greater variability in the nominal exchange rate and aggregate inflation.

However, whether nontradables inflation targeting is strictly preferable to aggregate inflation targeting generally depends on the nature of the shocks hitting the economy, in addition to their relative size, as can be shown by solving the model described earlier using either equations

17. A more general specification than equation 24 would account for the possibility that the central bank is also concerned about large shifts in competitiveness. Its period-by-period policy loss function would therefore look like as follows, in case of aggregate inflation targeting:

$L_{t}=\frac{\left(\pi_{t}-\tilde{\pi}\right)^{2}}{2}+\frac{\lambda y_{t}^{2}}{2}+\frac{\varphi\left(\Delta e_{t}-\pi_{t}^{N}\right)^{2}}{2}$,

where $\varphi>0$. It is intuitively clear that concerns about real exchange rate fluctuations would also affect the optimal instrument rule-in the sense of making policy changes more gradual than they would otherwise be-as shown earlier when minimizing output fluctuations was introduced as an additional policy objective. See Svensson (1999a) for a discussion. 
13 or 24 as the policy loss function. Targeting nontradables inflation may produce undesirable outcomes when the economy is subject to shocks other than to the exchange rate. For instance, in response to demand or supply shocks, a central bank with a nontradables inflation target is likely to attempt to restore inflation to its targeted path rapidly. This would occur through large adjustments in the interest rate, which would entail greater volatility in the exchange rate and aggregate inflation.

In sum, whereas an aggregate inflation target may induce excessive volatility in the interest rate (and thus output) to offset exchange rate shocks, a nontradables inflation target may induce excessive volatility in the exchange rate as the policy instrument is adjusted to offset supply or demand shocks. In the simulation results presented by Bharucha and Kent (1998), neither aggregate inflation targeting nor nontradables inflation targeting produced consistently lower volatility in both product and financial markets across all types of shocks.

\section{Comparison with Intermediate Target Strategies}

Price stability as a medium- to long-term goal can be achieved, in principle, not only by focusing directly on the final objective itself, namely, the inflation rate or the price level, but also by adopting either a pegged nominal exchange rate or a monetary target as an intermediate goal. This section reviews these two alternative frameworks for monetary policy and compares them with inflation targeting.

\subsection{Monetary versus Inflation Targeting}

Monetary targeting presumes the existence of a stable relationship between one or more monetary aggregates and the general level of prices. When this is the case, monetary policy can be directed at a particular growth rate in the monetary aggregate (the intermediate objective) that is compatible with low inflation. Specifically, monetary targeting requires adequate knowledge of the parameters characterizing the demand for money. These parameters-most notably the interest elasticity of money demand - may be highly unstable, however, in an economy undergoing rapid financial liberalization. Money then ceases to be a good predictor of future inflation; that is, the relation between the intermediate target and the final objective becomes unstable. In a context of disinflation, the demand for money may be subject to large and unpredictable shifts, and the information content of money for future inflation will therefore be very low. Both arguments suggest that rely- 
ing on monetary aggregates can be potentially risky. If, in addition, monetary targeting is viewed as minimizing money growth variability around the money-growth target - a characterization that is fairly adequate if the policy loss is quadratic - then this policy goal may not be consistent with the objective of minimizing inflation variability: a conflict often arises between stabilizing inflation around the inflation target and stabilizing money growth around the monetary target (see Svensson, 1997a). In fact, monetary targeting generally implies greater inflation variability than inflation targeting. It also leads to increased variability in output by inducing higher volatility in interest rates (Clarida, Galí, and Gertler, 1999). ${ }^{18}$

Several industrial countries did indeed adopt inflation targeting after abandoning (or being abandoned by) their monetary targets as a result of increased distortions in the link between the money supply and overall prices, as documented by Estrella and Mishkin (1997). ${ }^{19}$ However, although some researchers argue that the relationship between monetary aggregates and prices has also weakened in developing countries (see, for instance, Mishkin and Savastano, 2000, p. 22, for Latin America), systematic formal evidence on this issue remains limited, particularly for the late 1990s, and subject to different interpretations. The study by Arrau and others (1995), for instance, shows that the alleged instability in money demand documented in several studies of developing countries in the 1980s may well be the result of an omitted variable, namely financial innovation.

\subsection{Exchange Rate versus Inflation Targeting}

Many countries, particularly in the developing world, have viewed pegging their nominal exchange rate to a stable low-inflation foreign currency as a means of achieving domestic price stability, through a disciplining mechanism with two dimensions. First, to the extent that higher domestic relative to foreign inflation results in a real exchange

18. See McCallum (1999) for a further discussion of the lack of efficiency of monetary targeting.

19. It has also been argued that in practice, those countries that pursue monetary targeting recognize the lack of stability and predictability in the assumed relationships between interest rates and the target monetary aggregate and between the target aggregate and inflation. See, for instance, the discussion of German monetary policy in Bernanke and others (1999). Studies of the reaction function of the Bundesbank also suggest that in addition to monetary variables, real variables have had a significant influence on policy decisions. See Clarida, Galí, and Gertler (2000). 
rate appreciation, the demand for domestic goods will fall, inducing a cyclical downswing that puts downward pressure on domestic prices. Second, to the extent that wage- and price-setting decisions anticipate these consequences of excessive wage and price increases, they should make higher domestic inflation less likely to occur in the first place. In a sense, countries that target their exchange rates against an anchor currency attempt to "borrow" the foreign country's monetary policy credibility.

In a world of high capital mobility and unstable capital movements, however, conventional pegged exchange rates have proved fragile (see Agénor and Montiel, 1999). Simply pegging the exchange rate does not substitute for maintaining monetary stability and credibility at home. In fact, recent experiences suggest that exchange rate pegs can be sustainable only when they are credible, and credibility is largely determined by domestic macroeconomic policies. From that perspective, an inflation-targeting regime may operate better than an exchange rate targeting framework. The domestic currency has been attacked in many developing countries because the central bank had an implicit or explicit exchange rate objective that was not perceived to be credible. In such cases, the adoption of inflation targeting may lead to a more stable currency if it signals a clear commitment to macroeconomic stability and a freely floating exchange rate.

A key characteristic of inflation-targeting regimes in comparison with other approaches to controlling inflation is that the adjustment of policy instruments relies on a systematic assessment of future (rather than past or current) inflation, as opposed to an arbitrary forecast. Under this regime, the central bank must explicitly quantify an inflation target and establish precise mechanisms for achieving this target. This implies that there is an important operational difference between an inflation-targeting regime, on the one hand, and monetary and exchange rate targeting, on the other. ${ }^{20}$ Changes in monetary policy instruments usually affect the money supply and the exchange rate faster than inflation itself; as discussed earlier, this leads to the existence of a control lag and a reaction function that relates the policy instrument to an inflation forecast. The implication, as pointed out by Haldane

20. An important difference between exchange rate targeting and monetary targeting is that while it is possible to deviate temporarily from monetary targets if the underlying relationships appear to have changed, it is generally not possible to temporarily depart from an exchange rate peg (or a target band, for that matter) without incurring a loss of credibility and possibly a currency crisis. 
(1998), is that the credibility of an inflation-targeting regime depends not on achieving a publicly observable, intermediate target that is viewed as a leading indicator of future inflation (as is the case under monetary or exchange rate targeting), but rather on the credibility of a promise to reach the inflation target in the future. This, in turn, depends on whether the public believes that the central bank will stick to the objective of price stability. The credibility and reputation of the monetary authorities may therefore play an even more crucial role in dampening inflation expectations under inflation targeting. At the same time, because performance can only be observed ex post, the need for transparency and accountability becomes more acute under inflation targeting, in order to help the public assess the stance of monetary policy and determine whether deviations from target are due to unpredictable shocks rather than policy mistakes.

\section{Basic Requirements for Inflation Targeting}

There are three basic requirements for implementing an inflationtargeting regime. The first is a high degree of central bank independence, not so much in choosing the inflation target itself but rather in the choice and manipulation of policy instruments. The second is the absence of a de facto targeting of the nominal exchange rate (or, equivalently, the predominance of the inflation target), and the third is increased transparency and accountability.

\subsection{Central Bank Independence and Credibility}

Inflation targeting requires that the central bank be endowed with a clear mandate to pursue the objective of price stability and, most importantly, with a large degree of independence in the conduct of monetary policy—namely, in choosing the instruments necessary to achieve the target rate of inflation. ${ }^{21}$ This implies, in particular, the ability to resist political pressures to stimulate the economy in the short term and the absence of fiscal dominance, that is, of a situation in which fiscal policy considerations play an overwhelming role in monetary policy decisions. Such requirements are difficult to satisfy in countries that

21. Several countries, such as Israel and the United Kingdom, have followed a contractual approach to inflation targeting: the government sets an inflation target in a contract with the central bank and gives the central bank operational independence so that it can manipulate its policy instruments to achieve the agreed target. 
systematically rely on seigniorage as a source of revenue, which is quite common in some developing countries where government borrowing from the central bank is large. ${ }^{22}$ In such conditions, fiscally induced inflationary pressures will undermine the effectiveness of monetary policy, for instance by forcing the central bank to maintain low interest rates in an attempt to prevent unsustainable public debt dynamics. Alternatively, the government may force the central bank to adopt an inflation target that is dictated by seigniorage requirements as opposed to price stability. ${ }^{23}$

Inflation targeting calls not only for a high degree of central bank independence, but also for a sufficient degree of credibility—or more properly (following Drazen and Masson, 1994, and Agénor and Masson, 1999) an adequate anti-inflation reputation. Independence, credibility, and reputation are, of course, related, but they may evolve differently over a given period of time. In countries where the financial system is perceived to be highly vulnerable to, say, exchange rate shocks (as discussed below) and the central bank is perceived to be likely to inject liquidity to prevent a full-blown crisis, the credibility of an announced inflation target may be seriously undermined — even if the central bank is deemed independent. Lack of confidence in the policymakers' commitment to or ability to maintain low inflation may be one of the reasons why inflation often tends to display a strong degree of persistence in developing countries, as illustrated by the autocorrelation functions for twelve developing countries (with the exception of India, Korea, and the Philippines) displayed in figure $3 .{ }^{24}$ But establishing credibility or improving reputation, particularly in countries with a history of high inflation and macroeconomic instability, is a difficult process. Analytically, it has been shown - most notably by Walsh (1995) and Svensson (1997b) - that inflation targets can be used to overcome credibility problems because they can mimic optimal performance incentive contracts. Furthermore, by increasing the accountability of monetary policy, inflation targeting may reduce the inflation bias inherent in discretion-

22. The ability of the central bank to conduct an independent monetary policy is also hampered in some countries by severe weaknesses in the financial system, which may force the central bank to repeatedly inject large amounts of liquidity to support ailing banks.

23. In practice, it has proved difficult to establish a close, stable relationship between fiscal deficits and inflation in developing countries. As discussed by Agénor and Montiel (1999), this may be the result of changes in deficit financing rules or shifts in expectations over time.

24. Inflation persistence may also be the result of backward-looking inflation expectations or overlapping and asynchronized wage and price contracts. 
Figure 3. Autocorrelation Function of Inflation Rate ${ }^{\text {a }}$
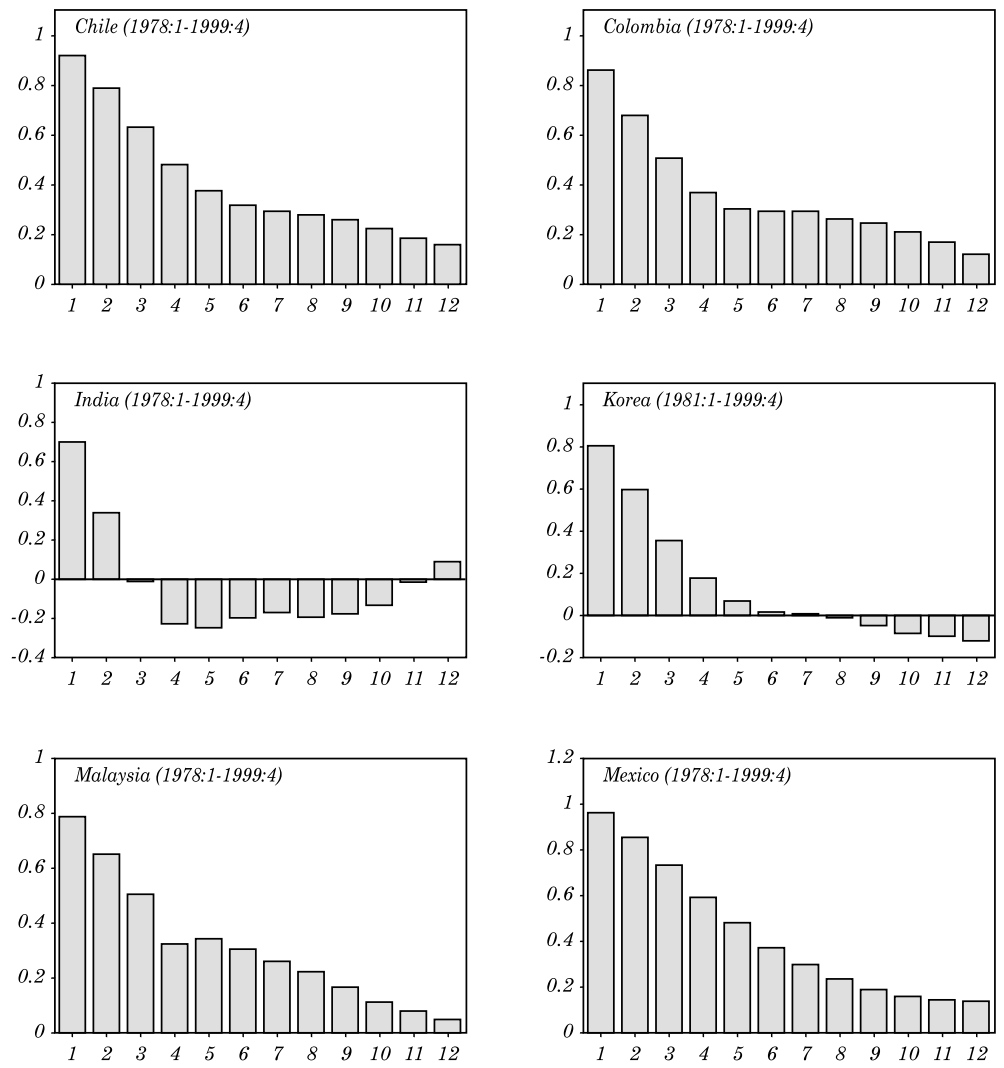

ary policy regimes. The public announcement of inflation targets in itself may help to improve the credibility of the central bank when its policy preferences are uncertain (see Walsh, 1999).

However, the link between inflation performance and the degree of de jure central bank independence does not appear to be particularly strong in developing countries, at least not for the 1980s. Figure 4 illustrates this point for different measures of independence, and it is shown more formally in some recent research (see, for instance, Sikken and De Haan, 1998; De Haan and Kooi, 2000). What matters is de facto independence. For instance, to the extent that a lack of actual autonomy translates into uncertainty about the central bank's preferences over output and inflation, delegating monetary policy involves a trade-off 


\section{Figure 3. (continued)}
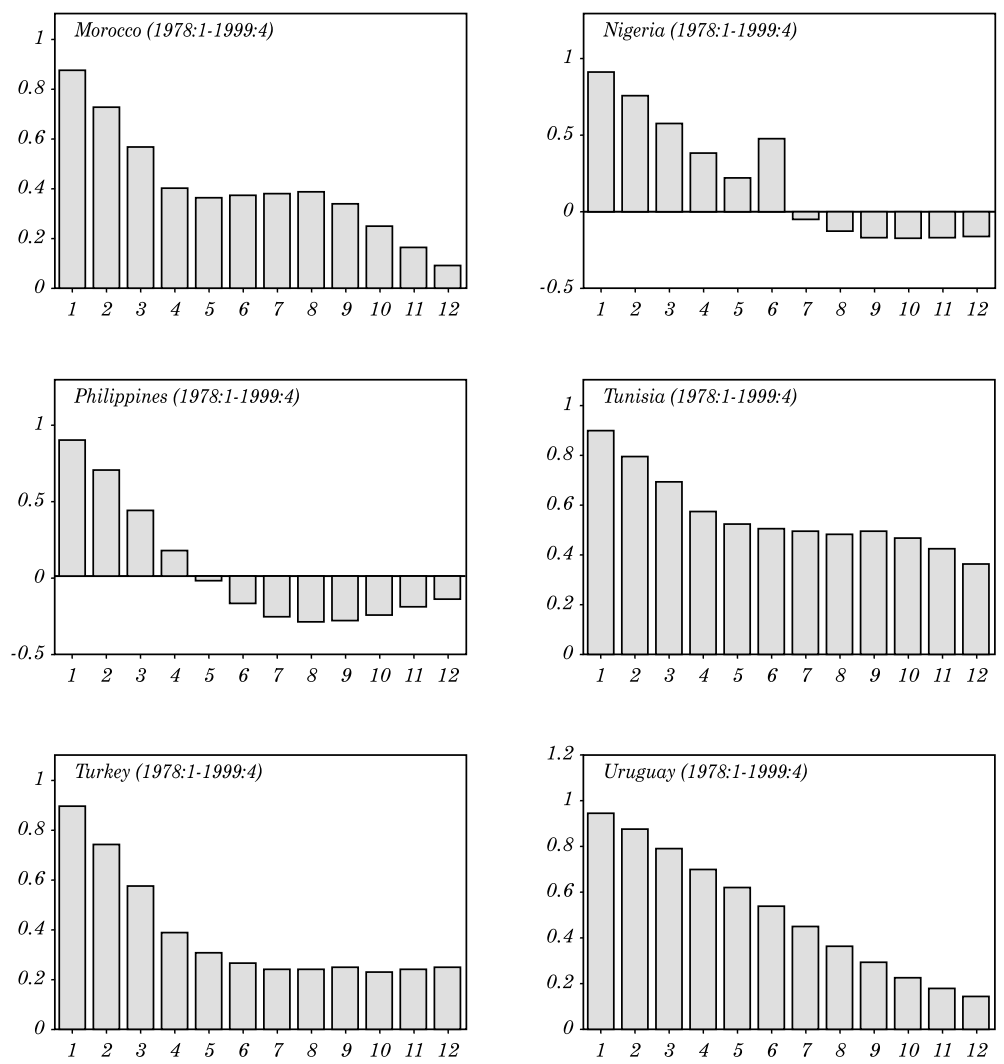

Source: Author's calculations.

a. Quartely annualized growth rates.

between credibility and stabilization, and an optimal contract can perform better than an inflation target (Beetsma and Jensen, 1998). ${ }^{25}$

\subsection{Absence of De Facto Exchange Rate Targeting}

Adopting a low, stable inflation rate as the main objective of monetary policy requires, in principle, the absence of any commitment to a particular value of the exchange rate, as is the case under a floating

25. Muscatelli $(1998,1999)$ argues that neither inflation targeting nor an optimal contract is likely to be superior to Rogoff-type conservatism if central bank preferences are uncertain. 
Figure 4. Average Inflation Rate and Central Bank Independence Index, 1980 - 89a
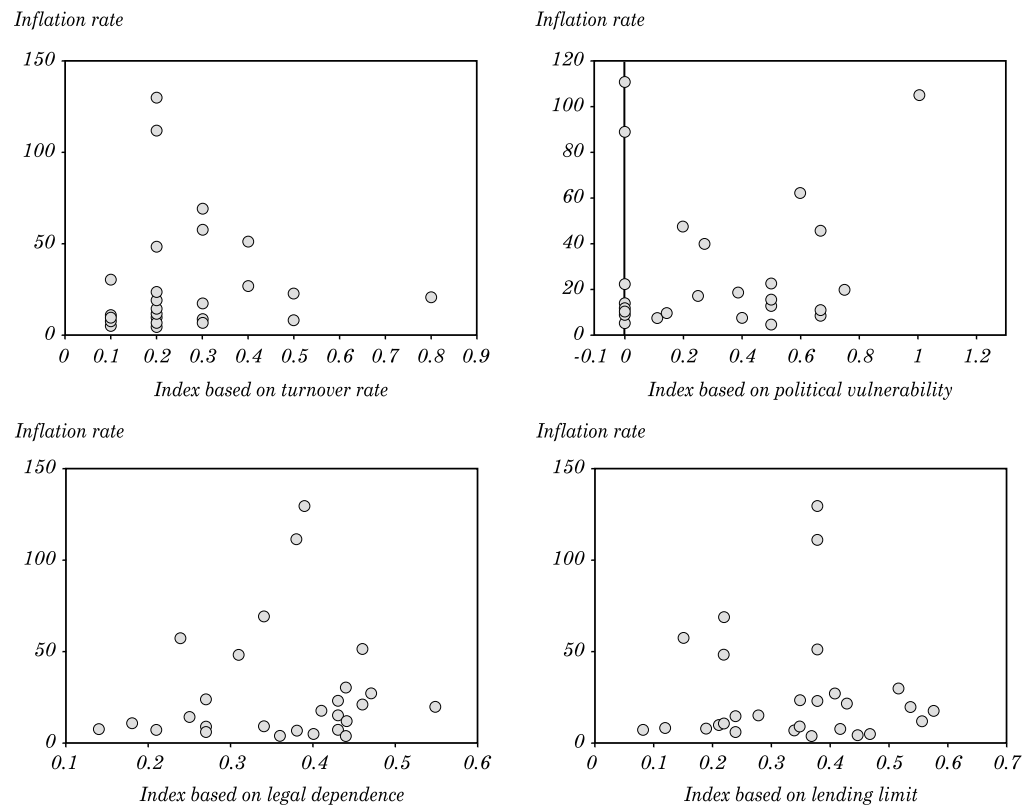

Source: Author's calculations.

a. The countries are Barbados, Chile, Colombia, Costa Rica, Ethiopia, Ghana, Greece, Honduras, India, Indonesia, Israel, Kenya, Korea, Malaysia, Malta, Mexico, Morocco, Nepal, Pakistan, the Philippines, Portugal, South Africa, Tanzania, Thailand, Turkey, Uganda, Uruguay, and Venezuela.

exchange rate regime. In practice, however, in many of the developing countries that have opted for a de jure flexible exchange rate, monetary authorities have continued to pay considerable attention to the value of the domestic currency - often adopting a de facto target path or band. There are various reasons for the central bank to be concerned with nominal exchange rate movements, even when it enjoys a high degree of independence and is thus able to commit itself only to the pursuit of price stability. As noted earlier, the exchange rate has a direct impact on inflation and plays a key role in transmitting monetary policy shocks to prices. If the pass-through effect is indeed high, the central bank may be tempted to intervene on the foreign exchange market to limit currency fluctuations. A high degree of nominal exchange rate instability may also be of concern to policymakers to the extent that it translates into a high degree of variability in the real exchange rate and distorted relative price signals to domestic producers. Furthermore, in 
partially dollarized economies such as Peru or Turkey, large fluctuations in exchange rates can lead to banking and financial instability by inducing large portfolio shifts between domestic- and foreign-currency denominated assets. Finally, in countries where the corporate and banking sectors hold large foreign-currency liabilities, exchange rate depreciations can have significant adverse effects on their balance sheets. This was, indeed, one of the important features of the Asia crisis. ${ }^{26}$

When limiting (or preventing) exchange rate fluctuations is a stated or implicit policy target, it will usually be very difficult for the central bank to credibly and transparently convey to the public its intention to give priority to price stability over other monetary policy objectives. Private agents are likely to discount public pronouncements heavily, and the lack of credibility will translate into higher inflation expectations. The absence of commitment (whether implicit or explicit) to a particular level for the exchange rate — or, equivalently, giving the inflation target unambiguous priority over other policy objectives-is thus an important prerequisite for adopting inflation targeting. In fact, a credible commitment to an inflation-targeting regime in developing economies, by enhancing macroeconomic and financial stability, may well provide a greater degree of stability to a flexible nominal exchange rate than a pegged arrangement that is subject to recurrent speculative pressures (and possibly frequent crises and forced devaluations) stemming from perceived inconsistencies in macroeconomic policy.

\subsection{Transparency and Accountability}

Openness and transparency in the conduct of monetary policy are important ways to improve credibility in an inflation-targeting framework. By making the central bank publicly accountable for its decisions, they raise the incentive to achieve the inflation target and therefore enhance the public's confidence in the ability of the monetary authorities to do so. They may also lead to improved decision-making on the part of the central bank by exposing to public scrutiny the process through which monetary policy decisions are taken (see Briault, Haldane, and King, 1997). The fact, for instance, that monetary authorities must announce policy changes and explain the reason for these

26. See, for instance, Alba and others (1999). These last two points can also be viewed as calling for adequate regulation and supervision of the domestic banking system, rather than as arguments in favor of rejecting inflation targeting as a policy regime. 
changes to the public may increase the effectiveness of monetary policy under inflation targeting. Finally, transparency reduces uncertainty about the central bank's preferences, which may lead to a lower expected rate of inflation and a lower propensity to respond to supply shocks (see Eijffinger, Hoeberichts, and Schaling, 2000). ${ }^{27}$

Faust and Svensson (1998) examine the role of transparency in a model similar to the one developed by Cukierman and Meltzer (1986). The central bank in the model is tempted to deviate from an announced inflation target because of fluctuations in an idiosyncratic component of its employment target. The employment target is private information to the central bank and unobservable to the public. Private agents, nevertheless, observe macroeconomic outcomes (contemporaneous inflation and employment) and imperfectly infer the central bank's employment target. This inference process affects the central bank's perceived reputation by the public, which in turn affects private inflation expectations. In this setting, increased transparency allows the public to infer the bank's employment target with greater precision, thereby rendering the central bank's reputation and the private-sector inflation expectations more sensitive to its actions. This, in turn, increases the cost for the central bank of deviating from the announced inflation target and pursuing its idiosyncratic employment target. Consequently, increased transparency induces the central bank to stick more closely to the announced policy. It provides an implicit commitment mechanism that reduces the temptation for the monetary authorities to act in a discretionary fashion and deviate from the announced policy.

A potential problem with accountability in an inflation-targeting framework is related to the difficulty of assessing performance only on the basis of inflation outcomes. The lag between policy actions and their impact on the economy makes it possible (or tempting) for the central bank to blame unforeseen or totally unpredictable events for inadequate performance, instead of taking responsibility for policy mistakes. To mitigate this risk, the central bank in an inflation-targeting country is usually required to justify its policy decisions and publicly explain differences between actual outcomes and inflation targets. ${ }^{28}$ In what is arguably the strongest case of central bank accountability in inflationtargeting countries, the government in New Zealand can dismiss the

27. This assumes that the public is familiar with the inflation target and the specific price index on which the target is based; see the discussion below.

28. The distinction between goal independence and instrument independence implies that the latter is essential for the accountability of the monetary authorities. 
central bank governor if the inflation target is breached, even temporarily (see Archer, 2000). Openness and transparency have been promoted by the regular publication of an Inflation Report, which sets out the central bank's analysis of recent economic developments, and a forecast of inflation (as well as of other variables, including output) over the coming year or years. In the words of Archer (2000, p. 16),

It is harder for the central bank to "cheat" on its mandate when it is forced to lay out an internally consistent basis for the decisions to be made. To be sure, a good publicist can make almost any position sound reasonable, but when it matters financial markets seem to have good noses for spin-doctoring.

Accountability has been promoted by providing public explanations (in the form of a public letter from the governor of the central bank to the government) of why the rate of inflation deviated from the target by more than a given percentage on either side, how long these deviations are expected to persist, and what policies the central bank intends to implement to bring inflation back to target.

\section{The Operational Framework of Inflation Targeting}

Establishing an operational framework for implementing an inflation-targeting regime requires monetary authorities to take various steps. They must, in particular, specify a price index to target and then quantify the target. They must also determine under what circumstances escape clauses or exemptions to the inflation target are warranted (taking into account the potential credibility loss that their discretionary nature may involve), decide ways through which they can convince the public that achieving the inflation target takes precedence over all other objectives of monetary policy, and devise a forwardlooking operating procedure in which monetary policy instruments are adjusted (in line with the assessment of future inflation) to achieve the target. This section reviews these various requirements, with a particular emphasis on their implications for developing countries.

\subsection{Establishing Inflation Targets}

Establishing inflation targets requires that the central bank specify an index to target, set a level for the target, and identify an explicit quantitative target for inflation for some periods ahead - a process that 
requires deciding whether to set the target as a point or as a band (for instance, between 2 and 4 percent) and choosing the number of quarters or years over which the target will be averaged. They must also set up a model or methodology for inflation forecasting that uses indicators containing information on future inflation.

\section{The Choice of a Price Index}

How to measure inflation is naturally a key issue in the context of inflation targeting. A first question to ponder in this context is whether the chosen price index should reflect the prices of goods and services for current consumption only or for both current and future consumption. Economic theory suggests that a correct measure of inflation captures the prices of both present and future consumption, because only such an index can recognize the scope for intertemporal substitution in consumption (Alchian and Klein, 1973). In practice, however, price indexes do not include prices of present claims over goods and services for future consumption, except indirectly when they incorporate prices of services provided by consumer durables that can be acquired today. Markets for future goods and services generally do not exist, and producing such a comprehensive price index simply is not feasible. ${ }^{29}$

A second point is that the consumer price indexes typically found in developing countries are not adequate measures of the cost of living, despite several advantages such as general acceptance among the public, availability on a monthly basis, publication without long delays, and infrequent data revisions, unlike, say, GDP deflators. In almost all of these countries, consumer price indexes are typically fixed-weight averages of the prices of a basket of goods and services. Price data are gathered by statistical agencies through regular visits to specified sales outlets. The weights are based on the distribution of consumer expenditure by product and are revised at regular intervals to reflect changes in the composition of household expenditures. These indexes are not designed to measure the effect of changes in the types, amounts, and quality of the goods and services that households purchase.

29. In addition, using asset prices (which can be viewed as reflecting the current money prices of claims on future consumption) is fraught with practical difficulties. However, excluding asset prices from the price index used for inflation targeting does not necessarily preclude the possibility of taking these prices into account in the formulation of monetary policy; see the discussion below. 
Existing price indexes thus suffer from three main sources of bias, whose relative importance for measuring inflation varies across countries. Substitution bias arises because consumers switch expenditure away from more expensive products and stores toward cheaper ones. Regular reviews of the weights in the index and of the selection of outlets chosen for sampling purposes helps to reduce substitution bias, but the bias is likely to persist in the periods between these reviews. Quality bias arises because the quality of goods and services within a particular category may change, but the change may not be fully reflected in computing the price index. If quality increases over time (as tends to be the case for many products), failure to account for it fully will lead to overstatement of inflation. New products bias stems from the fact that new goods are continually introduced, whereas existing ones are continuously withdrawn. To the extent that new products widen choice opportunities for households and allow them to achieve a given level of utility at a lower cost than previously, failure to account for them will lead to an overestimate of inflation.

These sources of bias can be quite significant in practice. For instance, the Boskin Report estimates that in the United States, substitution bias (including outlet substitution bias) was about 0.5 percent a year in terms of CPI inflation, whereas quality and new products bias represented about 0.6 percent a year in 1995-96 (Boskin and others, 1996). Accounting for bias is generally very difficult, however. Estimates of bias tend to be very unreliable, and the intensity of bias may vary significantly over time.$^{30}$ Inflation targets are thus usually set with some degree of arbitrariness on the basis of price indexes that suffer from potentially significant measurement problems. In addition, the presence of a considerable amount of transitory noise makes the measurement of inflation difficult, particularly in developing countries. In many of these countries (as in most industrial countries), the consumer price index is a Laspeyres index, that is, an arithmetic mean of the relative prices of the goods and services contained

30. Gordon (1999, p. 17) suggests that the estimates of inflation bias published in the Boskin Report (of which he is a coauthor) were probably under stated, in part because the sharp declines in the prices of new products were not fully taken into account. Cellular phones, for instance, appeared in 1985 in the United States as a consumer product, but they were introduced into the CPI only in 1998 , by which time there were already 55 million subscribers to cellular phone services in the country. The price of these services dropped dramatically between 1985 and 1997. 
Figure 5. Developing Countries: Average Volatility of Consumer Price Inflation and Food Price Inflation, 1981 - $98^{\mathrm{a}}$

Standard deviation of food price inflation

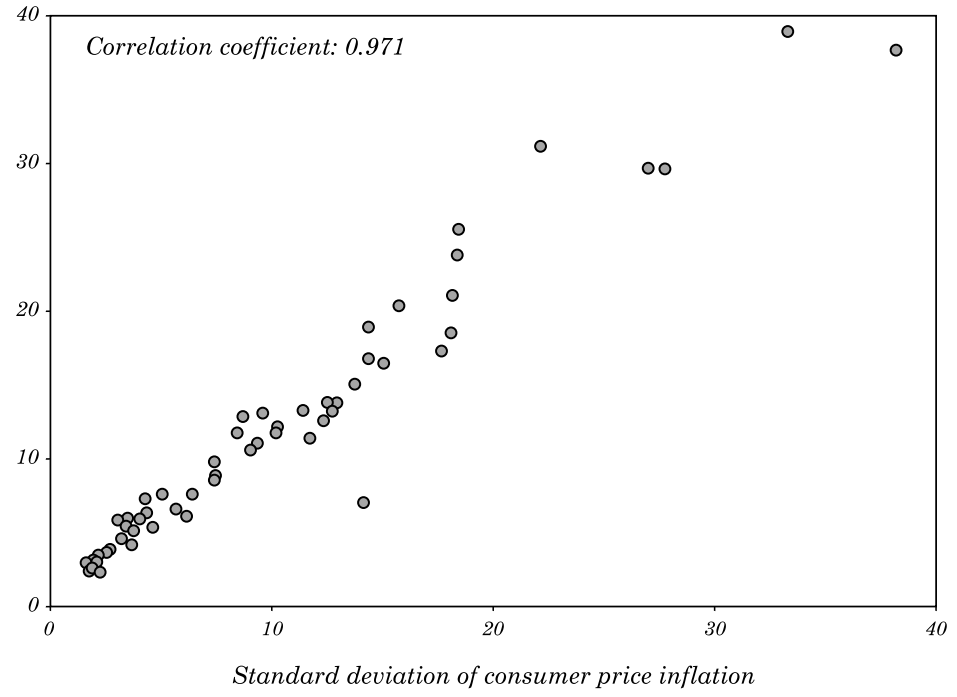

Source: World Bank.

a. The countries are Bangladesh, Benin, Botswana, Burkina Faso, Burundi, Central African Republic, Chad, Chile, Colombia, Congo Republic, Costa Rica, Dominican Republic, Ecuador, Egypt, Arab Rep., El Salvador, Ethiopia, Fiji, Gabon, Gambia, Ghana, Guatemala, Haiti, Honduras, India, Indonesia, Jamaica, Jordan, Kenya, Korea, Lesotho, Madagascar, Malawi, Malaysia, Mauritius, Mexico, Morocco, Namibia, Nepal, Nigeria, Panama, Paraguay, the Philippines, Saudi Arabia, Senegal, South Africa, Sri Lanka, Syria, Tanzania, Thailand, Trinidad and Tobago, Tunisia, Turkey, Uganda, Uruguay, Venezuela, and Zimbabwe.

in a representative basket of goods, with the mean being weighted according to expenditure shares in a base period. ${ }^{31}$ The annual inflation rate is thus measured as the weighted average of the rates of change for individual prices. If the price of a particular component is subject to large short-term movements, then the measured rate of overall inflation will reflect the corresponding movements, in propor-

31. Formally, if $p_{t}^{i}$ denotes the price of good $i$ at period $t(i=1, \ldots n)$ and $q_{t}$ the quantity of good $i$ purchased at period $t$, then the Laspeyres price index between periods $t$ and $t+1$ is $P_{t / t+1}^{L}=\sum^{n} p_{t+1}^{i} q_{t}^{i} / \sum^{n} p_{t}^{i} q_{t}^{i}$. This index tends to overstate inflation, because it assumes no $\stackrel{i=1}{\text { substitution }} \stackrel{i=1}{1}$ consumption expenditures in response to changes in relative prices. By contrast, a current-weighted Paasche index, defined as $P_{t / t+1}^{P}=\sum_{i=1}^{i} p_{t+1}^{i} q_{t+1}^{i} / \sum_{i=1} p_{t}^{i} q_{t+1}^{i}$, uses current quantities as weights and thus tends to overstate substitution and to understate inflation. 
tion with the relative weight of that component in the consumption basket. Such problems can be significant in countries where domestic food prices are a large component of the consumption basket, as they can be highly volatile. Figure 5 illustrates the high correlation between variability in food prices and variability in consumer prices in developing countries. Shocks to the exchange rate, wages, controlled prices, and external inflation that affect price developments can also be beyond the control of monetary authorities.

To alleviate the problem of noisy or erratic short-run movements in prices, inflation-targeting central banks often use a measure of core (or long-term) inflation as their policy target. ${ }^{32}$ Such measures are generally calculated by removing some components of the price indexes, particularly those that appear to be substantially more volatile than prices of other goods and services. The argument is that short-term movements in these prices result from rapid adjustment to frequent real shocks that are often reversed, and so they contain substantially less information about the long-term trend in inflation. By choosing an adjusted price index instead of the general consumer price index, central banks may thus avoid unnecessary fluctuations in interest rates, employment, and output.

In general, inflation-targeting central banks have attempted to remove three types of price disturbances, of which the first two are particularly relevant for developing countries. The first group encompasses disturbances associated with temporary changes in the rate of inflation. Examples are movements in highly volatile, but eventually offsetting, CPI components, such as food and energy prices; shocks to the exchange rate; and changes in indirect taxes or regulated prices that lead to jumps in the price level, without sustained, longer-term effects on the inflation rate. The second type of disturbance involves shocks to inflation that may have long-lasting effects, but for which a strong monetary response would produce very large fluctuations in the real economy. Examples include natural disasters and large changes in prices of imported inputs. Finally, the central bank may seek to remove disturbances associated with the direct effects of policy changes on inflation, in cases in which the targeted price index contains components (such as mortgage payments) that vary directly with the level of shortterm interest rates. The reason is that a tightening in monetary policy may translate into a spurious rise in inflation.

32. See Roger (1998) and Wynne (1999) for recent reviews of the literature on core inflation. 
The identification of these three types of disturbance makes it possible to distinguish between core inflation (as defined above), cyclical inflation (caused, for instance, by food prices), and transitory inflation (price increases generated by specific shocks, such as changes in indirect taxes and imported energy prices, or by shocks to the exchange rate and controlled prices).

In practice, there are several techniques for calculating core inflation (see Wynne, 1999). One method, used by the Bank of Canada, consists of using weights that are linked to the relative price variability of individual goods and services in the consumption basket. Each expenditure weight is divided by the standard deviation of its relative price change (calculated as the difference between the inflation rate of the subcomponent and the overall index), and they are all renormalized (using a single- or double-weighted method) to ensure that they add up to unity. The higher the standard deviation of any given component (that is, the higher its volatility), the lower is its adjusted weight. In this way, all components are kept in the basket, but the effect of the more volatile ones on the overall index is reduced.

Nevertheless, the practical difficulties involved in the calculation of adjusted measures of underlying inflation should not be underestimated. ${ }^{33}$ Truly temporary shocks are rare in practice, and characterizing shocks as such may be the result of an incorrect assessment of general equilibrium effects. Consider, for instance, a rise in indirect taxes that lowers the inflation rate for a limited period of time, after which inflation returns to its previous level. Such changes in taxes will generally also affect the rest of the economy; they may reduce aggregate demand and production, which could have an additional downward effect on inflation in the longer term; they may also alter inflation expectations or wage settlements and thereby affect price-setting decisions. These second-round effects may be protracted, and they must be taken into consideration when establishing an inflation forecast. The proper response to an increase in indirect taxes may not be to refrain from increasing interest rates, but indeed to lower them, if the inflation forecast has fallen below target. A similar argument can be made in relation to temporary energy price shocks. Mechanically excluding certain components of the consumer price index from the policy reaction function can translate into a loss of potentially important information regarding future inflation developments.

33. There remains some disagreement in the literature regarding the very definition of core inflation. Quah and Vahey (1995), for instance, define core inflation as the component of inflation that does not affect real output in the long run. They propose a structural VAR approach for calculating it. 
Differences in price movements between adjusted inflation and total CPI inflation could potentially generate conflict or uncertainty. If the target is not easy for the public to understand and follow, these differences can create credibility problems, particularly in countries with a history of high inflation and a poor reputation for the central bank (see the discussion of the Brazilian experience below). Under such conditions, a headline inflation target, which is more familiar to the public, would make monetary policy more transparent-even if it is subject to some defects in measuring underlying price pressures.

\section{Width of the Target Band}

Many inflation-targeting countries have chosen to specify their inflation target in the form of a band rather than a single point target. A key reason for doing so is the recognition that because economic behavior and outcomes are not completely predictable, it is difficult to hit a single point target continuously. Trying to do so could cause interest rates to be excessively volatile and could destabilize financial markets. By recognizing uncertainty, a target band for inflation can stabilize price expectations. At the same time, a band introduces some degree of flexibility in the conduct of monetary policy. It gives the central bank some discretion over which point in the band it aims for in taking its policy decisions, and it allows the bank to accommodate transitory shocks to inflation - which can provide a partial substitute for targeting a core inflation rate (Orphanides and Wieland, 2000, p. 1383). This flexibility is important not only for stabilizing output fluctuations, but also for accommodating movements in the nominal exchange rate. A large depreciation, for instance, puts upward pressure on domestic prices (as discussed earlier) and thus requires a rise in policy interest rates that may be sizable with a point target. However, the depreciation may weaken corporate balance sheets if firms are highly indebted in foreign currency, pushing them into bankruptcy; the rise in interest rates would only exacerbate the problem. A sufficiently wide band would allow the central bank to accommodate the inflationary impact of exchange rate market pressures (at least to some extent) without large and potentially destabilizing policy changes.

The foregoing discussion suggests that the width of the band should depend on the variability of the inflation rate (which itself depends on the nature, size, and variability of underlying shocks to prices and changes in behavioral patterns), the policy horizon (the further ahead the horizon, the more difficult it is to forecast inflation and predict the 
effects of monetary policy actions), and the degree of discretion that the central bank maintains in the conduct of monetary policy. There is obviously a trade-off between credibility and flexibility in the choice of the optimal target band: the wider the bands, the more likely it is that the target will be achieved, but the less credible is the target. ${ }^{34}$

Another issue is whether the band should be asymmetric. In practice, inflation-targeting countries have tended to adopt symmetric bands on announcing a central target. The signal that central banks attempt to convey in doing so is that they view deflation as being as costly as inflation. Asymmetry may sometimes be desirable, however. If, for instance, the central bank believes that the credibility loss associated with overshooting the target is higher than the loss incurred by undershooting it, an asymmetric band may provide a somewhat higher degree of flexibility. ${ }^{35}$

\section{Horizon of the Inflation Target}

Because inflation is subject to unpredictable shocks and monetary policy operates with a lag, inflation-targeting central banks cannot continuously achieve their target. At what time horizon, then, should monetary policy aim to achieve the inflation target?

Suppose, for instance, that the inflation forecast indicates that with unchanged interest rates inflation will rise above target in the first year of the forecast period and fall below target in later years. If interest rate changes implemented today affect inflation only after a lag of, say, two years, then it is too late to prevent a rise in inflation above target in the first year and interest rates should be lowered so as to bring inflation in the second year and beyond up to target. But suppose now that the control lag is only six months. Increasing interest rates today may therefore allow the central bank to bring inflation down toward target in the second half of the first year of the forecast. At the same time, however, the increase in interest rates today is likely to reduce inflation even further below the forecast at the beginning of the second year. If the lag between policy actions and their effect on inflation are distributed over a period of time, rather than being concen-

34. In a sense, the choice of an optimal inflation target band is reminiscent of the problem of choosing the optimal width of an exchange rate target zone, as discussed by Cukierman, Kiguel, and Leiderman (1994). See Orphanides and Wieland (2000) for a different perspective.

35. As discussed below, asymmetric policy preferences may also lead to an asymmetric optimal instrument rule, regardless of whether a formal band is in place. 
trated at a particular lag length, inflation will remain below forecast for at least part of the second year. The central bank has to use interest rates to manage the path of inflation relative to the inflation target, starting from the point at which monetary policy decisions taken today start affecting inflation in the future. Thus the target horizon cannot be shorter than the control horizon.

At the same time, the central bank needs to take into account the trade-off that may arise between reducing deviations of inflation from target and preventing a high degree of output variability. Suppose an adverse supply shock causes inflation to increase above target. How quickly should the central bank aim to bring inflation back to target? As discussed earlier, there are two conflicting considerations (see figure 2). On the one hand, the quicker the disinflation, the shorter is the period during which inflation is above target; on the other, the quicker the disinflation, the greater are the potential fluctuations in output. The optimal length of the target horizon therefore depends on policy preferences, in addition to the magnitude of the shocks affecting inflation. The greater the relative importance attached to output stabilization relative to inflation stabilization, the longer the optimal length. ${ }^{36}$ If there is an inflationary bias, however, a longer targeting horizon will hamper the credibility of monetary policy, because agents will understand the central bank's greater temptation to inflate and create surprise inflation. This creates a trade-off between credibility and flexibility (Garfinkel and Oh, 1993). Whether a finite targeting period is desirable depends on the cost of limiting flexibility so as to reduce the severity of the credibility problem.

\section{Forecasting Procedure}

Inflation targeting requires that the monetary authorities have the technical and institutional capacity to model and forecast inflation, that they understand the monetary transmission mechanism, and that they are able to estimate the time lag between the adjustment of monetary instruments and their effect on output and prices. This, in turn, implies greater reliance on forward indicators of inflation than in other monetary policy regimes, together with a continuous assessment of the relationship between the instruments of monetary policy and the inflation target.

36. See Batini and Haldane (1999) and Isard and Laxton (2000) for recent quantitative research on policy trade-offs of this type. In practice, stabilizing movements in output can also be achieved by a temporary widening of the target band, if one is in place. 
Figure 6. Developing Countries: Average Consumer Price Inflation and Inflation Volatility, $1981-$ 98 $^{\mathrm{a}}$

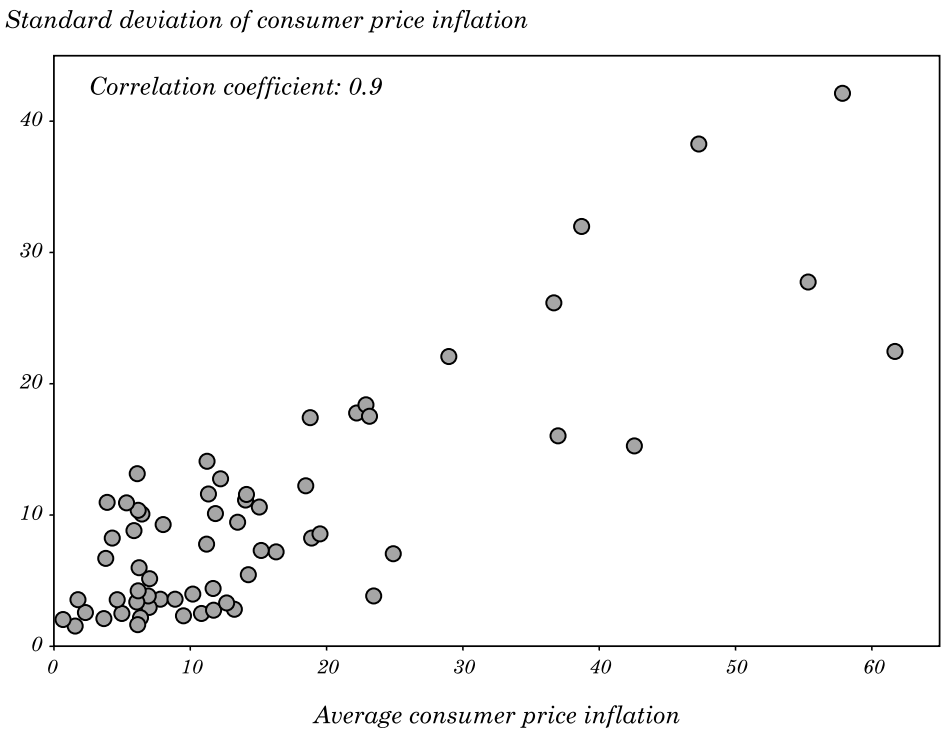

Source: World Bank.

a. For the list of countries represented in this figure, see the note to figure 5 .

Establishing an accurate inflation forecast and a relatively precise estimate of how inflation is likely to be affected by changes in monetary policy instruments is not an easy task when the structure of the economy is unstable and behavioral relationships are unreliable. ${ }^{37}$ Moreover, at higher levels of inflation, the inflation rate tends to be more volatile (as shown in figure 6), and it is thus more difficult to predict future price developments accurately. Under such conditions, setting point targets may actually damage the central bank's credibility. In practice, inflation-targeting central banks have combined economic models (generally small in size) with qualitative judgement regarding how economic behavior and relationships are likely to differ in the future from what has been observed in the past. They have also increasingly recognized

37. In many developing countries, administered or controlled prices are an important component of aggregate price indexes and are thus important factors in the short-run behavior of inflation. A proper inflation-forecasting procedure also needs to incorporate explicit assumptions about the timing and magnitude of changes in these prices. 
in their inflation reports the uncertainty surrounding economic forecasts, that is, the fact that forecasts embody probability distributions of future values of economic variables. The Bank of England, for instance, and many other central banks in its wake-including those of Brazil, Chile, and Sweden-have used a so-called fan chart to present their forecasts (see, for instance, Blix and Sellin, 1998). De-emphasizing, or even not providing, point forecasts helps communicate to the public the inherent uncertainties associated with forecasting.

Releasing an inflation forecast does not necessarily enhance the transparency of the decision process of monetary policy, however. Repeated forecasting errors can eventually reduce the credibility of the central bank by raising doubts about the bank's ability to assess the future behavior of prices. ${ }^{38}$ Another issue is how best to establish and release forecasts to the public. The Bank of England recently began releasing inflation projections based on market expectations of future interest rates. In contrast, many inflation-targeting central banks publish forecasts based on the assumption that policy interest rates will remain constant over the projection horizon. If the predicted path for inflation is too high relative to target, this gives a signal that interest rates will be raised in the near future, which may influence economic conditions and potentially make the forecasts internally inconsistent. ${ }^{39}$ Basing the inflation forecast on endogenous monetary policy responses would make the forecast itself irrelevant, because it would always be on target at the horizon over which the central bank acts to achieve its goals. Public interest would therefore shift to the implied sequence of policy rates embedded in the forecasts. However, central banks may not be willing to release projections of future short-term interest rates, because this may carry the risk that any deviation of policy rates from the forecast level (even if caused by new information) could be perceived as inconsistent behavior by the central bank, thereby harming its credibility. Finally, information regarding the expected path of interest rates is not necessarily useful to the public unless it is specified how short-term interest rates are determined in the first place. Knowledge of the central bank's policy reaction function is essential for determining the implications of new information for the setting of policy instruments.

38. Releasing inflation forecasts can be problematic if they have an undesirable effect on nominal wages, for instance by becoming a floor for centralized wage negotiations.

39. Market observers may also wonder why the future tightening implied by publishing a forecast that shows inflation moving above target has not yet been implemented-and this may hurt the central bank's credibility. 


\subsection{Interest Rates Rules in Practice}

As shown earlier, under strict inflation forecast targeting, the optimal rule is to set the interest rate so as to bring expected inflation in line with the inflation target at the control horizon. By contrast, the optimal rule under flexible inflation forecast targeting is to close less than fully any gap between expected inflation and the inflation target. In practice, inflation-targeting central banks have tended to use simple feedback interest rate rules rather than complicated, optimal targeting rules. Simple feedback rules have some clear advantages. They tend to be more robust when there is uncertainty about the true structure of the economy, they are easier to monitor, and they may help improve credibility. These factors are important in the context of inflation targeting. However, simple rules are also subject to one major weakness: they tend to be less efficient than an optimal rule in the use of information, most notably about the economy's structure.

Two additional issues to consider in this context are, first, whether simple rules display evidence of flexible inflation targeting and, second, whether they embed forward-looking components. Regarding the first issue, some recent research attempts to determine whether the behavior of inflation-targeting central banks can be characterized as strict or flexible inflation targeting. This is done in some cases by testing whether the output gap enters significantly in an empirically estimated interest rate rule. Leiderman and Bar-Or (2000), for instance, estimate the policy reaction function of the Central Bank of Israel using monthly data for the period 1994-99; they find that interest rates are positively related to current inflation, lagged changes in output, and the previous period's interest rate. However, the fact that a significant coefficient is attached to output in an estimated interest rate reaction function does not necessarily imply that in practice monetary policy is guided in part by an output stabilization objective. To the extent that current inflation is only an imperfect proxy for future inflation, and to the extent that the latter depends on the level of economic activity, it is possible for output to appear in the reaction function with a significant coefficient-without, by itself, being indicative of a departure from strict inflation targeting. Indeed, the derivation of the optimal interest rate rule in Svensson's model given above shows that even when the output gap does not enter the policy loss function $(\lambda=0)$, it will (together with current inflation) affect the value of the instrument, because both variables help predict future inflation. 
The second issue relates to the role of forward-looking components in actual policy reaction functions. This is important because simple forecast-based rules have some clear similarities with the type of optimal flexible inflation-forecast targeting rules derived earlier; monetary policy under both types of rules seeks to offset deviations between expected inflation and the inflation target at some horizon. ${ }^{40}$ The Reserve Bank of New Zealand's policy projections, for instance, are based on an explicit, forward-looking policy reaction function that takes a relatively simple form (Archer, 2000). Econometric studies show that monetary policy in the United States, Japan, and Germany can be characterized fairly well by a reaction function that includes a forward-looking measure of inflation, the contemporaneous output gap, and lagged interest rates (to account for smoothing considerations) (see Clarida, Galí, and Gertler, 1998, 2000). The kind of policy rule that underlies this specification is what Clarida, Galí, and Gertler call soft-hearted inflation targeting: in response to a rise in expected inflation relative to target, the central bank raises nominal interest rates sufficiently to push up real rates, but each rule also contains a pure stabilization component. Mehra (1999) estimates a policy reaction function for the Federal Reserve Board that contains both backward- and forward-looking elements; the federal funds rate is shown to depend on actual inflation, increases in expected future inflation, the expected output gap, and the long-term bond rate. The latter variable, which captures the effect of long-term inflation expectations on policy decisions, became particularly important after 1979, the beginning of the Volcker-Greenspan era.

\subsection{Asset Prices and Inflation Targeting}

The role of asset prices - stock prices, house prices, and bond yieldsin the conduct of monetary policy has been the subject of renewed debate in industrial countries (see Cecchetti and others, 2000). Part of the reason is the growing importance of equities in households' financial wealth, as documented, for instance, by Boon, Giorno, and Richardson (1998), and the high degree of volatility exhibited by stock prices in recent years. In the specific context of inflation targeting, (unexpected) movements in asset prices may affect the central bank's inflation forecast. There are at least two reasons why that should be so (see Bernanke and Gertler, 1999;

40. Batini and Haldane (1999), Isard and Laxton (2000), Parrado (1999), and Rudebush and Svensson (1999) analyze the dynamic properties of both simple and optimal forecast-based rules using simulation techniques. 
Smets, 1997). First, changes in asset prices may have a direct impact on aggregate demand. For instance, changes in stock prices may affect private consumption expenditure (through their impact on wealth) and investment spending (by affecting the ability of firms to pledge collateral and raise funds). Second, higher house prices may increase the ability of households to borrow and spend, whereas sharp changes in exchange rates may affect the demand for foreign goods and the ability of firms to sell domestic goods abroad.

To the extent that movements in asset prices are not the result of changes in underlying fundamentals, offsetting these changes through adjustments in monetary policy instruments (essentially a lean-againstthe-wind interest rate policy) may avoid costly fluctuations in output and prices. In addition, asset prices are strongly influenced by expectations of future returns, which, in turn, are related to expectations of future economic activity, inflation, and monetary policy. Even if their impact on aggregate demand is limited, they may contain useful information about current and future economic conditions. This information may be used to improve the inflation forecast on which the direction of monetary policy is based.

The information contained in asset price movements may be limited, however, because the movements may reflect erratic changes in expectations. It may be difficult to gauge the extent to which this is actually the case, because existing asset price models are based on unobserved variables; their empirical predictions are subject to wide margins of error. This makes it difficult to specify the "right" price (reflecting, say, future profit growth rates or productivity shocks) and, therefore, to correctly identify an erratic movement or speculative bubble. Under such conditions, systematically incorporating asset prices in monetary policy feedback rules may be unwarranted (see Fuhrer and Moore, 1992). Moreover, the risk premium that is typically embedded in asset prices tends to vary over time. Basing monetary policy on a broader, asset-based measure of prices or monetary conditions may actually lead to greater variability in current and future output and inflation.

\section{ReCENT EXPERIENCES}

As noted in the introduction, a number of industrial and developing countries have adopted an inflation-targeting regime in recent years. To put matters in perspective, consider the results of the survey of monetary policy frameworks conducted in late 1998 by the 
Bank of England and summarized by Sterne (1999). The survey covers ninety-one countries, of which forty-three are considered developing countries. Almost all the central banks surveyed directly targeted either the money supply, the exchange rate, or inflation. Several central banks in both industrial and developing countries stated that instability in the velocity of money (often induced by financial liberalization) led them to abandon money targeting. In 1998, fiftyfour countries used an explicit inflation target (compared with eight in 1990), thirty-seven used an explicit monetary aggregate target, and forty-seven used an explicit exchange rate target. Explicit targets (whether for money, inflation, or the exchange rate) became more widespread between 1990 and 1998. Of the fifty-four countries that had inflation targets, thirteen (or 14 percent of the total sample) had inflation targets only; thus many countries had more than one explicit target. ${ }^{41}$ The majority of countries that abandoned their exchange rate target, including Mexico in 1995 and Russia in 1998, did so in response to a currency crisis. The fastest growing regime was the combined use of explicit money and inflation targets: 24 percent of the countries in the sample in 1998 employed this regime-more than the combined total of inflation targets only (14 percent) and money targets only (5 percent). In a related study, Morandé and Schmidt-Hebbel (1999) list a total of forty-five countries that adopted some form of inflation target in the 1990s, including twelve industrial countries, twelve transition economies and twenty-one developing countries. They also identify thirty-four countries that targeted primarily money and thirty-six that targeted primarily the exchange rate. Although there is some scope for disagreement with the classification schemes used in these two studies, the broad message is quite clear: a growing number of countries have turned to inflation targeting as a monetary policy framework.

There is now a large literature assessing country experiences with inflation targeting, particularly in the industrial world. Among the most recent publications are those of Bernanke and others (1999), Blejer and others (2000), Landerretche, Morandé, and Schmidt-Hebbel (1999), and Schaechter, Stone, and Zelmer (2000). This section provides a brief summary of these experiences, with a focus on developing countries-most notably Brazil, Thailand, and South Africa.

41. The use of multiple explicit targets may reflect the fact that in practice, monetary authorities view targets more as benchmarks against which outcomes are measured than as objectives that must be achieved. 


\subsection{Industrial Countries}

The first country to introduce inflation targeting was New Zealand in late 1989. Other countries followed suit, including Canada (February 1991), Israel (January 1991), the United Kingdom (late 1992), Australia, Finland, and Sweden (all in 1993), and Spain (January 1995). ${ }^{42}$ These countries adopted inflation targeting in response to either increased instability in the relationship between monetary aggregates and prices or exchange rate crises. In the United Kingdom, for instance, inflation targeting was introduced after the country left the European exchange rate mechanism in September 1992. With the exception of Israel and Spain, all countries implementing inflation targeting did so in the context of a highly flexible exchange rate regime. Israel, for instance, has maintained a diagonal exchange rate band since 1991; the presence of this band acts as a constraint on the inflation objective, and the economy has experienced episodes over the past few years in which the level of interest rates necessary to achieve the inflation target was inconsistent with the level required to maintain the nominal exchange rate within the band (Leiderman and Bufman, 2000). Spain also maintained an exchange rate commitment in the 1990s and therefore cannot be viewed as a pure inflation targeter. In any case, both Spain and Finland dropped formal targets for domestic inflation when they joined the European single currency in 1999.

Table 1 provides a concise summary of the basic elements of the inflation-targeting regimes in eight industrial countries with explicit targets for inflation, including the date their inflation target was first introduced. The table reveals the following facts:

-Most industrial countries specify their inflation target as a range, and the desired target is usually the middle of that range, even if this is not always made explicit. Several countries, such as New Zealand, established intermediate target ranges to reflect an initially high level of inflation and the desire for gradual disinflation.

-Australia, Spain, and the United Kingdom explicitly exclude mortgage interest payments from their headline measures; Australia also excludes government-controlled prices and energy prices. Canada excludes indirect taxes, as well as food and energy prices, while Fin-

42. See Allen (1999) for a review of the United Kingdom's experience with inflation targeting, Freedman (2000) for Canada, Archer (2000) for New Zealand, Leiderman and Bar-Or (2000) for Israel, and the various chapters in Blejer and others (2000). Schaechter, Stone, and Zelmer (2000) provide a general overview. Note that the European Central Bank's monetary policy framework also incorporates elements of inflation targeting. 
land excluded housing capital costs, indirect taxes, and government subsidies. Sweden has no formal exemptions.

-Formal escape clauses (that is, conditions under which the inflation target may be missed) are rarely specified or used. Shocks to inflation have typically been accommodated by allowing fluctuations within the target band or by relying on a measure of core inflation.

-The inflation target typically is not a legislated objective, except in New Zealand, but rather represents an understanding between the government and the governor or president of the central bank. It can be changed either by an amendment to central bank legislation or by a decision of the government.

-Only three of the eight central banks listed in the table now define a term over which the inflation target is to be met, following a transitional period during which an explicit horizon was specified. In most cases the target horizon is indefinite.

-Responsibility for setting the inflation target varies across countries. The target is determined by the central bank in four of the eight countries, whereas the government sets the target in two countries (Australia and the United Kingdom). The decision is joint in the two remaining cases (Canada and New Zealand).

-In six of the eight countries, the central bank provides a formal report on inflation prospects, either voluntarily or by mandate. Four out of eight central banks make explicit inflation forecasts available to the public.

Inflation was on a downward trend in many of these countries prior to the introduction of inflation targets, and inflation persistence continued to drop significantly after the adoption of inflation targets (Siklos, 1999). Furthermore, the degree of risk aversion to inflation volatility in inflation-targeting countries increased significantly in the 1990s (Cecchetti and Ehrmann, 1999). The available evidence does not conclusively indicate, however, whether inflation targeting has lowered inflationary expectations and enhanced credibility, thereby mitigating the real output costs that disinflation typically entails. In fact, sacrifice ratios, which measure the cumulative loss in actual output relative to trend output per percentage point fall in inflation, do not appear to have been much affected by inflation targeting. ${ }^{43}$ In addition, the

43. The computation of the sacrifice ratio is fraught with difficulty, however, as can be inferred from the previous discussion on the measurement of potential output. Empirical estimates often fail to disentangle the impact of disinflation policies from other shocks. Conceptually, the sacrifice ratio also suffers from serious shortcomings; in particular, it focuses only on short-run costs and therefore does not capture the longer-run benefits of disinflation. 


\section{Table 1. Industrial Countries: Basic Features of Inflation Targeting Regimes}

\begin{tabular}{|c|c|c|c|c|c|c|c|c|c|c|}
\hline Country & $\begin{array}{l}\text { Inflation } \\
\text { measure }\end{array}$ & $\begin{array}{l}\text { Items excluded } \\
\text { from inflation } \\
\text { measure }\end{array}$ & Inflation target & $\begin{array}{l}\text { Calculation } \\
\text { period }\end{array}$ & $\begin{array}{l}\text { Contingencies for } \\
\text { breaches of the } \\
\text { inflation target }\end{array}$ & $\begin{array}{l}\text { Targeting } \\
\text { horizon }\end{array}$ & $\begin{array}{l}\text { Adoption } \\
\text { date }\end{array}$ & $\begin{array}{l}\text { Separate } \\
\text { inflation } \\
\text { report }\end{array}$ & $\begin{array}{l}\text { Who sets } \\
\text { target }\end{array}$ & $\begin{array}{l}\text { Published } \\
\text { inflation } \\
\text { forecast }\end{array}$ \\
\hline Australia & CPI & $\begin{array}{l}\text { Mortgage inte- } \\
\text { rest; government } \\
\text { controlled } \\
\text { prices; energy } \\
\text { prices }\end{array}$ & $\begin{array}{l}2-3 \text { percent, } \\
\text { on average, over } \\
\text { the business cycle }\end{array}$ & $\begin{array}{l}\text { Over the } \\
\text { cycle }\end{array}$ & None & None & $\begin{array}{l}\text { 1 Jan } \\
1993\end{array}$ & $\mathrm{No}^{\mathrm{a}}$ & $\begin{array}{l}\text { Govern- } \\
\text { ment }\end{array}$ & No \\
\hline Canada & $\mathrm{CPI}^{\mathrm{b}}$ & $\begin{array}{l}\text { Indirect taxes; } \\
\text { food and energy } \\
\text { prices }\end{array}$ & $\begin{array}{l}2-4 \text { percent by the } \\
\text { end of } 1992 \\
1.5-3.5 \text { percent } \\
\text { by June1994 (original) } \\
1-3 \text { percent Dec } 1993 \text { t } \\
\text { Feb } 2001^{\circ} \text { (revised) }\end{array}$ & $\begin{array}{l}\text { Annual } \\
\text { to }\end{array}$ & None & Yes & $\begin{array}{l}26 \mathrm{Feb} \\
1991\end{array}$ & Yes & Joint & No \\
\hline Finland & CPI & $\begin{array}{l}\text { Housing costs; } \\
\text { capital indirect } \\
\text { taxes; govern- } \\
\text { ment subsidies }\end{array}$ & $\begin{array}{l}2 \text { percent annual } \\
\text { average from } 1995\end{array}$ & Annual & None & No & $\begin{array}{l}02 \mathrm{Feb} \\
1993\end{array}$ & $\mathrm{No}^{\mathrm{d}}$ & $\begin{array}{l}\text { Central } \\
\text { bank }\end{array}$ & No \\
\hline Israel & CPI & None & $\begin{array}{l}\text { 14-15 percent } \\
\text { (1991-92) } \\
\text { 8-11 percent }(1995)\end{array}$ & Annual & $\begin{array}{l}\text { Short-term } \\
\text { influences } \\
\text { embodied in certain } \\
\text { components of the } \\
\text { price index (e.g., } \\
\text { prices of fruits and } \\
\text { vegetables, housing, } \\
\text { and imports) }\end{array}$ & Yes & $\begin{array}{l}\text { 1 Jan } \\
1991\end{array}$ & Yes & $\begin{array}{l}\text { Central } \\
\text { bank }\end{array}$ & Yes \\
\hline
\end{tabular}


Table 1. (continued)

\begin{tabular}{|c|c|c|c|c|c|c|c|c|c|c|}
\hline Country & $\begin{array}{l}\text { Inflation } \\
\text { measure }\end{array}$ & $\begin{array}{l}\text { Items excluded } \\
\text { from inflation } \\
\text { measure }\end{array}$ & Inflation target & $\begin{array}{l}\text { Calculation } \\
\text { period }\end{array}$ & $\begin{array}{l}\text { Contingencies for } \\
\text { breaches of the } \\
\text { inflation target }\end{array}$ & $\begin{array}{l}\text { Targeting } \\
\text { horizon }\end{array}$ & $\begin{array}{l}\text { Adoption } \\
\text { date }\end{array}$ & $\begin{array}{l}\text { Separate } \\
\text { inflation } \\
\text { report }\end{array}$ & $\begin{array}{l}\text { Who sets } \\
\text { target }\end{array}$ & $\begin{array}{l}\text { Published } \\
\text { inflation } \\
\text { forecast }\end{array}$ \\
\hline $\begin{array}{l}\text { New } \\
\text { Zealand }\end{array}$ & $\mathrm{CPI}^{\mathrm{e}}$ & $\begin{array}{l}\text { Commodity } \\
\text { prices; govern- } \\
\text { ment-controlled } \\
\text { prices; interest, } \\
\text { credit charges }\end{array}$ & $\begin{array}{l}3-5 \text { percent (Dec } 1990) \text {; } \\
\text { 2.5-4.5 percent } \\
\text { (Dec 1991) } \\
\text { 1.5-3.5 percent } \\
\text { (1992:1-1992:4) } \\
0-2 \text { percent }(1993-96) \\
0-3 \text { percent since } \\
\text { Dec } 1996^{f}\end{array}$ & Annual & $\begin{array}{l}\text { Unusual events that } \\
\text { do not generate } \\
\text { general inflationary } \\
\text { pressures }\end{array}$ & Yes & $\begin{array}{l}02 \mathrm{Mar} \\
1990^{\mathrm{g}}\end{array}$ & Yes & Joint & Yes \\
\hline Spain & CPI & $\begin{array}{l}\text { Mortgage } \\
\text { interest costs }\end{array}$ & $\begin{array}{l}\text { 3.5-4 percent } \\
\text { (June 1996) } \\
\text { 3.0-3.25 percent (1997:1) } \\
3 \text { percent upper } \\
\text { limit for } 1997 \\
\text { 2.50-2.75 percent } \\
\text { upper limit for } \\
\text { late } 1997 \\
2 \text { percent for } 1998^{\mathrm{h}}\end{array}$ & Annual & None & Yes & $\begin{array}{l}\text { 1 Jan } \\
1995\end{array}$ & Yes & $\begin{array}{l}\text { Central } \\
\text { bank }\end{array}$ & No \\
\hline Sweden & CPI & $\begin{array}{l}\text { Nominally none, } \\
\text { but conditional } \\
\text { on indirect taxes, } \\
\text { subsidies }\end{array}$ & $\begin{array}{l}1-3 \text { percent since } \\
1995\end{array}$ & Annual & None & No & $\begin{array}{l}\text { 15 Jan } \\
1993\end{array}$ & Yes & $\begin{array}{l}\text { Central } \\
\text { bank }\end{array}$ & Yes \\
\hline
\end{tabular}


Table 1. (continued)

\begin{tabular}{|c|c|c|c|c|c|c|c|c|c|c|}
\hline Country & $\begin{array}{l}\text { Inflation } \\
\text { measure }\end{array}$ & $\begin{array}{l}\text { Items excluded } \\
\text { from inflation } \\
\text { measure }\end{array}$ & Inflation target & $\begin{array}{l}\text { Calculation } \\
\text { period }\end{array}$ & $\begin{array}{l}\text { Contingencies for } \\
\text { breaches of the } \\
\text { inflation target }\end{array}$ & $\begin{array}{l}\text { Targeting } \\
\text { horizon }\end{array}$ & $\begin{array}{l}\text { Adoption } \\
\text { date }\end{array}$ & $\begin{array}{l}\text { Separate } \\
\text { inflation } \\
\text { report }\end{array}$ & $\begin{array}{l}\text { Who sets } \\
\text { target }\end{array}$ & $\begin{array}{l}\text { Published } \\
\text { inflation } \\
\text { forecast }\end{array}$ \\
\hline $\begin{array}{l}\text { United } \\
\text { Kingdom }\end{array}$ & RPI & $\begin{array}{l}\text { Mortgage interest } \\
\text { payments }\end{array}$ & $\begin{array}{l}\text { 1-4 percent until } \\
\text { June } 1997 \text { elections } \\
2.5 \text { percent since } \\
\text { June } 1997\end{array}$ & Annual & None & No & $\begin{array}{l}08 \text { Oct } \\
1992\end{array}$ & Yes $^{\mathrm{i}}$ & $\begin{array}{l}\text { Gover- } \\
\text { nment }\end{array}$ & Yes \\
\hline
\end{tabular}

Source: Author's compilation, based on Allen (1999); Archer (2000); Leiderman and Bar-Or (2000); Schaechter, Stone, and Zelmer (2000); and national central bank reports a. However, the Governor is available to report on the conduct of monetary policy twice a year to the House of Representatives Standing Committee on Financia Institutions and Public Administration.

b. Although the target is officially specified in terms of overall CPI, the Bank of Canada focuses on the CPI excluding food, energy, and the effect of indirect taxes. c. Renewed in February 1998.

d. Finland reports quarterly on the inflation outlook in its Monthly Bulletin.

e. Since December 1997, the CPI excluding credit services is targeted. Before that date, overall CPI was targeted. In late 1999, mortgage interest rates were removed from the index.

f. The term of the new Policy Targets Agreement (PTA) coincides with the current term of the Governor, which expires August 31, 2003. The PTAs were specified in December. g. The Reserve Bank's announced policy included a specific target for inflation and a specific date for that target to be achieved as early as mid-1989 (Archer, 2000 ). h. The Law of Autonomy was put in place in June 1994, and although the inflation target was announced in December 1994, it was formally adopted only as of 1 January 1995. Between 1995 and 1997 the aim was to reduce inflation to the 2 percent range. In 1998, the aim was to keep the annual inflation rate close to 2 percent throughout the year. i. Only since 12 June 1997 
introduction of inflation targets does not appear to have dramatically affected inflation expectations, as revealed either by surveys or by the level of long-term nominal interest rates (Bernanke and others, 1999). Inflation expectations have come down, in most cases, mainly because inflation-targeting central banks were able to demonstrate that they were capable of achieving and maintaining low inflation. A recent quantitative analysis of the performance of inflation targeting in Canada, New Zealand, and the United Kingdom provides some support for this view (Honda, 2000). Honda estimates an unrestricted VAR model with four variables (namely, inflation, deviations of output from trend, the short-term nominal interest rate, and the rate of change of the nomi-

nal exchange rate) over a sample period prior to the introduction of inflation targeting and then simulates the model dynamically over the period following the adoption of inflation targeting. If predicted values from the model tend to overestimate actual values of inflation and the other variables in the system, then inflation targeting can be deemed to have had some favorable impact on inflation and other macroeconomic variables. On this basis, Honda finds no evidence that inflation targeting had an effect on either inflation or any other variable in the system. The power of alternative stability tests in a VAR context is an open issue, but Honda's analysis appears to be a promising way of analyzing the impact of inflation targeting on actual inflation performance.

\subsection{Developing Countries}

Few developing countries have adopted inflation targeting to date, but the number of potential candidates appears to have risen significantly in the past two or three years. Not all developing countries that have floated their currency in recent years have adopted an inflationtargeting framework, whether explicit or implicit. Mexico is a case in point. Carstens and Werner (2000) argue, for instance, that the high frequency and incidence of both domestic and external exogenous shocks to domestic prices, including nominal exchange rate fluctuations and movements in wages and public sector prices, make the adoption of an explicit inflation-targeting framework unfeasible in the case of Mexico. In Peru, the central bank has announced an annual inflation target since 1994, but it does not pursue a formal inflation-targeting regime. Nevertheless, both countries have been viewed by some observers as moving toward the adoption of such a framework (see Mishkin and Savastano, 2000). By contrast, Chile has a long history of announcing one-year-ahead inflation targets that goes back to 1990, although the 
authorities only recently started to make its inflation report publicly available (in May 2000). ${ }^{44}$ Brazil, South Africa, and Thailand recently adopted such a regime, and several other countries, including those in East Asia that adopted a floating exchange rate following the 1997-98 financial crisis, are currently pondering the feasibility of such an approach. ${ }^{45}$ Chile's experience is well documented by Landerretche, Morandé, and Schmidt-Hebbel (1999); this section therefore provides a brief discussion of the cases of Brazil, South Africa, and Thailand.

Table 2 summarizes the main characteristics of inflation-targeting regimes in Chile, Brazil, South Africa, and Thailand. Brazil adopted an inflation-targeting framework for monetary policy on 21 June 1999, following the real crisis of January 1999 and the adoption of a floating exchange rate (see Bogdanski, Tombini, and Werlang, 2000). The inflation targets, as well as the tolerance bands, are set by the National Monetary Council, on the basis of a proposal by the Finance Minister. In principle, these targets must be set two years in advance. The price index chosen for setting the inflation targets is the Broad Consumer Price Index (IPCA), reported by the National Bureau of Geography and Statistics (IBGE), although monthly measures of core inflation have also been published since March 2000 (see Figueiredo, 2000). The choice of a full index was dictated by the need to mitigate potential credibility problems associated with perceptions of deliberate manipulation of the index.

The operational framework of Brazil's inflation-targeting program consists of a set of models to support the monetary policy decisionmaking process, including a small-scale structural econometric model and shortterm univariate forecasting models. The models are supplemented with surveys of market expectations of major macroeconomic variables, including inflation and growth. The econometric model focuses on the aggregate demand channel of monetary policy, with a direct effect through changes in nominal interest rates and an indirect effect through relative prices induced by the effect of changes in the nominal interest rate on the exchange rate.

The targets are considered to be met whenever the observed accumulated inflation during the period January to December of each year (measured on the basis of variations in the IPCA) falls within the band.

44. Because Chile maintained a crawling peg exchange rate regime until September 1999, some observers have argued that the adoption of a full-fledged inflation-targeting framework is only a recent phenomenon; see Schaechter, Stone, and Zelmer (2000, p. 12)

45. In countries like Korea, for instance, the central bank is now required by law to set a price stability target every year, in consultation with the government. 
Table 2. Developing Countries: Basic Features of Inflation Targeting Regimes

\begin{tabular}{|c|c|c|c|c|}
\hline \multirow[b]{2}{*}{ Feature } & \multicolumn{4}{|c|}{ Country } \\
\hline & Brazil & Chile & South Africa & Thailand \\
\hline Inflation measure & CPI & CPI & CPI & CPI \\
\hline $\begin{array}{l}\text { Items excluded from } \\
\text { inflation measure }\end{array}$ & None & None & Mortgage interest costs & Raw food and energy prices \\
\hline Inflation target & $\begin{array}{l}\text { 1999: } 8 \text { percent } \pm 2 \text { percent } \\
\text { 2000: } 6 \text { percent } \pm 2 \text { percent } \\
\text { 2001: } 4 \text { percent } \pm 2 \text { percent } \\
\text { 2002: } 3.5 \text { percent } \pm 2 \text { percent }\end{array}$ & $\begin{array}{l}\text { 1991: } 18 \text { percent } \\
\text { 2000: } 3.5 \text { percent } \\
2001 \text { onwards: } 3 \text { percent } \pm 1 \text { percent }\end{array}$ & 2002: 3-6 percent & 2000-01: 0-3.5 percent \\
\hline Calculation period & Annual & Annual & Annual & Annual \\
\hline $\begin{array}{l}\text { Contingencies for breaches } \\
\text { of the inflation target }\end{array}$ & None & None & $\begin{array}{l}\text { Major unforeseen events } \\
\text { outside central bank control }\end{array}$ & None \\
\hline Targeting horizon & Yes & No & Yes & Yes \\
\hline Adoption date & 21 June 1999 & 1 Sept 1990 & 1 Feb 2000 & 1 May 2000 \\
\hline Separate inflation report & Yes & $\mathrm{Yes}^{\mathrm{a}}$ & $\mathrm{Yes}^{\mathrm{c}}$ & Yes $^{b}$ \\
\hline Who sets target & Joint & Central bank & Joint & Central bank \\
\hline Publishes inflation forecast & Yes & Yes & No & Yes \\
\hline
\end{tabular}

Source: Author's compilation, based on Landerretche, Morandé, and Schmidt-Hebbel (1999); Bogdanski, Tombini, and Werlang (2000); Schaechter, Stone, and Zelmer (2000); and national central bank reports.

a. The first inflation

first inflation report was published in July 2000

c. The Reserve Bank has prepared an inflation report since the end of 1996. At this stage, the report is not distributed outside the Bank. 
Figure 7. Brazil: Consumer Price Inflation and Inflation Targets, 1995 - 2002

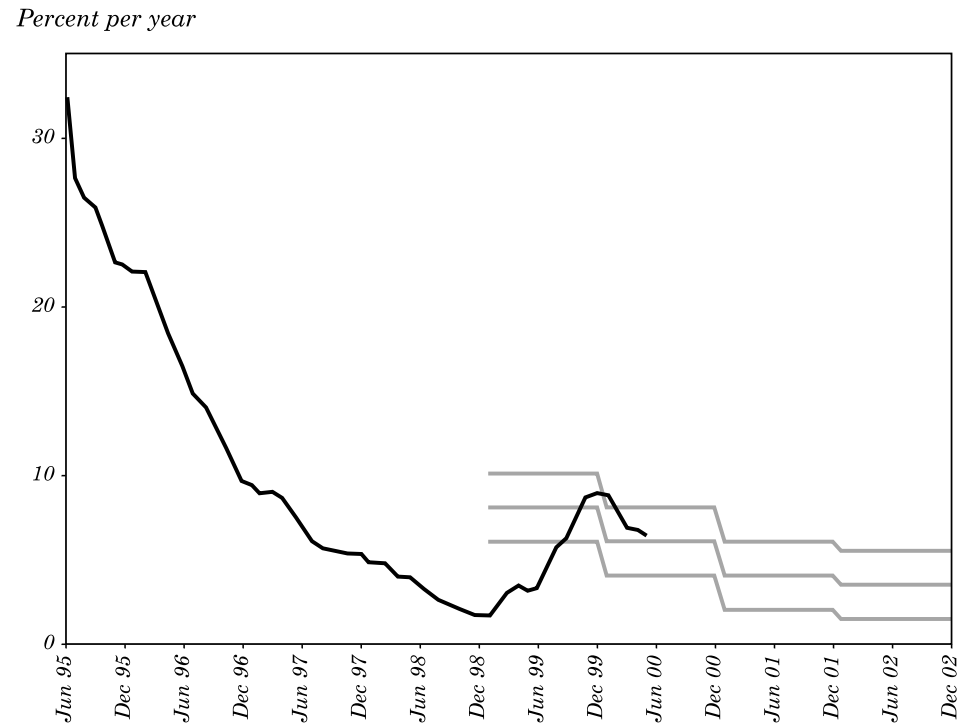

Source: International Monetary Fund and Banco Central do Brasil.

If the target is missed, the Central Bank Governor must issue an open letter to the Finance Minister explaining the causes of the breach, the measures to be adopted to ensure that inflation returns to the target band, and the period of time that will be needed for these measures to have the intended effect. Since September 1999, the Central Bank also issues a quarterly inflation report (in both Portuguese and English) that provides information on current and future inflation performance and on the effect of monetary policy on prices. Minutes of the monthly Monetary Policy Committee meetings are released with a two-week lag, which is soon to be reduced to one week. In June 1999, official inflation goals were announced for the coming three years: 8 percent in 1999, 6 percent in 2000, and 4 percent in 2001 (accumulated annual variations by year-end). Tolerance intervals were set at 2 percent for each year. As shown in figure 7 , inflation has been on a downward path since the introduction of the inflation-targeting regime and has remained well within the target band.

South Africa adopted a full-fledged inflation-targeting framework in February 2000, at a time when the country's inflation performance 
was continuing to improve-falling to 5.2 percent in 1999 from 8.6 percent in 1997 and 6.9 percent in $1998 .^{46} \mathrm{~A}$ key reason for doing so was the perceived growing instability between monetary aggregates and inflation in a context of financial liberalization (Schaechter, Stone, and Zelmer, 2000). The inflation objective is currently expressed in terms of an adjusted inflation rate, namely, the headline consumer price index excluding mortgage interest costs. Escape clauses include major unforeseen events deemed to be outside the control of the Reserve Bank. The target range for the year 2002 is a band of 3 to 6 percent average inflation. This medium-term target was set in view of estimated lags between monetary policy decisions and their impact on inflation: changes in interest rates in South Africa have been estimated to take from eighteen to twenty-four months to affect inflation. The relatively large width of the band was chosen to account for the fact that the targeted price index includes a large number of volatile items, whose movements are beyond the control of the Reserve Bank. Attempts to improve transparency have taken the form of public explanations of the monetary policy stance following meetings of the Monetary Policy Committee of the Reserve Bank (although full minutes of the deliberations are not yet released), the creation of a Monetary Policy Forum that meets twice a year (in May and November), and the publication of a semiannual Monetary Policy Review beginning in 2001, which will represent the Reserve Bank's inflation report. At this stage, inflation forecasts and the underlying forecasting models are not released to the public.

Thailand, in turn, adopted a floating rate regime after the collapse of the Thai baht in July 1997, after almost five decades of pegged exchange rate regimes. The new regime initially contemplated monetary targeting, with quarterly monetary base targets (agreed with the IMF) that were implemented and achieved through daily liquidity management. However, growing evidence of instability in the relationship between money, output, and inflation led Thailand to announce the adoption of inflation targeting as a monetary policy framework in May 2000. Under this regime, monetary policy is decided by the Monetary Policy Board (MPB), which was appointed in April 2000 and comprises both high-level central bank officials and external experts. A recent amendment to the Bank of Thailand's charter gives the MPB official status and operational independence in conducting monetary policy; it also

46. Before February 2000, the Reserve Bank had an informal goal of maintaining inflation at a level that would be more or less in line with the average inflation rate in South Africa's major trading partners and international competitors. 
reaffirms that price stability is the overriding objective of monetary policy. The price index targeted by the central bank is an index of core inflation, which excludes raw food and energy prices from headline inflation as both components are deemed to be highly volatile. The target core inflation rate is set in the form of a band (between 0 and 3.5 percent for 2000-01) that explicitly aims to give the Bank of Thailand room for cushioning temporary shocks and reduce interest rate volatility. At the time of the adoption of inflation targeting, annual headline and core inflation were at 2 percent and 1.2 percent, respectively. Deviations from the target band are monitored on the basis of quarterly averages of core inflation, to avoid the high degree of volatility that may characterize monthly observations. If core inflation breaches the target band, the MPB must explain why the breach occurred, identify the measures that it intends to take in response, and estimate the amount of time required to bring inflation back within the desired range. Finally, the first quarterly inflation report was issued in July 2000; risks associated with inflation forecasts are shown in fan charts, as is now the practice among several other inflation-targeting central banks.

\section{Unresolved Analytical Issues}

Analytical and operational aspects of inflation-targeting regimes continue to generate a large amount of research. How best to measure core inflation, for instance, continues to be actively discussed. This section focuses on three important issues of debate in the analytical literature: the implications of asymmetries for the design and operation of an inflation-targeting regime; the implications of uncertainty (regarding the variables to be measured, behavioral parameters, and policy lags); and the treatment of credibility and reputational factors in empirical models of inflation.

\subsection{Effects of Asymmetries}

This section considers two types of asymmetries: those related to policy preferences and those dealing with the slope of the trade-off between inflation and the output gap.

\section{Nonquadratic Policy Preferences}

The central bank's instantaneous policy loss functions, as defined by equations 3 and 13, were taken to be symmetric; positive output 
gaps, for instance, were considered to be just as costly as negative output gaps. Adopting this approach is justified not only because of its tractability but also because it is a reasonable approximation of an underlying utility-based welfare function (Rotemberg and Woodford, 1999). In general, however, the short-run cost of disinflation may matter a great deal to the central bank and may lead to a situation in which a higher weight is attached to negative output gaps-for instance by adding a term that is linear in $-y$ in equation 13 . As a result, the optimal inflation rate may be greater than $\tilde{\pi}$ even if there is no longrun trade-off between output and inflation.

More fundamentally, Orphanides and Wieland (2000) question the use of a quadratic objective function for policymakers in the analysis of inflation-targeting regimes. They begin by noting that in practice, most inflation-targeting central banks specify a target band as opposed to point targets, as discussed above. They then argue that the existence of a target range implies a nonlinear optimal policy rule. A simple way to specify policy preferences that are consistent with a target band is to write the instantaneous loss function as follows, replacing equation 13:

$L_{t}=\frac{\left(\pi_{t}-\tilde{\pi}\right)^{2}}{2}+\frac{\lambda y_{t}^{2}}{2}+\frac{\phi\left|y_{t}\right|}{2}$,

where $\phi>0$. As shown by Orphanides and Wilcox (1996), this specification implies an asymmetric policy response: as long as inflation is relatively close to target, the optimal interest rate policy is simply to stabilize output. Otherwise, policy should keep inflation within a range, which varies positively with $\lambda$, and then wait for favorable supply shocks (positive shocks to $\varepsilon_{t}$ ) to move it closer to the desired value of $\tilde{\pi}$.

Orphanides and Wieland (2000) consider a more general specification than equation 25, namely, a zone-quadratic policy loss function. In this type of specification, the loss function assigns a quadratic loss to inflation deviations outside an explicit target band and a near-zero loss as long as inflation fluctuates within the band. If the central bank assigns some weight to fluctuations in output (as is generally the case in practice), the output objective will dominate during periods in which inflation is within the band and will lose some importance when inflation is outside the band. They argue that this specification of policy preferences is consistent with the often-observed tendency of central banks to show overwhelming concern with inflation only when it is beyond some range. Using numerical analysis, Orphanides and Wieland also find that with nonquadratic preferences (and a nonlinear infla- 
tion-output trade-off, as discussed below), uncertainty with regard to unexpected shocks has important effects on the width of the target band and on the relative size of the policy response inside and outside the band. The optimal policy rule under uncertainty does not call for a mechanical response only when inflation falls outside the band. Rather, it is optimal to respond to inflation deviations that are still within the band and then to respond more aggressively if inflation continues to evolve outside the desired range. ${ }^{47}$

Although intuitively appealing, Orphanides and Wieland's results deserve further scrutiny. Growing evidence appears to support nonlinearities regarding aggregate behavioral functions, such as the Phillips curve discussed below, but the empirical research on the structure of policy preferences is less conclusive. Other recent studies support the standard approach. Chadha and Schellekens (1999), for instance, compare several alternative specifications of the central bank's loss function; they suggest that the assumption of quadratic losses may not be too far off the mark. Of course, such results may also be model specific.

\section{The Convex Phillips Curve}

As discussed earlier, establishing forecasts in the context of inflation targeting requires a reasonable understanding of the structure of the economy and adequate parameterization of some key aggregate relationships, most notably between interest rates and output and between output and inflation. A growing literature appears to indicate that the relationship between changes in the output gap and inflation may be nonlinear in industrial countries. Specifically, it suggests that the Phillips curve has a convex shape, that is, positive deviations of aggregate output from potential (or booms) tend to be more inflationary than negative deviations (or recessions) are disinflationary. As discussed in detail by Dupasquier and Ricketts (1998), several analytical models may justify the existence of an asymmetric relationship between inflation and the output gap. One of these models emphasizes the role of capacity constraints, that is, the fact that some firms may find it difficult to increase their capacity to produce beyond a certain range in the very short run. As a result, when aggregate demand is increasing, the impact on inflation will tend to be greater than during periods of low demand, and the Phillips curve will have a convex shape.

47. In addition, they show that in the case in which the Phillips curve is linear, the width of the band increases with the variance of shocks to inflation. 
These nonlinearities in inflation targeting may imply the need for possible asymmetries in monetary policy decisions. For instance, the policy response to deviations of inflation above target may need to be stronger than actions taken when inflation is lower than target. Recent analytical research on this issue includes the study by Schaling (1999), who extends Svensson's basic closed-economy model presented earlier to consider the case of a convex Phillips curve of the type proposed by Chadha, Masson, and Meredith (1992) and Laxton, Meredith, and Rose (1995). He shows that the optimal instrument-setting rule is asymmetric and implies a higher level of nominal interest rates than the rule derived by Svensson.

Specifically, suppose that the Phillips curve takes the convex form

$\pi_{t}-\pi_{t-1}=\theta\left(y_{t-1} ; \omega\right)=\frac{\alpha_{1} y_{t-1}}{1-\alpha_{1} \omega y_{t-1}}$,

where, as before, $\alpha_{1}>0$ and $0 \leq \omega<1$ is a parameter that measures the degree of convexity of the curve. This specification is consistent with the capacity constraint argument stated earlier. The $\theta(\cdot)$ function is such that $\theta(0 ; \omega)=0$, and the slope of the output-inflation trade-off is given by

$\theta^{\prime}=\frac{\alpha_{1}}{\left[1-\alpha_{1} \omega y_{t-1}\right]^{2}}$,

with $\theta^{\prime}(0 ; \omega)=\alpha_{1}$ and limit values of

$\lim _{\omega \rightarrow 0} \theta^{\prime}=\alpha_{1}, \lim _{y_{t-1} \rightarrow 1 / \alpha_{1} \omega} \theta^{\prime}=\infty$, and $\lim _{y_{t-1} \rightarrow-\infty} \theta^{\prime}=0$.

The quantity $1 / \alpha_{1} \omega$ thus represents an upper bound that the output gap cannot exceed in the short run. As $\omega \rightarrow 0$, equation 26 tends to a linear relationship between the (lagged) output gap and (changes in) inflation. Figure 8 summarizes the properties of this curve.

In addition to equation 26 , suppose that the output gap evolves in a way similar to equation 2 with, for simplicity, $\beta_{2}=1$ :

$y_{t}=\beta_{1} y_{t-1}-\left(i_{t-1}-\pi_{t-1}\right)+\eta_{t}$,

where the aggregate demand disturbance, $\eta_{t}$, is again assumed to be an i.i.d. shock.

Assuming that the monetary authorities pursue pure inflation target- 


\section{Figure 8. The Convex Phillips Curve}

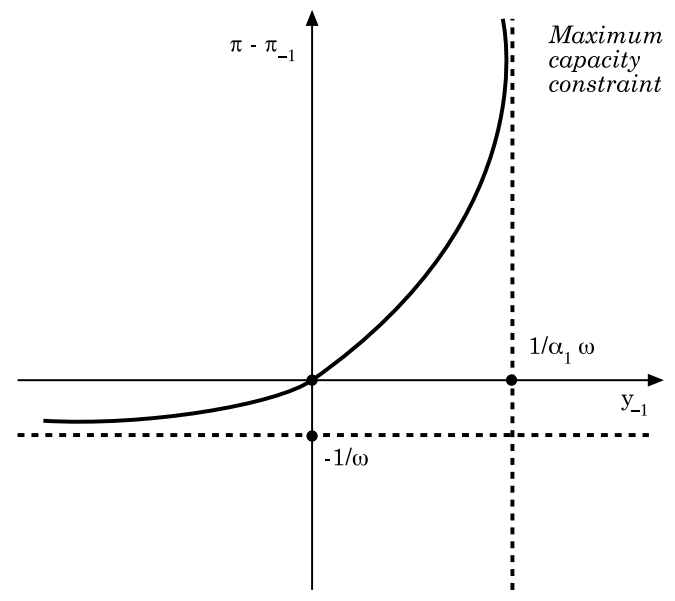

Source: Schaling (1999, p. 11).

ing and that the loss function takes the quadratic form of equation 3 , the optimal interest rate rule can again be found by solving a period-byperiod problem (as shown in equation 7), that the first-order condition is again $\pi_{t+2 \mid t}=\tilde{\pi}$ (see Schaling, 1999). The instrument rule, however, is now a nonlinear relationship given by

$r_{t}-\frac{1-\alpha_{1} \omega\left(\beta_{1} y_{t}-r_{t}\right)}{\alpha_{1}}\left(\pi_{t}-\tilde{\pi}\right)+\frac{1+\beta_{1}-\alpha_{1} \omega\left(2 \beta_{1} y_{t}-r_{t}\right)}{1-\alpha_{1} \omega y_{t}} y_{t}=0$

where $r_{t}=i_{t}-\pi_{t}$ denotes the real interest rate. From this equation it can be verified that for $\omega \rightarrow 0$, the interest rate rule boils down to

$r_{t}=\frac{1}{\alpha_{1}}\left(\pi_{t}-\tilde{\pi}\right)+\left(1+\beta_{1}\right) y_{t}$,

which is identical to equation 11 . In general, however, the optimal shortterm interest rate is a nonlinear function of both deviations of current inflation from target and the output gap. ${ }^{48}$ As shown by Schaling (1999),

48. Bean (2000) proposes a specification of a convex Philips curve that results in a linear policy rule. In general, however, the optimal rule will be nonlinear if the Phillips curve is nonlinear. 
positive deviations from the inflation target imply larger movements in interest rates (in absolute terms) than negative deviations. Positive output gaps imply larger increases in interest rates (in absolute terms) than negative output gaps. In addition, the nonlinear rule implies that increases in interest rates - for instance, in response to positive output shocks-are larger than those obtained with the linear rule, which implies that the latter underestimates the appropriate level of the policy instrument.

The notion that the output-inflation trade-off depends on the initial state of the economy is crucial in an inflation-targeting framework. All the available evidence, however, pertains to industrial countries (see Laxton, Meredith, and Rose, 1995; Pyyhtia, 1999). Following Laxton, Meredith, and Rose (1995), tables 3 and 4 present estimates of linear and nonlinear Phillips curves (using ordinary least squares in the first case and nonlinear least squares in the second), using quarterly data for six developing countries (Colombia, Korea, Mexico, Nigeria, the Philippines, and Turkey). The explained variable is the rate of inflation, INF $=\Delta^{4} \ln P$, where $P$ is the consumer price index. The explanatory variables are as follows (see appendix B for details):

-Lagged inflation (one and two periods), to capture persistence and expectations.

- The output gap, given by the log of the ratio of actual output, $Y$, to potential output, $Y_{T}$. The latter is measured using two different filters: the standard Hodrick-Prescott filter (with a smoothing parameter of 1600) and a quadratic trend. For the nonlinear Phillips curve, the specification is

$f(G A P)=\frac{\omega^{2}}{\omega-G A P}-\omega$,

where $\omega$ is a parameter to be estimated. ${ }^{49}$

-Current and lagged values of the rate of change of the nominal effective exchange rate, to assess the direct pass-through effect of currency depreciations.

49. As noted by Laxton, Meredith, and Rose (1995, p. 353), using detrended actual output may result in downward-biased estimates of potential output because positive output gaps have larger effects on inflation than negative output gaps. To correct for this bias, they measure the output gap in their empirical results as $\ln \left[Y /(1+\alpha) Y_{T}\right]$, where $\alpha$ is a parameter to be estimated. Here, however, preliminary regressions yielded an estimated value of $\alpha$ that was very small and never significantly different from zero. Accordingly, the output gap was specified simply as $\ln \left(Y / Y_{T}\right)$. 
Table 3. Estimation Results: Linear Phillips Curve ${ }^{a}$

\begin{tabular}{|c|c|c|c|c|c|c|c|c|c|c|c|c|}
\hline \multirow[b]{2}{*}{ Explanatory variabl } & \multicolumn{2}{|c|}{ Colombia } & \multicolumn{2}{|c|}{ Korea } & \multicolumn{2}{|c|}{ Mexico } & \multicolumn{2}{|c|}{ Nigeria } & \multicolumn{2}{|c|}{ Philippines } & \multicolumn{2}{|c|}{ Turkey } \\
\hline & le $H P$ & $Q T$ & $H P$ & $Q T$ & $H P$ & $Q T$ & $H P$ & $Q T$ & $H P$ & $Q T$ & $H P$ & $Q T$ \\
\hline Constant & $\begin{array}{c}0.026 \\
(2.237)\end{array}$ & $\begin{array}{c}0.026 \\
(2.289)\end{array}$ & $\begin{array}{c}0.007 \\
(3.216)\end{array}$ & $\begin{array}{c}0.008 \\
(3.232)\end{array}$ & $\begin{array}{c}0.021 \\
(2.956)\end{array}$ & $\begin{array}{c}0.017 \\
(2.454)\end{array}$ & $\begin{array}{c}0.021 \\
(1.951)\end{array}$ & $\begin{array}{c}0.025 \\
(2.218)\end{array}$ & $\begin{array}{l}0.015 \\
(2.618)\end{array}$ & $\begin{array}{c}0.020 \\
(3.707)\end{array}$ & $\begin{array}{c}0.012 \\
(0.802)\end{array}$ & $\begin{array}{c}0.022 \\
(1.165)\end{array}$ \\
\hline $\mathrm{INF}_{t-1}$ & $\begin{array}{c}1.097 \\
(9.490)\end{array}$ & $\begin{array}{l}1.096 \\
(9.474)\end{array}$ & $\begin{array}{c}0.822 \\
(27.641)\end{array}$ & $\begin{array}{c}0.794 \\
(19.011)\end{array}$ & $\begin{array}{c}1.312 \\
(14.429)\end{array}$ & $\begin{array}{c}1.284 \\
(12.962)\end{array}$ & $\begin{array}{c}1.461 \\
(15.514)\end{array}$ & $\begin{array}{c}1.454 \\
(15.371)\end{array}$ & $\begin{array}{c}1.207 \\
(11.325)\end{array}$ & $\begin{array}{c}1.119 \\
(11.454)\end{array}$ & $\begin{array}{c}0.872 \\
(18.009)\end{array}$ & $\begin{array}{r}0.866 \\
(17.145)\end{array}$ \\
\hline $\mathrm{INF}_{t-2}$ & $\begin{array}{l}-0.226 \\
(-1.955)\end{array}$ & $\begin{array}{c}-0.266 \\
(-1.956)\end{array}$ & & & $\begin{array}{l}-0.465 \\
(-6.401)\end{array}$ & $\begin{array}{l}-0.436 \\
(-5.534)\end{array}$ & $\begin{array}{l}-0.566 \\
(-5.958)\end{array}$ & $\begin{array}{l}-0.572 \\
(-6.012)\end{array}$ & $\begin{array}{c}-0.443 \\
(-5.048)\end{array}$ & $\begin{array}{l}-0.389 \\
(-4.781)\end{array}$ & & \\
\hline $\mathrm{GAP}_{t}$ & $\begin{array}{c}0.019 \\
(0.465)\end{array}$ & $\begin{array}{c}-0.002 \\
(-0.283)\end{array}$ & $\begin{array}{l}-0.019 \\
(-0.473)\end{array}$ & $\begin{array}{c}0.021 \\
(1.009)\end{array}$ & & & & & $\begin{array}{c}-0.018 \\
(-0.283)\end{array}$ & $\begin{array}{c}0.002 \\
(0.154)\end{array}$ & & \\
\hline $\mathrm{GAP}_{t-1}$ & & & & & $\begin{array}{c}-0.136 \\
(-0.619)\end{array}$ & $\begin{array}{c}0.021 \\
(1.380)\end{array}$ & & & & & $\begin{array}{c}0.107 \\
(1.356)\end{array}$ & $\begin{array}{c}-0.040 \\
(-0.815)\end{array}$ \\
\hline $\mathrm{GAP}_{t-2}$ & & & & & & & $\begin{array}{c}0.101 \\
(0.873)\end{array}$ & $\begin{array}{c}-0.011 \\
(-0.649)\end{array}$ & & & & \\
\hline NEERGR $_{t}$ & & & 0.107 & 0.109 & 0.180 & 0.190 & & & 0.118 & 0.097 & 0.387 & 0.374 \\
\hline & & & $(6.582)$ & $(6.834)$ & $(5.687)$ & $(6.401)$ & & & $(5.385)$ & $(4.530)$ & $(8.825)$ & $(8.152)$ \\
\hline NEERGR $_{t-1}$ & & & $\begin{array}{c}-0.052 \\
(-2.900)\end{array}$ & $\begin{array}{c}-0.048 \\
(-2.658)\end{array}$ & $\begin{array}{c}-0.058 \\
(-1.408)\end{array}$ & $\begin{array}{c}-0.072 \\
(-1.830)\end{array}$ & & & & & $\begin{array}{c}-0.275 \\
(-5.333)\end{array}$ & $\begin{array}{c}-0.276 \\
(-5.290)\end{array}$ \\
\hline $\mathrm{GAP}_{t}^{*} \mathrm{NEERGR}_{t}$ & & & & & & & & & $\begin{array}{c}0.807 \\
(1.832)\end{array}$ & $\begin{array}{c}0.733 \\
(3.388)\end{array}$ & & \\
\hline $\operatorname{GAP}_{t-1}^{*}{ }^{*} \mathrm{NEERGR}_{t-1}$ & & & & & $\begin{array}{c}0.753 \\
(1.935)\end{array}$ & $\begin{array}{l}-0.030 \\
(-0.632)\end{array}$ & & & & & & \\
\hline $\mathrm{PMGR}_{t}$ & & & & & & & & & $\begin{array}{c}0.074 \\
(3.418)\end{array}$ & $\begin{array}{c}0.045 \\
(2.017)\end{array}$ & & \\
\hline $\operatorname{PMGR}_{t-1}$ & & & $\begin{array}{c}0.094 \\
(5.026)\end{array}$ & $\begin{array}{c}0.086 \\
(4.457)\end{array}$ & & & & & & & $\begin{array}{c}0.058 \\
(1.190)\end{array}$ & $\begin{array}{c}0.047 \\
(0.925)\end{array}$ \\
\hline
\end{tabular}


Table 3. (continued)

\begin{tabular}{lcccccccccc}
\hline & \multicolumn{2}{c}{ Colombia } & \multicolumn{2}{c}{ Korea } & \multicolumn{2}{c}{ Mexico } & \multicolumn{2}{c}{ Nigeria } & \multicolumn{2}{c}{ Philippines } \\
Explanatory variable
\end{tabular}

Source: Author's calculations.

a. Dependent variable is the inflation rate; regressions are an ordinary least squares estimation; $t$-statistics are in parentheses. INF is the inflation rate. GAP is the log difference of output and trend component of output which is calculated using either Hodrick and Prescott method (HP) or quadratic trend method (QT). NEERGR is the growth rate of nominal effective exchange rate. PMGR is the growth rate of the import price index. PXGR_DEVED is the growth rate of the export price index of industrial countries. 
Table 4. Estimation Results: Nonlinear Phillips Curve ${ }^{a}$

\begin{tabular}{|c|c|c|c|c|c|c|c|c|c|c|c|c|}
\hline \multirow[b]{2}{*}{ Explanatory variable } & \multicolumn{2}{|c|}{ Colombia } & \multicolumn{2}{|c|}{ Korea } & \multicolumn{2}{|c|}{ Mexico } & \multicolumn{2}{|c|}{ Nigeria } & \multicolumn{2}{|c|}{ Philippines } & \multicolumn{2}{|c|}{ Turkey } \\
\hline & $H P$ & $Q T$ & $H P$ & $Q T$ & $H P$ & $Q T$ & $H P$ & $Q T$ & $H P$ & $Q T$ & $H P$ & $Q T$ \\
\hline Constant & $\begin{array}{c}0.028 \\
(2.380)\end{array}$ & $\begin{array}{c}0.027 \\
(2.291)\end{array}$ & $\begin{array}{c}0.007 \\
(3.183)\end{array}$ & $\begin{array}{c}0.007 \\
(3.296)\end{array}$ & $\begin{array}{c}0.022 \\
(3.119)\end{array}$ & $\begin{array}{c}0.016 \\
(2.205)\end{array}$ & $\begin{array}{c}0.023 \\
(2.137)\end{array}$ & $\begin{array}{c}0.022 \\
(1.878)\end{array}$ & $\begin{array}{c}0.015 \\
(2.621)\end{array}$ & $\begin{array}{c}0.026 \\
(4.395)\end{array}$ & $\begin{array}{c}0.013 \\
(0.847)\end{array}$ & $\begin{array}{c}0.016 \\
(1.010)\end{array}$ \\
\hline $\mathrm{NFF}_{t-1}$ & $\begin{array}{c}1.096 \\
(9.531)\end{array}$ & $\begin{array}{c}1.093 \\
(9.351)\end{array}$ & $\begin{array}{c}0.823 \\
(27.486)\end{array}$ & $\begin{array}{c}0.821 \\
(27.228)\end{array}$ & $\begin{array}{c}1.289 \\
(14.253)\end{array}$ & $\begin{array}{c}1.332 \\
(14.205)\end{array}$ & $\begin{array}{c}1.489 \\
(15.881)\end{array}$ & $\begin{array}{c}1.455 \\
(15.251)\end{array}$ & $\begin{array}{c}1.209 \\
(11.375)\end{array}$ & $\begin{array}{c}1.125 \\
(11.472)\end{array}$ & $\begin{array}{c}0.880 \\
(17.784)\end{array}$ & $\begin{array}{c}0.873 \\
(18.010)\end{array}$ \\
\hline $\mathrm{NNF}_{t-2}$ & $\begin{array}{l}-0.234 \\
(-2.029)\end{array}$ & $\begin{array}{l}-0.225 \\
(-1.923)\end{array}$ & & & $\begin{array}{l}-0.446 \\
(-6.176)\end{array}$ & $\begin{array}{l}-0.473 \\
(-6.284)\end{array}$ & $\begin{array}{l}-0.599 \\
(-6.323)\end{array}$ & $\begin{array}{l}-0.566 \\
(-5.877)\end{array}$ & $\begin{array}{c}-0.448 \\
(-5.105)\end{array}$ & $\begin{array}{l}-0.430 \\
(-5.043)\end{array}$ & & \\
\hline$f\left(\mathrm{GAP}_{t}\right)$ & $\begin{array}{c}-0.001 \\
(-0.195)\end{array}$ & $\begin{array}{c}0.002 \\
(0.105)\end{array}$ & $\begin{array}{c}-0.004 \\
(-0.748)\end{array}$ & $\begin{array}{c}0.002 \\
(0.232)\end{array}$ & & & & & $\begin{array}{c}0.017 \\
(0.724)\end{array}$ & $\begin{array}{c}0.067 \\
(1.721)\end{array}$ & & \\
\hline$f\left(\mathrm{GAP}_{t-1}\right)$ & & & & & $\begin{array}{c}-0.073 \\
(-0.458)\end{array}$ & $\begin{array}{c}-0.026 \\
(-0.774)\end{array}$ & & & & & $\begin{array}{c}-0.022 \\
(-0.542)\end{array}$ & $\begin{array}{c}0.026 \\
(0.548)\end{array}$ \\
\hline$f\left(\mathrm{GAP}_{t-2}\right)$ & & & & & & & $\begin{array}{c}0.087 \\
(1.605)\end{array}$ & $\begin{array}{c}0.015 \\
(0.146)\end{array}$ & & & & \\
\hline$\omega$ & $\begin{array}{c}0.049 \\
(48.498)\end{array}$ & $\begin{array}{c}0.052 \\
(2.782)\end{array}$ & $\begin{array}{c}0.047 \\
(19.978)\end{array}$ & $\begin{array}{c}0.055 \\
(13.177)\end{array}$ & $\begin{array}{c}0.081 \\
(5.713)\end{array}$ & $\begin{array}{c}0.060 \\
(10.175)\end{array}$ & $\begin{array}{c}0.051 \\
(27.717)\end{array}$ & $\begin{array}{c}0.043 \\
(4.806)\end{array}$ & $\begin{array}{c}0.045 \\
(13.894)\end{array}$ & $\begin{array}{c}0.042 \\
(19.390)\end{array}$ & $\begin{array}{c}0.048 \\
(15.601)\end{array}$ & $\begin{array}{c}0.044 \\
(26.268)\end{array}$ \\
\hline NEERGR $_{t}$ & & & $\begin{array}{c}0.110 \\
(6.819)\end{array}$ & $\begin{array}{c}0.109 \\
(6.795)\end{array}$ & $\begin{array}{c}0.207 \\
(5.855)\end{array}$ & $\begin{array}{c}0.197 \\
(6.365)\end{array}$ & & & $\begin{array}{c}0.119 \\
(5.340)\end{array}$ & $\begin{array}{c}0.095 \\
(4.564)\end{array}$ & $\begin{array}{c}0.389 \\
(8.601)\end{array}$ & $\begin{array}{c}0.382 \\
(8.719)\end{array}$ \\
\hline NEERGR $_{t-1}$ & & & $\begin{array}{c}-0.052 \\
(-2.922)\end{array}$ & $\begin{array}{c}-0.050 \\
(-2.796)\end{array}$ & $\begin{array}{c}-0.080 \\
(-1.840)\end{array}$ & $\begin{array}{c}-0.091 \\
(-2.308)\end{array}$ & & & & & $\begin{array}{r}-0.289 \\
(-5.464)\end{array}$ & $\begin{array}{c}-0.281 \\
(-5.458)\end{array}$ \\
\hline $\mathrm{GAP}_{t}^{*} \mathrm{NEERGR}_{t}$ & & & & & & & & & $\begin{array}{c}0.763 \\
(2.120)\end{array}$ & $\begin{array}{c}0.835 \\
(4.146)\end{array}$ & & \\
\hline $\operatorname{GAP}_{t-1}{ }^{*} \mathrm{NEERGR}_{t-1}$ & & & & & $\begin{array}{l}0.642 \\
2.102)\end{array}$ & $\begin{array}{c}-0.008 \\
(-0.189)\end{array}$ & & & & & & \\
\hline $\mathrm{PMGR}_{t}$ & & & & & & & & & $\begin{array}{c}0.072 \\
(3.305)\end{array}$ & $\begin{array}{c}0.039 \\
(1.804)\end{array}$ & & \\
\hline $\operatorname{PMGR}_{t-1}$ & & & $\begin{array}{c}0.092 \\
(5.019)\end{array}$ & $\begin{array}{c}0.096 \\
(5.150)\end{array}$ & & & & & & & $\begin{array}{c}0.053 \\
(1.076)\end{array}$ & $\begin{array}{c}0.069 \\
(1.401)\end{array}$ \\
\hline
\end{tabular}




\section{Table 4. (continued)}

\begin{tabular}{|c|c|c|c|c|c|c|c|c|c|c|c|c|}
\hline \multirow[b]{2}{*}{ Explanatory variable } & \multicolumn{2}{|c|}{ Colombia } & \multicolumn{2}{|c|}{ Korea } & \multicolumn{2}{|c|}{ Mexico } & \multicolumn{2}{|c|}{ Nigeria } & \multicolumn{2}{|c|}{ Philippines } & \multicolumn{2}{|c|}{ Turkey } \\
\hline & e HP & $Q T$ & $H P$ & $Q T$ & $H P$ & $Q T$ & $H P$ & $Q T$ & $H P$ & $Q T$ & $H P$ & $Q T$ \\
\hline PXGR_DEVED $_{t}$ & & & & & & & $\begin{array}{c}0.028 \\
(0.343)\end{array}$ & $\begin{array}{c}0.070 \\
(0.829)\end{array}$ & & & & \\
\hline \multicolumn{13}{|l|}{ Summary statistic } \\
\hline Adjusted $R^{2}$ & 0.794 & 0.789 & 0.958 & 0.958 & 0.983 & 0.981 & 0.900 & 0.895 & 0.946 & 0.956 & 0.923 & 0.924 \\
\hline $\begin{array}{l}\text { Standard error } \\
\text { of regression }\end{array}$ & 0.015 & 0.015 & 0.011 & 0.011 & 0.031 & 0.032 & 0.054 & 0.056 & 0.021 & 0.019 & 0.039 & 0.038 \\
\hline No. observations & 76 & 76 & 79 & 79 & 79 & 79 & 81 & 81 & 64 & 64 & 75 & 75 \\
\hline Period & \multicolumn{2}{|c|}{ 1980:1 - 1998:4 } & \multicolumn{2}{|c|}{ 1980:2 - 1999:4 } & \multicolumn{2}{|c|}{ 1980:2 - 1999:4 } & \multicolumn{2}{|c|}{ 1979:3 - 1999:3 } & \multicolumn{2}{|c|}{ 1981:1 - 1999:3 } & \multicolumn{2}{|c|}{ 1981:2 - 1999:4 } \\
\hline
\end{tabular}

Source: Author's calculations. a. Dependent variable is the inflation rate; regressions are a nonlinear least squares estimation; $t$-statistics are in parentheses. INF is inflation rate. GAP is the log difference
of output and trend component of output which is calculated using either Hodrick and Prescott method (HP) or quadratic trend method (QT)) $f(G A P)$ is a function of GAP such that $\left[\omega^{2} /(\omega-\mathrm{GAP})\right]-\omega$. The parameter $\omega$ identifies maximum short-run level of GDP; its starting value is 0.049 . NEERGR is the growth rate of nominal effective exchange

rate. PMGR is the growth rate of the import price index. PXGR DEVED is the growth rate of the export price index of industrial countries.
rateminal effective exchange 
-An interactive term given by the product of the nominal effective exchange rate and the output gap. This term is included in the regressions to test the possibility of a nonlinear effect of exchange rate movements on inflation, following Leiderman and Bar-Or (2000). The assumption is that the strength of the pass-through effect depends on the state of the economy, such that the pass-through may be larger in booms than in recessions, when falls in aggregate demand tend to put downward pressure on prices. ${ }^{50}$

-Foreign inflation, measured by the price of imported goods.

Consider first the results for the linear Phillips curve given in table 3. Overall, the regressions fit the data fairly well. Lagged values of inflation are significant in all cases, whereas the value of the interactive term is significant only for the Philippines and Mexico (using the Hodrick-Prescott estimate of trend output). Foreign inflation is significant only for Korea. The rate of depreciation of the nominal effective exchange rate is highly significant for both current and one-period lagged values, except in the cases of Colombia and Nigeria. Finally, the output gap is not significant in any equation, regardless of the detrending method used or the lag considered. ${ }^{51}$

Consider now the results for the nonlinear Phillips curve shown in table 4 . The explanatory power of the regressions (as measured by the adjusted $R$-squared and the standard error of the regression) is about the same as before, and the degree of significance and size of the coefficients estimated for all variables, except the output gap, are very similar. With regard to the output gap, the results now suggest that the coefficient $\omega$ is significantly different from zero in virtually every case, regardless of the detrending technique used. The coefficient of the function $f(\mathrm{GAP})$, however, is significant only at the 10 percent level and only for the Philippines (where the current value of GAP is used, with a quadratic trend to measure potential output) and Nigeria (where a two-period lag is used, with the Hodrick-Prescott filter).

50. An alternative assumption worth exploring in future research is the possibility that low inflation itself may result in a lower pass-through, owing to reduced perceived persistence of exchange rate movements (as suggested by Taylor, 2000). Another possibility to consider is that the strength of the pass-through effect may decline over time as the inflation-targeting regime gains credibility. This may explain why in Chile, for instance, the large exchange rate depreciation that followed the Asian and Russian crises in mid-1997 and mid-1998 did not translate into major upward pressure on domestic prices.

51. Higher-order lags than those shown in the table were also tried, with no success. In addition, following Pyyhtia (1999), the model was estimated by entering separately positive and negative output gaps; the results remained qualitatively similar to those reported in the table. 
The linear and nonlinear specifications are compared using a nonnested test, namely, the $J$ test developed by MacKinnon, White, and Davidson (1983), which is briefly discussed in appendix B. The results indicate that for Colombia, the linear model is rejected against the nonlinear alternative, regardless of whether the Hodrick-Prescott filter or quadratic trend filter is used. For Korea, neither model hypothesis is rejected, suggesting that the data do not provide enough information to discriminate between them. For Mexico, although the linear model is rejected against the nonlinear one when the HodrickPrescott filter is used, both models are rejected when the quadratic trend method is used. For Nigeria, the nonlinear model is accepted against the linear alternative when the Hodrick-Prescott filter is used; but neither model is rejected when the quadratic trend method is used. In the case of the Philippines, the nonlinear model is accepted against the linear specification. Finally, in the case of Turkey, the nonlinear model is rejected against the linear alternative using the HodrickPrescott filter and at a 10 percent significance level. Neither model can be rejected when the quadratic trend is used in the regressions.

The above results should be viewed as preliminary. Further testing is clearly needed to assess other possible sources of nonlinearities in the Phillips curve, as discussed by Dupasquier and Ricketts (1998). While this is a difficult task, the source of the nonlinearity in the Phillips curve is important from a policy viewpoint, because different sources may have very different policy implications. With nonlinearities, the policy rule is state contingent; parameters (elasticities) that capture the response of interest rates to movements in the output gap and deviations of current inflation from target depend on the current levels of inflation and the output gap. This has considerable practical implications in the present context, given the relative lack of experience that inflation-targeting central banks have with the conduct of monetary policy during a cyclical downturn, particularly in developing countries.

\subsection{Uncertainty and Optimal Policy Rules}

The implications of uncertainty for the design of policy rules under inflation targeting receives considerable attention in the most recent literature. Analytically, it is convenient to distinguish between four sources of uncertainty. First, uncertainty about some of the determinants of inflation arises because some economic series are unobservable and must be estimated. The most obvious example in the present case is the measurement of potential output in the calculation of the output gap. 
Potential output is very often approximated by trend output (as done earlier), but alternative detrending techniques may sometimes give large discrepancies. ${ }^{52}$ Second, uncertainty about the parameters of the model can be interpreted in two ways: either the underlying model itself is uncertain, or the true model is deterministic but policymakers cannot be certain that this is so and therefore must estimate it. Econometric techniques normally provide a sense of the degree of uncertainty that accompanies empirical estimates, because they yield not only point estimates of parameters but also their variances and covariances. The third source is uncertainty about the transmission lag and the timing of policy actions. The transmission lag depends on a variety of economic and institutional factors, such as the degree of development of financial markets and the intensity of competition on both the supply and demand sides, the degree of trade openness, and the composition of private agents' financial wealth. ${ }^{53}$ Finally, uncertainty about the nature and degree of persistence of shocks to which the economy is subject encompasses whether the shocks are on the supply or demand side of the economy and whether they are temporary or permanent.

Whereas some of these sources of uncertainty cause optimal policy to become more cautious, others have the opposite effect. To illustrate these results and their implications for inflation targeting, it is sufficient to consider two analytical examples: uncertainty about parameters and uncertainty about the degree of persistence of macroeconomic variables, including inflation.

In a seminal paper, Brainard (1967) argues that when policymakers are uncertain about the effect of their actions, it may be optimal to adopt a more gradual policy stance than when they are certain (or, more generally, under certainty equivalence, which holds in a linear model with a quadratic loss function and additive shocks). The impli-

52. The error in measuring potential output is not necessarily problematic if it takes an additive form and is uncorrelated over time. A related problem is the significant revisions in economic time series (owing to changes in seasonal adjustment factors, redefinitions, and so on) that often occur after a preliminary release of data, particularly those dealing with the real sector. Large revisions in the variables entering the instrument rule, in particular, may complicate the use of preliminary data as a basis for policy decisions.

53. As discussed earlier, there are lags in the response of aggregate demand to changes in interest rates, as well as lags in the response of inflation to the output gap. There are also lags in the response of inflation expectations to policy changes, lags in the response of inflation to changes in inflation expectations, lags in the response of aggregate demand to changes in relative prices induced by exchange rate changes, and lags in response of supply to exchange-rate-induced movements in the domestic price of imported inputs. 
cations of Brainard-type uncertainty can be illustrated using Svensson's model of strict inflation targeting described in equations 1 through 4 . To simplify the analysis, suppose that output immediately affects inflation, $\alpha_{1}=1, \beta_{1}=0$, and that there are no supply shocks $\left(\varepsilon_{t}=0\right.$ for all $t$ ). The behavioral equations of the model therefore become

$\pi_{t}-\pi_{t-1}=\alpha_{1} y_{t}$ and

$y_{t}=-\beta_{2}\left(i_{t-1}-\pi_{t-1}\right)+\eta_{t}$,

where the demand shock, $\eta_{t}$, is once again an additive, serially uncorrelated shock with zero mean. Substituting equation 28 into equation 29 yields

$\pi_{t+1}=\gamma_{1} \pi_{t}-\gamma_{2} i_{t}+\eta_{t+1}$,

where $\gamma_{1}=\left(1+\alpha_{1} \beta_{2}\right)$ and $\gamma_{2}=\alpha_{1} \beta_{2}$. By assuming the same intertemporal loss function as before (equation 4 ) and for simplicity setting the target $\tilde{\pi}=0$, I obtain the following optimal interest rate rule:

$i_{t}=\frac{\gamma_{1}}{\gamma_{2}} \pi_{t}$

This rule is certainty equivalent: the same interest rate rule would be optimal in a world with no uncertainty about aggregate demand shocks. But suppose that the central bank does not know for sure the values of $\gamma_{1}$ and $\gamma_{2}$; all that is known is that these parameters are drawn from independent, normal distributions with means $\bar{\gamma}_{1}$ and $\bar{\gamma}_{2}$ and variances $\sigma_{1}^{2}$ and $\sigma_{2}^{2}$, respectively. In this case, as shown by Martin (1999), the optimal instrument rule becomes

$i_{t}=\frac{\bar{\gamma}_{1} \bar{\gamma}_{2}}{\bar{\gamma}_{2}^{2}+\sigma_{2}^{2}} \pi_{t}$

This equation indicates that as uncertainty about the parameters in the transmission process of policy shocks increases (that is, as $\sigma_{2}^{2}$ rises), the optimal instrument response to movements in current inflation becomes smaller. ${ }^{54}$ The fundamental reason for this result is the following. The per-period loss function can be decomposed into the sum of the squared expected deviation of each variable from its target (or the squared bias), and the conditional variance of that variable (see 
equation 8). With additive uncertainty, the variance is independent of the policy rule, and so policy decisions aim only at minimizing expected deviations in inflation. By contrast, under uncertainty about the parameters of the model, the variance of future inflation depends on the level of nominal interest rates. Large movements in the policy instrument in response to deviations between actual and targeted inflation tend to reduce bias, as implied by the first term in equation 8 - at the cost, however, of increasing the variance of inflation, the second term in equation 8. The central bank therefore internalizes this effect by choosing a lower optimal level of interest rates. ${ }^{55} \mathrm{~A}$ similar result would hold in a more general, linear-quadratic setting in which the central bank pursues several policy objectives simultaneously.

Model-based simulation studies generally confirm the practical importance of the Brainard effect (see Ha, 2000; Martin and Salmon, 1999; Sack, 2000). The optimal interest rate rule calls for more gradual adjustment in the presence of parameter uncertainty. Ha (2000) uses a numerical model for New Zealand to examine the impact of uncertainty about the transmission lag of monetary policy (that is, lag uncertainty regarding the timing of policy actions, as opposed to the effect of these actions, as in Brainard's analysis) on the setting of monetary policy instruments in the context of inflation-forecast-based rules. His analysis shows that less aggressive policy rules are indeed more robust, in the sense that they are less affected by uncertainty about the monetary policy transmission lag. At the same time, however, more aggressive rules tend to produce lower inflation variability. Sack (2000) shows that accounting for parameter uncertainty in deriving an optimal interest rule from an estimated VAR model and a quadratic loss function in inflation and unemployment helps to explain the observed tendency for the Federal Reserve to change its policy rate (the federal funds rate) only gradually, despite the fact that interest rate smoothing is not a consideration for the central bank.

Several authors show that policy may be more aggressive when the degree of persistence in the economy is uncertain than when it is certain. Notable studies include Soderstrom (1999) and Shuetrim and Thompson (1999). In Soderstrom's model, for instance, uncertainty about the degree of persistence of inflation itself may lead to this result. Without full information regarding inflation persistence, a cautious monetary

55. Brainard himself qualifies this result by showing that it does not necessarily hold when the covariance between parameters (the policy multiplier, in his example) and the additive disturbance is sufficiently negative. 
policy may cause inflation to approach the target at below the desired rate or even to diverge from the target. The central bank can lower this risk by implementing large adjustments in interest rates, thereby reducing uncertainty regarding the path of inflation. This more aggressive policy leads to the expectation that inflation will return to target more quickly, so that the implicit targeting horizon is shortened. ${ }^{56}$

The sharp differences in these results suggest that more quantitative research is needed to fully understand the impact of uncertainty on policy rules under inflation targeting. In particular, the impact of uncertainty on the optimal policy rule may depend on which parameter, or which behavioral relationship, is being considered in the structural model. Put differently, uncertainty about particular parameters may be of relatively limited importance for the conduct of monetary policy, whereas others may have an unduly large effect on the setting of policy instruments. Identifying which parameters matter may well be model specific.

\subsection{Endogenizing Reputation and Credibility}

The foregoing discussion highlights the need, in setting policy instruments in an inflation-targeting framework, to account for the tradeoff between the cost of having inflation above target (which is reduced if disinflation is faster) and the cost of output fluctuations (which is increased if disinflation is faster). The trade-off stems from the assumption that to reduce inflation the central bank must necessarily induce a (temporary) reduction in output. The extent and duration of the reduction in output depend crucially on the credibility of the commitment to the inflation target and its evolution. The more credible the commitment becomes over time, the faster inflation expectations will fall, and the lower will be the output cost of reducing inflation. More generally, accounting for changes in credibility in forecasting inflation and simulating policy shocks may be important in the first stages of implementing an inflation-targeting framework, particularly in countries where the degree of confidence in the central bank's commitment to low inflation is not well established.

Nevertheless, relatively few studies attempt to endogenize credibility in empirical macroeconomic models used for forecasting and policy analysis under inflation targeting. One reason may be the difficulty of

56. Note that if the central bank cares only about stabilizing inflation, the implicit targeting horizon is already as short as possible (that is, equal to the control lag). In this case, it is not affected by uncertainty about the persistence of inflation. 
operationalizing theoretical concepts of credibility and its determinants. A simple approach is to assume that the expected inflation rate, $\pi_{t \mid t-1}$, is a weighted sum of lagged inflation, $\pi_{t-1}$, and the inflation target, $\tilde{\pi}$, with relative weights of $1-\sigma_{t}$ and $\sigma_{t}$, respectively:

$\pi_{t \mid t-1}=\left(1-\sigma_{t}\right) \pi_{t-1}+\sigma_{t} \tilde{\pi}$.

The weight on the announced inflation target $\sigma_{t}$ can be viewed as a measure of policy credibility, which can be modeled as

$\sigma_{t}=\Lambda \sigma_{t-1}+\psi\left(\pi_{t-1}-\tilde{\pi}, \pi_{t-2}-\tilde{\pi}, \ldots\right) \rightarrow \begin{cases}\Lambda \sigma_{t-1} & \text { when } \psi \rightarrow 0 \\ \Lambda \sigma_{t-1}+1 & \text { when } \psi \rightarrow 1,\end{cases}$

where $0<\Lambda<1$ and $\psi($.$) is a function of past inflation forecast errors,$ with the properties that $\psi \rightarrow 1$ when these errors become very small and $\psi \rightarrow 0$ when these errors become very large. Expectations are thus completely backward-looking when $\psi \rightarrow 0$ (because $\sigma_{t} \rightarrow 0$ as well), whereas when $\psi \rightarrow 1$ full credibility is achieved $\left(\sigma_{t} \rightarrow 1\right)$, with expectations depending only on the announced target. Isard, Laxton, and Eliasson (2001) provide a more elaborate treatment of this approach to endogenizing credibility. A key conclusion that emerges from simulation studies based on expectations formation schemes similar to equations 32 and 33 is that endogenous policy credibility strengthens the case for the type of forward-looking inflation-forecast-based rules discussed above.

An alternative and conceptually appealing approach to endogenizing credibility and learning in a tractable manner is that pursued by Drazen and Masson (1994) and Agénor and Masson (1999), who view credibility as consisting of two elements: an assessment of the central bank's type (which could be termed reputation) and, for a given type, an assessment of the probability that the central bank will actually decide to stick to the announced policy (that is, to maintain inflation close to target) in the presence of adverse shocks to prices. ${ }^{57}$ In this setting, inflation expectations reflect assessments about the central bank's type, as captured by the relative weights that the authorities attach to each of their policy objectives, which are not known by the public. Because private agents know that random shocks will alter the balance of costs

57. An alternative approach consists in defining credibility as the ability of the central bank to precommit its actions, that is, its capacity to convince private agents that it will carry out policies that may be time inconsistent. See, for instance, Cukierman (1992). 
and benefits associated with maintaining the inflation rate close to target, they will reevaluate on the basis of observed variables the probabilities that a particular type of policymaker will decide to stick to the inflation target in the future. Put differently, if there is significant persistence in the effects of policies, then a restrictive policy carried out today (which lowers inflation but also reduces output) may make it less likely that such a policy will be continued in the future.

To illustrate this approach, consider again the per-period policy loss function under flexible inflation targeting described in equation 13. The first component of (lack of) credibility, namely, the probability that the central bank places a high weight on limiting output fluctuations, can be modeled using Bayesian updating, under the assumption that there are two possible types of policymaker, each with a known set of weights on its objectives: a weak central bank, which sets $\lambda=\lambda_{\mathrm{w}}$, and a tough central bank, whose value of $\lambda$ is $\lambda_{T}<\lambda_{W}$. The policy loss function can thus be written as

$L_{t}=\frac{\left(\pi_{t}-\tilde{\pi}\right)^{2}}{2}+\frac{\lambda y_{t}^{2}}{2}, \lambda=\left\{\begin{array}{l}\lambda_{W} \\ \lambda_{T}<\lambda_{W}\end{array}\right.$.

In each period private agents calculate ex ante the likelihood of each type deciding to deviate from the inflation target. If inflation remains close to target ex post, this would give information about whether the central bank is weak (even if the shocks cannot be observed), so that initial priors about that probability are updated on the basis of the relative likelihood that each policymaker would have deviated from target, given the distribution of the unobserved shocks.

In this framework, inflation expectations depend on the probability that the central bank is weak or tough, as well as the ex ante probability that a given type will decide to deviate from the inflation target as a result of random supply shocks, as captured by $\varepsilon_{t}$. Private agents do not observe the supply shock; they form their expectations using an information set that includes variables known as of the end of $t-1$, that is, the lagged values of output, interest rates, and inflation, and whether the policymaker has allowed inflation to deviate from target or not. The central bank observes the supply shock and chooses whether to adjust interest rates and keep inflation close to target. In general, the central bank will allow inflation to deviate significantly from target when a negative shock to output is so large that the cost of maintaining inflation close to its target value will exceed the costs associated with flexibility (that is, higher inflation). Formally, let $L_{t}^{F}$ be the 
value of the loss function if inflation is kept close to target through changes in interest rates, and $L_{t}^{D}$ the value when it is allowed to deviate significantly from target with no change in policy instruments. The central bank will maintain interest rates constant when $L_{t}^{D}-L_{t}^{F}<0$. The results derived by Agénor and Masson (1999) establish that when equations 1 and 2 characterize the economy as above, then for $L_{t}^{D}-L_{t}^{F}$ to be negative, the supply shock $\varepsilon_{t}$ must be relatively large compared to a threshold value, $\tilde{\varepsilon}_{t}^{h}$, which depends on the type of central bank and other variables in the model. The threshold level is lower for a weak central bank than for a tough central bank $\left(\tilde{\varepsilon}_{t}^{W}<\tilde{\varepsilon}_{t}^{T}\right)$.

The expected inflation rate in this setting is the product of the probability of deviating from target, $\rho_{t}$, and the size of the deviation from target, $x_{t}$, which may or may not be constant over time. In turn, the private sector's assessment of $\rho_{t}$ is equal to the probability of a weak central bank, $\theta_{t}$, times the probability that a weak central bank will devalue, $\rho_{t}^{W}$, plus a corresponding term for a tough central bank:

$\rho_{t}=\theta_{t} \rho_{t}^{W}+\left(1-\theta_{t}\right) \rho_{t}^{T}$.

Expected inflation is thus

$\rho_{t} x_{t}=\left[\theta_{t} \rho_{t}^{W}+\left(1-\theta_{t}\right) \rho_{t}^{T}\right] x_{t}$.

Given knowledge of the authorities' objective function and of the distribution of the supply shock, the private sector can calculate the probabilities $\rho_{t}^{W}$ and $\rho_{t}^{T}$, which can be defined as

$\rho_{t}^{h}=\operatorname{Pr}\left(\varepsilon_{t}>\tilde{\varepsilon}_{t}^{h}\right)$.

Finally, the probability that a policymaker is weak, $\theta_{t}$, can be assumed to be updated using a Bayesian rule, starting from a prior estimate, $\theta_{t-1}$. Specifically, because private agents observe the absence of deviations of inflation from target at time $t-1$, they will revise $\pi_{t-1}$ on the basis of the relative likelihood that the two types would have chosen not to deviate from the inflation target:

$\theta_{t}=\frac{1-\rho_{t-1}^{W}}{\left(1-\rho_{t-1}^{W}\right) \theta_{t-1}+\left(1-\rho_{t-1}^{T}\right)\left(1-\theta_{t-1}\right)} \theta_{t-1}$.

The above approach may prove useful for endogenizing credibility and reputation in macroeconomic models designed to predict inflation and analyzing the performance of alternative policy rules, particularly in countries where the initial degree of confidence in the central bank's 
ability to maintain its commitment to price stability is relatively low. Other approaches are also possible, however, and sorting out the advantages and limitations of each remains a matter for further research.

\section{Summary and Conclusions}

In the past few years a number of central banks in industrial and developing countries alike have adopted an explicit inflation-targeting framework for the conduct of monetary policy. This paper has attempted to provide an analytical discussion of the issues involved in designing such a framework, with some emphasis on the particular features and recent experiences of developing countries. The first part of section 1 described an analytical framework for a closed economy, essentially drawing on Svensson (1997a, 1999a). The analysis generated two main results. First, because of lags in the transmission process of shortterm interest rates to prices, inflation targeting implies inflation forecast targeting. The central bank's forecast becomes an explicit intermediate target. Inflation targeting can then be viewed as a monetary policy framework under which policy decisions are guided by expected future inflation relative to an announced inflation target; the forwardlooking instrument rule takes into account lags in the transmission process. Second, if the central bank, aims at stabilizing output in addition to seeking to achieve its inflation target, it should allow for a slower adjustment of the inflation forecast to the target value than in a situation in which the inflation target is the only goal. Extension of the analysis to an open-economy setting showed that given the critical role of the exchange rate in the transmission process of monetary policy, inflation targeting may lead to a relatively high degree of output volatility by inducing excessive fluctuations in interest rates.

Section 2 compared inflation-targeting regimes with money supply and exchange rate targeting regimes. Monetary targeting requires a stable relationship between monetary aggregates and the price level, but such stability has become elusive as a result of financial liberalization and abrupt changes in inflation expectations. With regard to exchange rate targeting, a number of developing countries have been forced to abandon their exchange rate pegs in recent years as a result of unsustainable speculative pressures. These developments led in many cases to the adoption of inflation targeting as an operational framework for conducting monetary policy.

Section 3 discussed three basic requirements for implementing an inflation-targeting framework, namely, central bank independence, the 
absence of implicit exchange rate targeting, and transparency in the conduct of monetary policy. It is now well recognized that openness and transparency play an important role in achieving credibility in monetary policy. The announcement of inflation targets communicates the central bank's intentions to the financial markets and to the public, and in so doing it helps to reduce uncertainty about the future course of inflation. Transparency and accountability thus act as constraints on the temptation to adopt discretionary policies. The risks associated with the pursuit of an implicit exchange rate target were also highlighted. It is crucial for the central bank to be able to convince the public that the inflation target will take precedence over other policy goals in case of conflict. In particular, if the central bank is also concerned about fluctuations in the nominal exchange rate (as may be the case in countries where the pass-through rate to domestic prices is high or when the short-term foreign-currency liabilities of the private sector are large), there is a risk that inflation targets may lack credibility, thereby undermining the operation of the inflation-targeting framework.

The operational framework of inflation targeting was discussed in section 4. Among the issues reviewed were the measurement of inflation (including sources of imperfection in traditional measures), whether a target band for inflation should be chosen, the time horizon of monetary policy, difficulties associated with forecasting inflation, and whether asset prices should be taken into account in targeting inflation. The width of the inflation target range, in particular, depends on the variability of shocks to inflation, the policy horizon, and the desired speed of adjustment to economic disturbances, which itself depends on the relative weight the central bank attaches to output fluctuations and the desired degree of interest rate smoothing. There is also a trade-off between credibility and flexibility: if the band is made too wide to provide more flexibility (that is, more scope to accommodate transitory shocks to inflation), then the inflation target may lose credibility and inflation expectations may remain high. The section also noted that central banks may want to respond to financial prices in their pursuit of price stability for several reasons. Shocks to financial prices that are not driven by fundamentals may destabilize the economy through their effects on aggregate demand, in which case the central bank may want to offset them. However, asset prices are determined by arbitrage equations in which expectations of future returns play an important role. If expectations are subject to large and unpredictable shifts, these prices may contain limited additional information about current and future economic conditions. Finally, inflation forecasts are, in practice, based on a combination of quantitative 
models (generally small in size), indicator variables (such as survey expectations), and qualitative judgement.

Section 5 reviewed the recent experience of industrial and developing countries with inflation targets, with a particular emphasis on Brazil, South Africa, and Thailand. The evidence clearly suggests that the adoption of an inflation-targeting regime was not by itself sufficient to dampen inflation expectations and help countries deliver consistently better inflation performance. Nevertheless, for a subset of countries (most notably Canada, New Zealand, Sweden, and the United Kingdom), inflation persistence dropped significantly after the adoption of inflation targets, perhaps as a result of a significant and credible shift in policy preferences.

The last section focused on some ongoing issues of debate in inflation targeting, namely, the role of nonlinearities and asymmetric effects (related to both the structure of policy preferences and structural relationships, most notably the Phillips curve), uncertainty (about behavioral parameters and the transmission process of monetary policy), and how to account for credibility and reputational factors in empirical macroeconomic models. The first two issues have important implications for the design of optimal instrument rules and the operation of a state-contingent targeting regime. Specifically, whereas uncertainty about parameters may lead to more caution in the manipulation of policy instruments, uncertainty about the degree of inflationary persistence may lead to a more aggressive, as opposed to a more gradual, interest rate policy. New results regarding the convexity of the Phillips curve were also presented for six developing countries (Colombia, Korea, Mexico, Nigeria, the Philippines, and Turkey). Comparison of the linear and nonlinear specifications using the MacKinnon-WhiteDavidson nonnested test provided mixed support for the latter. Finally, accounting for changes in credibility in forecasting inflation and simulating policy shocks may be important, particularly in countries implementing an inflation-targeting framework from an initial position of low confidence in the central bank's commitment to price stability.

The main conclusion of this paper is broadly in line with several existing studies: inflation targeting is a flexible policy framework that allows the central bank to exercise constrained discretion, as emphasized by Bernanke and others (1999, p. 293). In middle- and high-income developing economies that have relatively low initial inflation and reasonably well-functioning financial markets and that can refrain from implicit exchange rate targeting, it has the potential to improve the design and performance of monetary policy compared with alternative 
operational procedures available to central banks. There are, of course, technical requirements (such as adequate data on prices, sufficient understanding of the links between monetary policy instruments and targets, and the ability to forecast relatively well price developments), which may not be satisfied in all countries and to the same extent. But such requirements should not be overstated; forecasting capability, for instance, can never be perfect and sensible projections always involve qualitative judgement. A more important and difficult task, in many cases, may be to design or improve the institutional framework in order to allow the central bank an effective degree of independence in pursuing the goal of low and stable inflation without undue pressure to stabilize output fluctuations or alleviate the public debt burden through low interest rates. 


\section{APPENDIX A}

\section{The Optimal Instrument Rule under Forward-Looking Expectations}

This appendix discusses the derivation of the optimal interest rate rule implied by inflation targeting under rational, forward-looking expectations. Following Clarida, Galí, and Gertler (1999), consider a closed economy in which the Phillips curve and aggregate demand are given by the following equations:

$$
\begin{aligned}
& \pi_{t}=\alpha_{1} y_{t}+\alpha_{2} E_{t} \pi_{t+1}+\varepsilon_{t}, \\
& y_{t}=E_{t} y_{t+1}-\beta\left(i_{t}-E_{t} \pi_{t+1}\right)+\eta_{t},
\end{aligned}
$$

where $0<\alpha_{2}<1$ and, as before, $\pi_{t}$ is the inflation rate, $y_{t}$ is the output gap, $i_{t}$ is the nominal interest rate, and $\varepsilon_{t}$ and $\eta_{t}$ are disturbances that obey

$$
\begin{aligned}
& \varepsilon_{t}=\rho_{\varepsilon} \varepsilon_{t-1}+v_{t} \text { and } \\
& \eta_{t}=\rho_{\eta} \eta_{t-1}+\xi_{t},
\end{aligned}
$$

where $0 \leq \rho_{\varepsilon}, \rho_{\eta} \leq 1$, and $\mathrm{v}_{t}$ and $\xi_{t}$ are random shocks with zero mean and constant variances, given respectively by $\sigma_{v}^{2}$ and $\sigma_{\xi}^{2}$.

Equation A1 relates inflation to the current value of the output gap (as opposed to the lagged value) and the one-period ahead expected future inflation rate. It can be derived from a Calvo-Taylor model with staggered nominal wage and price setting (see Roberts, 1995; Fuhrer, 1997a, 1997b). ${ }^{1}$ Equation A2 relates output to its future value and the ex ante real interest rate. It can be derived by log-linearizing the firstorder condition for consumption maximization obtained in a representative agent model and imposing equilibrium of the goods market (see Clarida, Galí, and Gertler, 1999). For simplicity, changes in interest rates are assumed to affect current output immediately.

The key difference in this specification with forward-looking expectations - which is readily apparent by iterating equations A1 and A2

1. It can also be shown that $\alpha_{1}$ is inversely related to the degree of price rigidity; the longer prices are held fixed, on average, the less responsive is inflation to cyclical fluctuations in output. 
forward - is that output depends on current and future values of the real interest rate (and thus on future policy decisions), whereas inflation depends on current and future values of the output gap. This dependence makes calculation of the optimal instrument rule more involved.

The central bank's policy objective is, as in equation 14,

$\min U_{t}=E_{t}\left\{\sum_{h=t}^{\infty} \delta^{h-t}\left[\frac{\left(\pi_{h}-\tilde{\pi}\right)^{2}+\lambda y_{h}^{2}}{2}\right]\right\}$,

where $\lambda>0$.

Under discretion, the central bank takes expectations as given in solving its optimization problem. Deriving the optimal policy rule proceeds in two stages. First, the objective function A5 is minimized by choosing $y_{t}$ and $\pi_{t}$, given the Phillips curve A1. This is possible because no endogenous-state variable appears in the objective function; thus future inflation and output are not affected by today's policy decisions and the central bank cannot directly affect private expectations. Second, the value of $i_{t}$ implied by the aggregate demand equation $\mathrm{A} 2$ is determined, conditional on the optimal values of $y_{t}$ and $\pi_{t}$.

The first stage thus consists in choosing $y_{t}$ and $\pi_{t}$ to minimize

$\frac{\left(\pi_{t}-\tilde{\pi}\right)^{2}+\lambda y_{t}^{2}}{2}+x_{t}$,

where

$x_{t}=E_{t}\left\{\sum_{h=t+1}^{\infty} \delta^{h-t}\left[\frac{\left(\pi_{h}-\tilde{\pi}\right)^{2}+\lambda y_{h}^{2}}{2}\right]\right\}$,

subject to (using equation A1)

$\pi_{t}=\alpha_{1} y_{t}+z_{t}$,

where $z_{t}=\alpha_{2} \mathrm{E}_{t} \pi_{t+1}+\varepsilon_{t}$. The first-order conditions for the first-stage problem are $\pi_{t}-\tilde{\pi}+\mu_{t}=0$ and $\lambda y_{t}-\mu_{t} \alpha_{1}=0$, where $\mu_{t}$ is a Lagrangian multiplier. Combining these conditions gives

$\pi_{t}=\tilde{\pi}-\left(\frac{\lambda}{\alpha_{1}}\right) y_{t}$.

Substituting this expression into equation A1 for $y_{t}$ yields 
$\pi_{t}=-\frac{\alpha_{1}^{2}}{\lambda}\left(\pi_{t}-\tilde{\pi}\right)+\alpha_{2} E_{t} \pi_{t+1}+\varepsilon_{t}$,

that is,

$\pi_{t}=\frac{\alpha_{1}^{2} \tilde{\pi}}{\lambda+\alpha_{1}^{2}}+\frac{\alpha_{2} \lambda E_{t} \pi_{t+1}}{\lambda+\alpha_{1}^{2}}+\frac{\lambda \varepsilon_{t}}{\lambda+\alpha_{1}^{2}}$.

This equation can be solved by using the method of undetermined coefficients. Conjecturing a solution of the form

$\pi_{t}=\kappa_{1} \tilde{\pi}+\kappa_{2} \varepsilon_{t}$

implies that $\pi_{t+1}=\kappa_{1} \tilde{\pi}+\kappa_{2} \varepsilon_{t+1}$, such that, using equation A3,

$E_{t} \pi_{t+1}=\kappa_{1} \tilde{\pi}+\kappa_{2} E_{t} \varepsilon_{t+1}=\kappa_{1} \tilde{\pi}+\kappa_{2} \rho_{\varepsilon} \varepsilon_{t}$.

Substituting this expression into equation $\mathrm{A} 7$ and rearranging terms yields

$\pi_{t}=\frac{\left(\alpha_{1}^{2}+\alpha_{2} \lambda \kappa_{1}\right)}{\lambda+\alpha_{1}^{2}} \tilde{\pi}+\frac{\lambda\left(1+\alpha_{2} \kappa_{2} \rho_{\varepsilon}\right)}{\lambda+\alpha_{1}^{2}} \varepsilon_{t}$.

Equating coefficients in equations A8 and A9 yields

$\kappa_{1}=\frac{\alpha_{1}^{2}+\alpha_{2} \lambda \kappa_{1}}{\lambda+\alpha_{1}^{2}}$ and

$\kappa_{2}=\frac{\lambda\left(1+\alpha_{2} \kappa_{2} \rho_{\varepsilon}\right)}{\lambda+\alpha_{1}^{2}}$,

which can be rearranged to give

$\kappa_{1}=\frac{\alpha_{1}^{2}}{\lambda\left(1-\alpha_{2}\right)+\alpha_{1}^{2}}<1$ and

$\kappa_{2}=\frac{\lambda}{\lambda\left(1-\alpha_{2} \rho_{\varepsilon}\right)+\alpha_{1}^{2}}$.

Thus the solution for $\pi_{t}$ is

$\pi_{t}=\kappa_{1} \tilde{\pi}+\lambda \theta \varepsilon_{t}$,

where

$\theta=\frac{1}{\lambda\left(1-\alpha_{2} \rho_{\varepsilon}\right)+\alpha_{1}^{2}}$. 
Substituting equation A10 in equation A6 yields

$y_{t}=-\left(\frac{\alpha_{1}}{\lambda}\right)\left(\pi_{t}-\tilde{\pi}\right)=-\left(\frac{\alpha_{1}}{\lambda}\right)\left\{\left(\kappa_{1}-1\right) \tilde{\pi}+\lambda \theta \varepsilon_{t}\right\}$,

that is

$y_{t}=\Lambda \tilde{\pi}-\alpha_{1} \theta \varepsilon_{t}, \Lambda=\frac{\alpha_{1}\left(1-\kappa_{1}\right)}{\lambda}$.

The second stage of the solution procedure consists in rewriting equation $\mathrm{A} 2$ as

$i_{t}=\frac{1}{\beta}\left[\left(E_{t} y_{t+1}-y_{t}\right)+\eta_{t}\right]+E_{t} \pi_{t+1}$,

and substituting for $\mathrm{E}_{t} y_{t+1}-y_{t}$. From equations $\mathrm{A} 3$ and A10, $\mathrm{E}_{t} \pi_{t+1}$ is given by

$E_{t} \pi_{t+1}=\kappa_{1} \tilde{\pi}+\lambda \theta E_{t} \varepsilon_{t+1}=\kappa_{1} \tilde{\pi}+\lambda \theta \rho_{\varepsilon} \varepsilon_{t}$,

whereas from equations $\mathrm{A} 3$ and $\mathrm{A} 11$

$E_{t} y_{t+1}=\Lambda \tilde{\pi}-\alpha_{1} \theta \rho_{\varepsilon} \varepsilon_{t}$.

Using this expression together with equation A11 yields

$E_{t} y_{t+1}-y_{t}=\alpha_{1}\left(1-\rho_{\varepsilon}\right) \theta \varepsilon_{t}$.

Equation A13 can be rewritten as

$\theta \varepsilon_{t}=-\frac{\kappa_{1} \tilde{\pi}}{\lambda \rho_{\varepsilon}}+\frac{E_{t} \pi_{t+1}}{\lambda \rho_{\varepsilon}}$.

Substituting this result into equation A14 yields

$E_{t} y_{t+1}-y_{t}=-\frac{\alpha_{1} \kappa_{1}\left(1-\rho_{\varepsilon}\right)}{\lambda \rho_{\varepsilon}} \tilde{\pi}+\left[\frac{\alpha_{1}\left(1-\rho_{\varepsilon}\right)}{\lambda \rho_{\varepsilon}}\right] E_{t} \pi_{t+1}$.

Substituting equation A15 into equation A12 and rearranging terms yields the optimal interest rate rule,

$i_{t}=-\frac{\alpha_{1} \kappa_{1}\left(1-\rho_{\varepsilon}\right)}{\beta \lambda \rho_{\varepsilon}} \tilde{\pi}+\frac{1}{\beta}\left[\frac{\alpha_{1}\left(1-\rho_{\varepsilon}\right)}{\lambda \rho_{\varepsilon}} E_{t} \pi_{t+1}+\eta_{t}\right]+E_{t} \pi_{t+1}$, 
or equivalently

$i_{t}=\Omega \tilde{\pi}+\delta E_{t} \pi_{t+1}+\frac{\eta_{t}}{\beta}$

where

$\Omega=-\frac{\alpha_{1} \kappa_{1}\left(1-\rho_{\varepsilon}\right)}{\beta \lambda \rho_{\varepsilon}}$,

$\delta=1+\frac{\alpha_{1}\left(1-\rho_{\varepsilon}\right)}{\beta \lambda \rho_{\varepsilon}}>1$.

Thus the optimal policy rule A16 also calls for inflation forecast targeting. Because $\delta>1$, an expected increase in future inflation calls for a more-than-proportional increase in the current nominal interest rate, in order to lower the real interest rate today and reduce aggregate demand now. If $\lambda \rightarrow 0$ (strict inflation targeting), then $1 / \delta \rightarrow 0, \lambda \theta \rho_{\varepsilon} \rightarrow 0$, and $\kappa_{1} \rightarrow 1$, and equation A13 then yields

$E_{t} \pi_{t+1}=\tilde{\pi}$,

which is analogous to what Svensson's model would predict in the absence of a lag between changes in the output gap and inflation (see equation 9 in the text). Put differently, strict inflation targeting is optimal-in the sense of equating the inflation target and the one-periodahead expected value of inflation-only if the central bank has no concern for output fluctuations. Otherwise, convergence to inflation back to target following a shock will be gradual, as implied by the discussion of flexible inflation targeting in the text. The optimal rule also calls for completely offsetting aggregate demand shocks because they do not imply a short-run trade-off between output and inflation. ${ }^{2}$

Both backward- and forward-looking components can be incorporated in a more general specification of the Phillips curve derived in equation $\mathrm{A} 1$ and the aggregate demand equation $\mathrm{A} 2$, as, for instance, in the new-Keynesian models discussed by Fuhrer (1997a, 1997b):

2. Equations A10 and A11 can be used to illustrate the output-inflation variability trade-off that arises in the presence of supply shocks. In general, $\sigma_{y}^{2}=\alpha_{1}^{2} \theta^{2} \sigma_{\varepsilon}^{2}$, and $\sigma_{\pi}^{2}=\lambda^{2} \theta^{2} \sigma_{\varepsilon}^{2}$. When $\lambda \rightarrow 0$ (the case of strict inflation targeting), $\theta \rightarrow 1 / \alpha_{1}^{2}, \sigma_{\pi} \rightarrow 0$, and $\sigma_{y} \rightarrow \sigma_{\varepsilon} / \alpha_{1}$. When $\lambda \rightarrow \infty$ (the case in which stabilizing output is the only policy goal), $\theta \rightarrow 0$ and (by applying L'Hospital's rule) $\lambda \theta \rightarrow 1 /\left(1-\alpha_{2} \rho_{\varepsilon}\right)$. As a result, $\sigma_{y} \rightarrow 0$ and $\sigma_{\pi} \rightarrow \sigma_{\varepsilon} /\left(1-\alpha_{2} \rho_{\varepsilon}\right)$. 


$$
\begin{aligned}
& \pi_{t}=\alpha_{1} y_{t}+\varphi \pi_{t-1}+(1-\varphi) \alpha_{2} E_{t} \pi_{t+1}+\varepsilon_{t} \text { and } \\
& y_{t}=\phi \beta_{1} y_{t-1}+(1-\phi) E_{t} y_{t+1}-\beta_{2}\left(i_{t}-E_{t} \pi_{t+1}\right)+\eta_{t},
\end{aligned}
$$

where $0<\varphi$ and $\phi \leq 1$. Equations A1 and A2 can be obtained from the above specifications by setting $\varphi=\phi=0$. The qualitative properties of the optimal instrument rule derived earlier remain essentially the same (see Clarida, Galí, and Gertler, 1999, pp. 1691-95). 


\section{APPENDIX B}

\section{Data Sources, Causality Tests, and Nonnested Tests for the Phillips Curve}

The data used to produce figure 1 are obtained from the quarterly database compiled by Agénor, McDermott, and Prasad (2000). The bivariate VAR includes the money market rate and the discount rate, in that order. Estimation periods are 1995:1-1999:4 for Colombia, 1978:11999:3 for Korea, 1978:1-1996:4 for Malaysia, 1983:2-1996:4 for Tunisia, 1986:2-1996:2 for Turkey, and 1994:1-1999:4 for Uruguay. The optimal lag length, chosen on the basis of the Akaike Criterion, was 2 for Colombia, 2 for Korea, 2 for Malaysia, 2 for Tunisia, 1 for Turkey, and 5 for Uruguay. Standard, bivariate Granger causality tests also showed that the discount rate causes the money market rate only in Korea ( $F$ statistic $3.122, P$ value 0.049 ). There is two-way causality in Malaysia and Turkey, and no statistically significant evidence of causality in Colombia, Tunisia, and Uruguay. ${ }^{1}$

The variables used in the regressions reported in tables 3 and 4 are defined as follows. Inflation (INF) is the log difference of the consumer price index (International Financial Statistics, or IFS, code 64) between periods $t$ and $t-4$. GAP is the log difference between the seasonally adjusted industrial production index (IFS code 66c or 66ey) and its trend value, calculated by using either the Hodrick-Prescott method or a quadratic trend (obtained by regressing output on a constant term, time and time squared). The growth rate of the nominal effective exchange rate (NEERGR) is the log difference of the nominal effective exchange rate (IFS code eneer) between periods $t$ and $t-4$. An increase in the nominal effective exchange rate is a depreciation. The growth rate of import prices (PMGR) is the log difference of the import price index (IFS code 75 or $75 \mathrm{~d}$ ) between periods $t$ and $t-4$. For Nigeria, imported inflation is measured by the growth rate of export prices in developed countries (PXGR_DEVED), which is the log difference of the export price index (IFS series code $74 \mathrm{~d}$ and country group code 110) of these countries between periods $t$ and $t-4$.

1. These results should be treated with some caution because during the estimation period, monetary policy procedures changed significantly in some of the countries considered. In Turkey, for instance, the repurchase rate has become the main interest rate instrument in recent years. 
The estimates of the linear and nonlinear Phillips curve models reported in tables 3 and 4 are compared using the $J$ test proposed by MacKinnon, White, and Davidson (1983). Specifically, suppose that the hypotheses to be tested are

$H_{0:} y=\alpha_{0+} \beta_{0} f(\mathbf{x}, \gamma)+\varepsilon_{0}$ and

$H_{1}: y=\alpha_{1}+\beta_{1} \mathbf{x}+\varepsilon_{1}$

where $y$ is the endogenous variable, $\mathbf{x}$ is a vector of exogenous variables, $\alpha_{i}, \beta_{i}$, and $\gamma$ are the parameters to be estimated, and $\varepsilon_{i}$ represents error terms with classical properties.

The basic idea of the $J$ test is that if one of the models (say, the model specified under $H_{0}$ ) is the correct one, then the fitted values from the other model (corresponding to $H_{1}$ ) should not have any explanatory power when estimating the $H_{0}$ model. In practical terms, testing the $H_{0}$ model against the $H_{1}$ model proceeds as follows. First, estimate the $H_{1}$ model and retrieve the fitted values. Next, estimate the $H_{0}$ model including the fitted values from the $H_{1}$ model. If the fitted values from the $H_{1}$ model enter significantly in the $H_{0}$ model, reject the $H_{0}$ model.

Similarly, the $H_{1}$ model can be tested against the $H_{0}$ model by first estimating the $H_{0}$ model, calculating the fitted values, and then estimating the $H_{1}$ model including the fitted values from $H_{0}$. If the fitted values from the $H_{0}$ model enter significantly in the $H_{1}$ model, reject the $H_{1}$ model. If only one of the models is not rejected by the test, this model is said to be superior to the other one. If both models are rejected against the alternative, this suggests that another model is needed. If neither model is rejected, the data do not provide enough information to discriminate between the two alternatives. The results are reported in the text. 


\section{REFERENCES}

Agénor, P., and J. Aizenman. 1998. "Contagion and Volatility with Imperfect Credit Markets.” IMF Staff Papers 45 (June): 207-35.

Agénor, P., and P. R. Masson. 1999. "Credibility, Reputation, and the Mexican Peso Crisis." Journal of Money, Credit and Banking 31 (February): 70-84.

Agénor, P., C. J. McDermott, and E. Prasad. 2000. "Macroeconomic Fluctuations in Developing Countries: Some Stylized Facts." World Bank Economic Review 14 (May): 251-86.

Agénor, P., and P. J. Montiel. 1999. Development Macroeconomics. Princeton University Press.

Alba, P., and others. 1999. "The Role of Macroeconomic and Financial Sector Linkages in East Asia's Financial Crisis." In Financial Crises: Contagion and Market Volatility, edited by P. R. Agénor and others. Cambridge University Press.

Alchian, A. A., and B. Klein. 1973. "On a Correct Measure of Inflation." Journal of Money, Credit and Banking 5 (February): 173-91.

Allen, W. A. 1999. "Inflation Targeting: The British Experience." Handbook in Central Banking Lecture Series 1. London: Bank of England.

Archer, D. D. 2000. "Inflation Targeting in New Zealand." Unpublished paper. Wellington: Reserve Bank of New Zealand.

Arrau, P., and others. 1995. "The Demand for Money in Developing Countries: Assessing the Role of Financial Innovations." Journal of Development Economics 46 (April): 317-40.

Ball, L. 1999. "Policy Rules for Open Economies.” In Monetary Policy Rules, edited by J. B. Taylor. University of Chicago Press.

Batini, N., and A. G. Haldane. 1999. "Forward-Looking Rules for Monetary Policy." In Monetary Policy Rules, edited by J. B. Taylor, University of Chicago Press.

Batini, N., and E. Nelson. 2000. "Optimal Horizons for Inflation Targeting." Working Paper 119. London: Bank of England.

Bean, C. 2000. "The Convex Phillips Curve and Macroeconomic Policymaking under Uncertainty." Unpublished paper. London School of Economics.

Beetsma, R. M., and H. Jensen. 1998. "Inflation Targets and Contracts with Uncertain Central Bank Preferences." Journal of Money, Credit and Banking 30 (August): 384-403.

Bernanke, B. S., and M. Gertler. 1999. "Monetary Policy and Asset Price Volatility." Federal Reserve Bank of Kansas City Economic Review 84(4): 17-51. 
Bernanke, B. S., and M. Woodford. 1997. "Inflation Forecasts and Monetary Policy." Journal of Money, Credit and Banking 29 (November): 653-86.

Bernanke, B. S., and others. 1999. Inflation Targeting: Lessons from the International Experience. Princeton University Press.

Bharucha, N., and C. Kent. 1998. "Inflation Targeting in a Small Open Economy.” Discussion Paper 9807. Sydney: Reserve Bank of Australia.

Blejer, M. I., and others, eds. 2000. Inflation Targeting in Practice. Washington: International Monetary Fund (IMF).

Blix, M., and P. Sellin. 1998. "Uncertainty Bands for Inflation Forecasts." Working Paper 65. Stockholm: Central Bank of Sweden.

Bogdanski, J., A. A. Tombini, and S. R. Werlang. 2000. "Implementing Inflation Targeting in Brazil." Unpublished paper. Brasília: Central Bank of Brazil.

Boon, L., C. Giorno, and P. Richardson. 1998. "Stock Market Fluctuations and Consumption Behavior: Some Recent Evidence." Working Paper 98-21. Paris: Organization for Economic Cooperation and Development (OECD).

Boskin, M. J., and others. 1996. "Toward a More Accurate Measure of the Cost of Living." Final Report to the Senate Finance Committee from the Advisory Commission to Study the Consumer Price Index. Washington.

Brainard, W. 1967. "Uncertainty and the Effectiveness of Policy." American Economic Review 57 (May): 411-25.

Briault, C., A. Haldane, and M. King. 1997. "Independence and Accountability." In Towards More Effective Monetary Policy, edited by I. Kuroda. New York: St. Martin's Press.

Carstens, A., and A. M. Werner. 2000. "Mexico's Monetary Policy Framework under a Floating Exchange Rate Regime." In Inflation Targeting in Practice, edited by M. I. Blejer, A. Ize, A. M. Leone, and S. Werlang. Washington: International Monetary Fund (IMF).

Cecchetti, S. G., and M. Ehrmann. 1999. "Does Inflation Targeting Increase Output Volatility? An International Comparison of Policymakers' Preferences and Outcomes." Working Paper 7426. Cambridge, Mass.: National Bureau of Economic Research.

Cecchetti, S. G., and others. 2000. Asset Prices and Central Bank Policy. London: Centre for Economic Policy Research (CEPR).

Chadha, B., P. R. Masson, and G. Meredith. 1992. "Models of Inflation and the Costs of Disinflation." IMF Staff Papers 39 (June): 395-431. 
Chadha, J. S., and P. Schellekens. 1999. "Monetary Policy Loss Functions: Two Cheers for the Quadratic.” Working Paper 101. London: Bank of England.

Clarida, R., J. Galí, and M. Gertler. 1998. "Monetary Policy Rules in Practice: Some International Evidence." European Economic Review 42 (June): 1033-68.

_. 1999. "The Science of Monetary Policy: A New Keynesian Perspective." Journal of Economic Literature 37 (December): 1661-707.

- 2000. "Monetary Policy Rules and Macroeconomic Stability: Evidence and Some Theory." Quarterly Journal of Economics 115(1): 147-80.

Cukierman, A. 1992. Central Bank Strategy, Credibility, and Independence. MIT Press.

Cukierman, A., M. A. Kiguel, and L. Leiderman. 1994. "Choosing the Width of Exchange Rate Bands: Credibility versus Flexibility." Discussion Paper 907. London: Centre for Economic Policy Research (CEPR).

Cukierman, A., and A. H. Meltzer. 1986. "Theory of Ambiguity, Credibility, and Inflation under Discretion and Asymmetric Information." Econometrica 54 (September): 1099-128.

De Haan, J., and W. J. Kooi. 2000. "Does Central Bank Independence Really Matter? New Evidence for Developing Countries Using a New Indicator." Journal of Banking and Finance 24 (April): 643-64.

Dittmar, R., W. T. Gavin, and F. E. Kydland. 1999. "The InflationOutput Variability Trade-off and Price-Level Targets." Federal Reserve Bank of St. Louis Review 81(1): 23-31.

Drazen, A., and P. R. Masson. 1994. "Credibility of Policies versus Credibility of Policymakers." Quarterly Journal of Economics 104 (August): $735-54$.

Dupasquier, Ch., and N. Ricketts. 1998. "Non-Linearities in the Output-Inflation Relationship: Some Empirical Results for Canada." Ottawa: Bank of Canada.

Eijffinger, S. C., M. Hoeberichts, and E.Schaling. 2000. "A Theory of Central Bank Accountability." Discussion Paper 2354. London: Centre for Economic Policy Research (CEPR).

Estrella, A., and F. S. Mishkin. 1997. "Is There a Role for Monetary Aggregates in the Conduct of Monetary Policy?" Journal of Monetary Economics 40 (October): 279-304.

Faust, J. W., and L. E. O. Svensson. 1998. "Transparency and Credibility: Monetary Policy with Unobservable Goals." Working Paper 6452. Cambridge, Mass.: National Bureau of Economic Research. 
Figueiredo, F. 2000. "Evaluation of Measures of Core Inflation.” Unpublished paper. Brasília: Central Bank of Brazil.

Freedman, C. 2000. "The Canadian Experience with Targets for Reducing and Controlling Inflation." Unpublished paper. Ottawa: Bank of Canada.

Fuhrer, J. C. 1997a. "Inflation-Output Variance Trade-Offs and Optimal Monetary Policy." Journal of Money, Credit and Banking 29 (May): 214-34.

. 1997b. "The (Un)Importance of Forward-Looking Behavior in Price Specifications." Journal of Money, Credit and Banking 29 (August): 338-50.

Fuhrer, J. C., and G. Moore. 1992. "Monetary Policy Rules and the Indicator Properties of Asset Prices." Journal of Monetary Economics 29 (April): 303-36.

Garfinkel, M. R., and S. Oh. 1993. "Strategic Discipline in Monetary Policy with Private Information: Optimal Targeting Horizons." American Economic Review 83 (March): 99-117.

Gordon, R. J. 1999. "The Boskin Commission Report and Its Aftermath." Unpublished paper. Northwestern University.

Ha, Y. 2000. "Uncertainty about the Length of the Monetary Policy Transmission Lag." Working Paper 2000/01. Wellington: Reserve Bank of New Zealand.

Haldane, A. G. 1998. "Some Issues in Inflation Targeting." Working Paper 74. London: Bank of England.

Honda, Y. 2000. "Some Tests on the Effects of Inflation Targeting in New Zealand, Canada, and the UK." Economics Letters 66 (January): $1-6$.

Isard, P., and D. Laxton. 2000. "Inflation Forecast Targeting and the Role of Macroeconomic Models." In Inflation Targeting in Transition Economies: The Case of the Czech Republic, edited by W. Coats. Washington: International Monetary Fund (IMF).

Isard, P., D. Laxton, and A. Eliasson. 2001. "Inflation Targeting with NAIRU Uncertainty and Endogenous Policy Credibility." Journal of Economic Dynamics and Control 25 (January): 115-48.

Jadresic, E. 1999. "Inflation Targeting and Output Stability." Working Paper 99/61. Washington: International Monetary Fund (IMF).

Landerretche, O., F. Morandé, and K. Schmidt-Hebbel. 1999. "Inflation Targets and Indexation in Chile." Working Paper 55. Santiago: Central Bank of Chile.

Laxton, D., G. Meredith, and D. Rose. 1995. "Asymmetric Effects of Economic Activity on Inflation.” IMF Staff Papers 2 (June): 344-74. 
Leiderman, L., and H. Bar-Or. 2000. "Monetary Policy Rules and Transmission Mechanisms under Inflation Targeting in Israel." Working Paper 71. Santiago: Central Bank of Chile.

Leiderman, L., and G. Bufman. 2000. "Inflation Targeting under a Crawling Band Exchange Rate Regime: Lessons from Israel." In Inflation Targeting in Practice, edited by M. I. Blejer and others. Washington: International Monetary Fund (IMF).

Leitemo, K. 1999. "Inflation Targeting Strategies in Small Open Economies." Unpublished paper. University of Oslo.

MacKinnon, J., H. White, and R. Davidson. 1983. "Tests for Model Specification in the Presence of Alternative Hypotheses: Some Further Results." Journal of Econometrics 21 (January): 53-70.

Martin, B. 1999. "Caution and Gradualism in Monetary Policy under Uncertainty." Working Paper 105. London: Bank of England.

Martin, B., and C. Salmon. 1999. "Should Uncertain Monetary PolicyMakers Do Less?” Working Paper 99. London: Bank of England.

Masson, P. R., M. A. Savastano, and S. F. Sharma. 1997. "The Scope for Inflation Targeting in Developing Countries." Working Paper 97/130. Washington: International Monetary Fund (IMF).

McCallum, B. T. 1999. "Issues in the Design of Monetary Policy Rules." In Handbook of Macroeconomics, edited by J. B. Taylor and M. Woodford. North Holland: Elsevier.

Mehra, Y. P. 1999. "A Forward-Looking Monetary Policy Reaction Function." Federal Reserve Bank of Richmond Economic Quarterly 85 (Spring): 33-53.

Mishkin, F. S. 2000. "Inflation Targeting in Emerging Market Countries." Working Paper 7618. Cambridge, Mass.: National Bureau of Economic Research.

Mishkin, F. S., and M. A. Savastano. 2000. "Monetary Policy Strategies for Latin America." Working Paper 7617. Cambridge, Mass.: National Bureau of Economic Research.

Morandé, F., and K. Schmidt-Hebbel. 1999. "The Scope for Inflation Targeting in Emerging Market Economies." Unpublished paper. Santiago: Central Bank of Chile.

Muscatelli, V. A. 1998. "Optimal Inflation Contracts and Inflation Targets with Uncertain Central Bank Preferences: Accountability through Independence." Economic Journal 108 (March): 529-42.

_. 1999. "Inflation Contracts and Inflation Targets under Uncertainty: Why We Might Need Conservative Central Bankers." Economica 66 (May): 241-54.

Orphanides, A., and V. Wieland. 2000. "Inflation Zone Targeting." European Economic Review 44 (June): 1351-87. 
Orphanides, A., and D. W. Wilcox. 1996. "The Opportunistic Approach to Disinflation." Unpublished paper. Board of Governors of the Federal Reserve System.

Parrado, E. 1999. "Inflation Targeting and Exchange Rate Rules in an Open Economy." Unpublished paper. New York University.

Pyyhtia, I. 1999. "The Nonlinearity of the Phillips Curve and European Monetary Policy." Working Paper 17/99. Helsinki: Bank of Finland.

Quah, D., and S. P. Vahey. 1995. "Measuring Core Inflation." Economic Journal 105 (September): 1130-44.

Roberts, J. M. 1995. "New Keynesian Economics and the Phillips Curve." Journal of Money, Credit and Banking 27 (November): 975-84.

Roger, S. 1998. "Core Inflation: Concepts, Uses and Measurement.” Working Paper 98/9. Wellington: Reserve Bank of New Zealand (July).

Rotemberg, J., and M. Woodford. 1999. "Interest Rate Rules in an Estimated Sticky Price Model.” In Monetary Policy Rules, edited by J. B. Taylor. University of Chicago Press.

Rudebusch, G., and L. E. O. Svensson. 1999. "Policy Rules for Inflation Targeting." In Monetary Policy Rules, edited by J. B. Taylor. University of Chicago Press.

Sack, B. 2000. "Does the Fed Act Gradually? A VAR Analysis." Journal of Monetary Economics 46 (August): 229-56.

Schaechter, A., M. R. Stone, and M. Zelmer. 2000. "Practical Issues in the Adoption of Inflation Targeting by Emerging Market Countries." Unpublished paper. Washington: International Monetary Fund (IMF).

Schaling, E. 1999. "The Non-Linear Phillips Curve and Inflation Forecast Targeting." Working Paper 98. London: Bank of England.

Shuetrim, G., and C. Thompson. 1999. "The Implications of Uncertainty for Monetary Policy." In Monetary Policy under Uncertainty, edited by B. Hunt and A. Orr. Wellington: Reserve Bank of New Zealand.

Sikken, B. J., and J. De Haan. 1998. "Budget Deficits, Monetization, and Central Bank Independence in Developing Countries." Oxford Economic Papers 50 (July): 493-511.

Siklos, P. L. 1999. "Inflation-Target Design: Changing Inflation Performance and Persistence in Industrial Countries." Federal Reserve Bank of St. Louis Quarterly Review 81 (March): 47-58.

Smets, F. 1997. "Financial Asset Prices and Monetary Policy: Theory and Evidence." In Monetary Policy and Inflation Targeting, edited by P. Lowe. Melbourne: Reserve Bank of Australia.

Soderstrom, U. 1999. "Should Central Banks Be More Aggressive?" Working Paper 84. Stockholm: Central Bank of Sweden. 
Sterne, G. 1999. "The Use of Explicit Targets for Monetary Policy: Practical Experiences of 91 Economies in the 1990s." Bank of England Quarterly Bulletin 39 (August): 272-81.

Svensson, L. E. O. 1997a. "Inflation Forecast Targeting: Implementing and Monitoring Inflation Targets." European Economic Review 41 (June): 1111-46.

. 1997b. "Optimal Inflation Targets, 'Conservative' Central Banks, and Linear Inflation Contracts.” American Economic Review 87 (March): 98-114.

_ 1999a. "Inflation Targeting: Some Extensions." Scandinavian Journal of Economics 101 (September): 337-61.

- 1999b. "Price-Level Targeting versus Inflation Targeting: A Free Lunch?" Journal of Money, Credit and Banking 31 (August): 277-95.

Taylor, J. B. 2000. "Low Inflation, Pass-through, and the Pricing Power of Firms." European Economic Review 44 (June): 1389-408.

Vestin, D. 2000. "Price-Level Targeting versus Inflation Targeting in a Forward-Looking Model.” Unpublished paper. Stockholm University.

Walsh, C. E. 1995. "Optimal Contracts for Central Bankers." American Economic Review 76 (March): 150-67.

. 1999. "Announcements, Inflation Targeting and Central Bank Incentives." Economica 66 (May): 255-69.

Wynne, M. A.. 1999. "Core Inflation: A Review of Some Conceptual Issues." In Measures of Underlying Inflation and Their Role in the Conduct of Monetary Policy. Basel: Bank for International Settlements (BIS). 
